\title{
OPTIMIZATION OF POINT-OF-USE WATER TREATMENT DEVICE FOR DISASTER RELIEF
}

\author{
A Thesis presented to \\ the Faculty of California Polytechnic State University, \\ San Luis Obispo
}

In Partial Fulfillment

of the Requirements for the Degree of

Master of Science in Civil and Environmental Engineering

by

Margaret June Herzog

March 2011 
(C) 2011

Margaret June Herzog

ALL RIGHTS RESERVED 


\section{COMMITTEE MEMBERSHIP}

TITLE: $\quad$ Optimization of Point-Of-Use Water Treatment Device for Disaster Relief

AUTHOR: $\quad$ Margaret June Herzog

DATE SUBMITTED: $\quad$ March 2011

COMMITTEE CHAIR: Dr. Tryg Lundquist

COMMITTEE MEMBER: Dr. Yarrow Nelson

COMMITTEE MEMBER: Dr. Patrice Engle 


\section{ABSTRACT \\ Optimization of Point-of-Use Water Treatment Device for Disaster Relief}

Margaret June Herzog

Point-of-use (POU) drinking water treatment is a common method of providing drinking water in disaster relief situations when critical water infrastructure is damaged. In these cases, POU treatment devices can be used to treat local water until relief organizations set up more permanent water provision methods. One such POU technology is PŪR ${ }^{\circledR}$ Purifier of Water, a combined coagulation/flocculation and disinfection chemical treatment sachet produced by Procter \& Gamble. PŪR ${ }^{\circledR}$ has been shown to treat contaminated water to meet water quality standards and guidelines set by the U.S. EPA for water purifiers and by the World Health Organization and The Sphere Project for emergency relief. However, the standard two-bucket method of use for $\mathrm{PU}^{\circledR}{ }^{\circledR}$ has two primary drawbacks: (1) the need for appurtenances that may not be readily available in disaster relief situations and (2) lack of a means to protect treated water from re-contamination post-treatment. An alternative to the two-bucket method is a waterbag system under development at the California Polytechnic State University, San Luis Obispo. The waterbag is a ten-liter plastic bladder with integrated filter that incorporates an all-in-one approach to drinking water treatment during emergencies. In previous studies, the first version of the waterbag consistently met World Health Organization and The Sphere Project emergency drinking water guidelines, but did not meet the pathogen reduction requirements of the U.S. EPA Guide Standard and Protocol for Testing Microbiological Water Purifiers.

A second (Mark II) version, with internal mixing baffles and a microfilter, was developed to overcome the inability of the first design to meet the U.S. EPA guidelines. The main purposes of the research presented herein were to (1) optimize the method of use and baffle configuration for the improved Mark II version of the waterbag, (2) determine ability of the waterbag to treat test waters with challenging initial water quality conditions, and (3) test the ability of the Mark II design and optimized method to meet the U.S. EPA Guide Standard and Protocol for Testing Microbiological Water Purifiers.

For the first and second objectives, the main metric of treatment performance was the extent of flocculation, which was characterized by the turbidity of waterbag supernatant after 30 
minutes of settling. The waterbag procedure was varied in several ways. The variables tested were mixing duration, mixing motion type, and the effect of a mixing delay. Several waterbag baffle designs were tested to determine the physical configuration of the waterbag which resulted in best turbulence during mixing. In addition, experiments were performed to test the ability of the Mark II waterbag to treat waters with various initial qualities, such as high organic carbon content and elevated E. coli concentrations. The results of these experiments helped to prepare for a final test in meeting the pathogen removal requirements of the U.S. EPA Guide Standard and Protocol for Testing Microbiological Water Purifiers.

The procedure determined to be optimal for the Mark II waterbag treatment included five minutes of mixing using rapid $180^{\circ}$ twisting motions at a moderate frequency of seventy $180^{\circ}$-twists per minute. The optimal baffle design was a $12.7 \mathrm{~cm}$-wide internal mixing baffle with two cut circular holes for the promotion of turbulence during mixing. The desired posttreatment chlorine residual was achieved for different durations depending on initial organic carbon concentration. Optimal $\mathrm{PU}^{\circledR}{ }^{\circledR}$ dose to provide pathogen removals required by the U.S. EPA in the presence of Challenge Water conditions was two sachets per $10 \mathrm{~L}$ of water to be treated. The optimization of these design and operational procedures led to the ability of the Mark II waterbag to meet the pathogen, turbidity, $\mathrm{pH}$, and non-microbiological constituent removals required by the U.S. EPA, The Sphere Project, and World Health Organization for emergency relief. 


\section{ACKNOWLEDGMENTS}

I would like to extend my sincere gratitude towards the following individuals for their knowledge and support:

Cal Poly Thesis Advisers: Dr. Tryg Lundquist, Dr. Yarrow Nelson, and Dr. Patrice Engle, for their encouragement and insight both through this project and from years of classes together.

Original developers of the Mark I waterbag: Dr. Tryg Lundquist, Tricia Compas, Steve Barr

Cal Poly Students: Katie Spahr, Kyle Fooks, Jason Kane, Seppi Henemann, Neal Adler, Ruth Spierling, Paul Ward, Giulia Samorì, Marylou Romero, Shasta Billings, Adam Wegener, Tyler Grossheim, Leslie Anderson, Rebecca Peters, Brian McMahon, Rebecca Vanni, Michael Jaoui, for their help with my experiments and research, and for their company during long hours in the lab.

Family: My mom and Philip Dutton, for their encouragement, insight, and editing support.

Professional Advisers: Tricia Compas (DayOne Response, Inc.), Greg Allgood (Procter \& Gamble), Dr. Robert Cooper (BioVir \& UC Berkeley)

Cal Poly Professors and Staff: Jeff Reimer, Alice Hamrick, Lily Laiho, Ian Woertz, Dr. Sema Alptekin

Cal Poly Research and Graduate Programs: Jim Dunning, Becky Powell, and Susan Opava Engineers Without Borders - Cal Poly, Thailand Team (2009) and India Team (2010)

Cascade Designs, Inc.

Reliance Products, L.P.

This project was entirely funded by grant and scholarship awards from the following organizations. I sincerely thank each of these groups and individuals for their financial and moral support in the success of this project.

National Collegiate Inventors and Innovators Alliance, especially staff members Rachel Agoglia, James Barlow, Patricia Boynton

Environmental Engineers of the Future Scholarship

Cal Poly Honors Program: Humanitarian Service Learning Competition 


\section{TABLE OF CONTENTS}

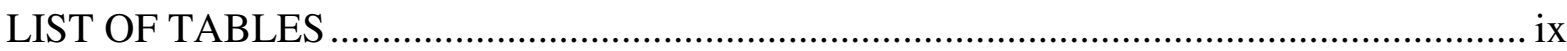

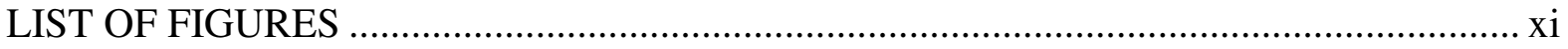

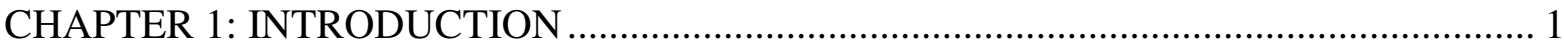

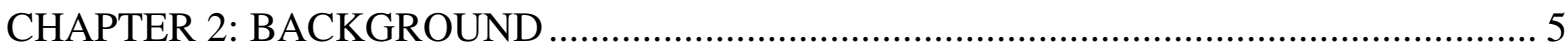

2.1 Drinking Water Contamination during Emergencies................................................. 5

2.1.1 Typical Characteristics of Source Water Contamination .................................... 6

2.1.2 Drinking Water Quality Objectives for Emergency Relief .............................. 11

2.2 Point-of-Use Drinking Water Treatment using PŪR ${ }^{\circledR}$ Purifier of Water...................... 13

2.2.1 Chemical Composition ............................................................................ 14

2.2.2 Coagulation, Flocculation, and Sedimentation................................................ 15

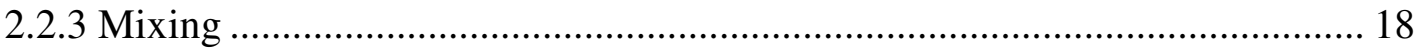

2.2.4 Chlorine Disinfection ............................................................................ 19

2.3 Waterbag Alternative for Drinking Water Treatment using PŪR ${ }^{\circledR}$.............................. 23

2.4 U.S. EPA Guide Standard and Protocol for Testing Microbiological Water Purifiers 26

2.4.1 Microbiological Water Purifier Test Protocol.................................................. 29

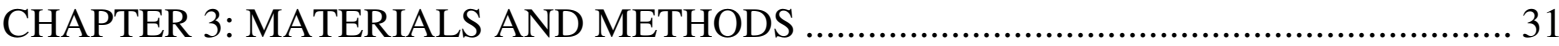

3.1 Mark II Prototype Construction .................................................................................. 31

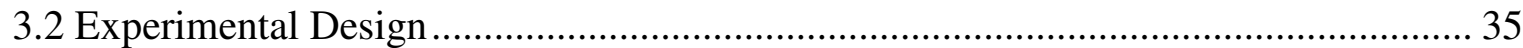

3.2.1 Experimental Objectives ………………………...................................... 36

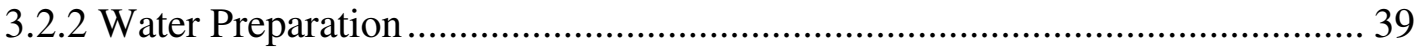

3.2.3 Experimental Testing Procedures .................................................................. 43

3.3 Water Quality Measurements............................................................................... 44

3.3.1 Non-Microbiological Variables ..................................................................... 44

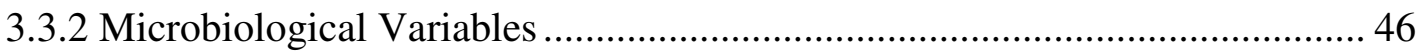

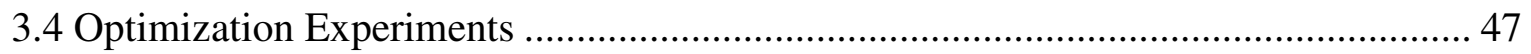

3.4.1 Water Preparation for Optimization Experiments ........................................... 48

3.4.2 Experimental Procedures for the Optimization Experiments ............................ 50 


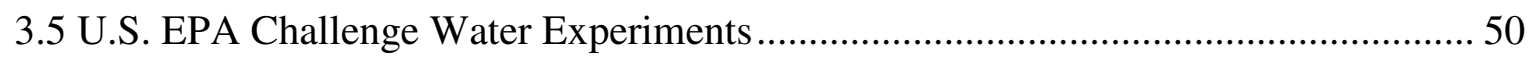

3.5.1 Water Preparation for Experiments D-1 and D-2 ……………………......... 51

3.5.2 Experimental Procedure for Experiments D-1 and D-2 ………………….... 54

3.5.3 Water Preparation at BioVir for Experiment E-1 ……………………….... 57

3.5.4 Experimental Procedure at BioVir for Experiment E-1 ................................... 57

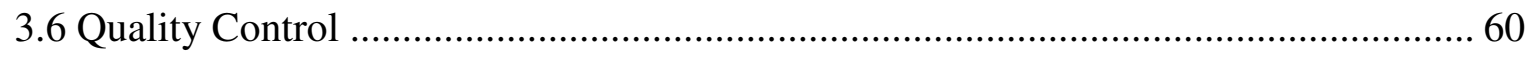

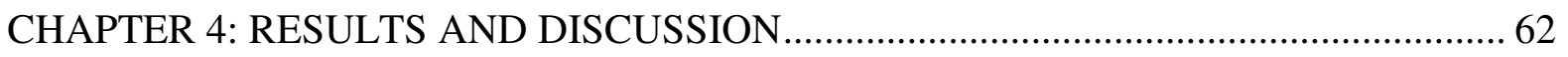

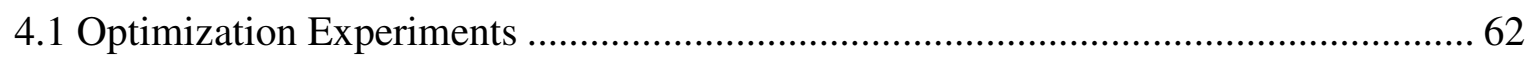

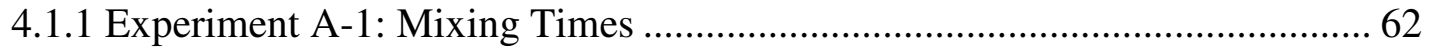

4.1.2 Experiment A-2: Mixing Method - Abrupt Motion vs. Fluid Motion............. 65

4.1.3 Experiment A-3: Delayed Mixing Start after PŪR ${ }^{\circledR}$ Addition ......................... 67

4.1.4 Experiment B-1: Baffle Configuration, Part I - Narrow Baffles ..................... 68

4.1.5 Experiment B-2: Baffle Configuration, Part II - Wide Baffles........................ 71

4.1.6 Experiment C-1: Chlorine Residual Over Time with Various Initial TOC

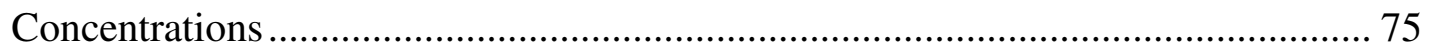

4.2 U.S. EPA Challenge Water Experiments ................................................................... 81

4.2.1 Experiment D-1: PŪR ${ }^{\circledR}$ Dose Needed with High TOC, Part I ……………..... 81

4.2.2 Experiment D-2: PŪR ${ }^{\circledR}$ Dose Needed with High TOC, Part II........................ 86

4.2.3 Experiment E-1: U.S. EPA Challenge Water Experiment at BioVir

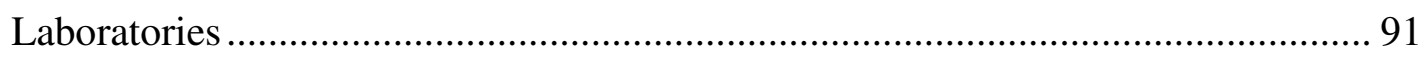

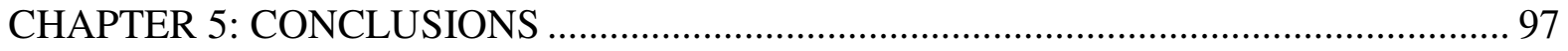

5.1 Optimization and U.S. EPA Challenge Water ……….................................................. 97

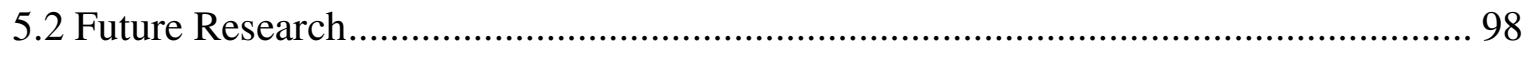

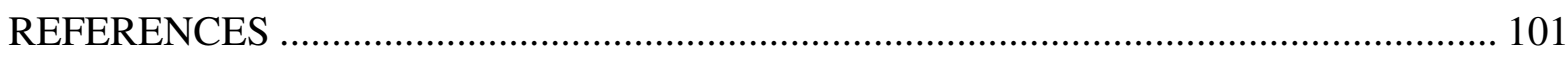

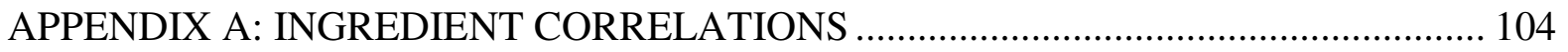

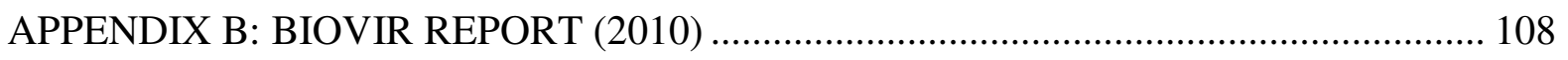

APPENDIX C: CHLORINE RESIDUAL BENCH METHOD ………………………....... 110

APPENDIX D: CHLORINE RESIDUAL CALIBRATION CURVE ................................. 113

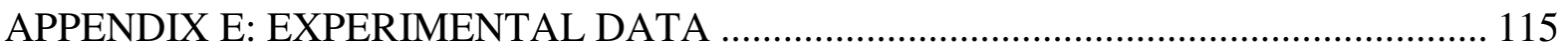




\section{LIST OF TABLES}

Table 2.1: Waterborne pathogens and their significance in water supplies. Table adapted from World Health Organization Guidelines for Drinking-Water Quality, (2006)..... 7

Table 2.2: Drinking water quality objectives for emergency response, issued by the Sphere Project (2004), WHO (2006), and U.S. EPA (1987).................................. 12

Table 2.3: PŪR ${ }^{\circledR}$ ingredients include an iron salt coagulant, disinfectants, and flocculants and flocculating aids (Souter, Cruickshank, \& Stoddart, 2007; Reller, et al., 2003; Compas, 2009a).

Table 2.4: Centers for Disasease Control Safe Water System summary on chlorine inactivation of selected pathogens (CDC, 2007).

Table 2.5: U.S. EPA initial challenge organisms, initial challenge concentrations, and reduction requirements for microbiological water purifiers.

Table 2.6: U.S. EPA Challenge Test Water characteristics for Test Water \#2 for units using halogen disinfection.

Table 3.1: Optimization experiment information including test water variables, source water types, ingredient amounts, mixing speeds, and mixing times

Table 3.2: Variables measured during the optimization experiments. The variables measured during each experiment depended on the objectives of the individual experiment.

Table 3.3: U.S. EPA Challenge Water experiment information including test water variables, source water types, ingredient amounts, mixing speeds, and mixing lengths

Table 3.4: Variables measured during U.S. EPA Challenge Water experiments. The constituents measured during each experiment depended on the objectives of the individual experiment. 55

Table 3.5: Characteristics of the U.S. EPA Challenge Water prepared by BioVir staff ........ 57

Table 4.1: Locations of narrow baffles within each prototype for Experiment B-1............ 69

Table 4.2: Description and location of baffles within prototypes for Experiment B-2. ........ 72

Table 4.3: E. coli removals of prototypes treated with different numbers of PŪR ${ }^{\circledR}$ sachets under conditions similar to the U.S. EPA challenge conditions. 88 
Table 4.4: E. coli (CFU/300 mL) removal results from the U.S. EPA Challenge Water experiment performed at BioVir Laboratories (BioVir, 2010)..................................... 93

Table 4.5: Coliphage (PFU/mL) removal results from the U.S. EPA Challenge Water experiment performed at BioVir Laboratories (BioVir, 2010)..................................... 93

Table 4.6: Microsphere (spheres/L) removal results from the U.S. EPA Challenge Water experiment performed at BioVir Laboratories (BioVir, 2010). 


\section{LIST OF FIGURES}

Figure 2.1: Electric double layer of a negatively charged colloid. Coagulation works by shrinking the double layer of a charged colloidal particle (Sawyer, McCarty, \& Parkin, 2003).

Figure 2.2: Distribution of $\mathrm{HOCl}$ and $\mathrm{OCl}-$ as a function of $\mathrm{pH}$ and temperature (Tchobanoglous \& Schroeder, 1987).

Figure 3.1: An empty Mark II waterbag. Note key design features such as wide-mouth opening, dry-bag closure, tapered bottom, outlet vale position, and internal baffles. 32

Figure 3.2: Dimensions of Mark II prototype (Compas, 2009b). 33

Figure 3.3: Braided rope handle attached to the prototype with grommets; dry-bag closure with plastic reinforcement. 34

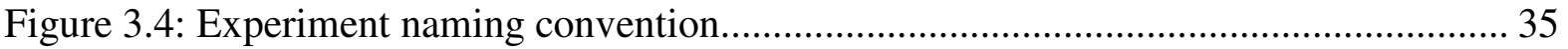

Figure 3.5: Mark II waterbag with two $16.51 \mathrm{~cm}$-long narrow internal mixing baffles........ 38

Figure 3.6: Final baffle configuration chosen for Experiments A-3, and C-1 through E-3.

This $12.7 \mathrm{~cm}$-wide baffle was chosen over two separate, narrow baffles because of the results obtained in Experiments B-1 and B-2.

Figure 3.7: 75-liter RubberMaid® refuse container ("large drum”) with a ball-valve outlet containing a Flotec ${ }^{\circledR}$ submersible sump pump (model FP0S2450A-08, $1 / 3 \mathrm{HP})$.

Figure 3.8: Interior of the large drum used to prepare and store the test water for each experiment. A submersible sump pump was used to homogenize the test water before distribution into prototypes.

Figure 3.9: For mixing, waterbags were hung from a horizontal post and twisted from side-to-side $\left(180^{\circ}\right)$. Mixing speeds were different based on experiment and were standardized using a metronome

Figure 3.10: Clamshell filter from Experiment D-1 with $1 \mu \mathrm{m}$ nominally-rated polypropylene filter pad. The filter is inundated with solids after treatment of the high humic test water of the U.S. EPA Challenge Water Test with four PŪR ${ }^{\circledR}$ sachets. 
Figure 3.11: Effluent valve attached $12.7 \mathrm{~cm}$ above the bottom seam of the prototype.

Filter tubing was attached directly to the valve. Notch marks on the valve were used to regulate and standardize the flow from all the bags tested

Figure 3.12: Empty Mark II prototypes hanging against an indoor mixing tank. This was the where the prototypes were hung during treatment, mixing, and sampling. 58

Figure 3.13: 0.2- $\mu \mathrm{m}$ absolute-rated $\mathrm{MSR}^{\circledR}$ AutoFlow ${ }^{\mathrm{TM}}$ Microfilter (microfilter),

provided by Cascade Designs, Inc. (Backcountry.com, 2010).

Figure 4.1: Final turbidities of prototypes mixed for between $30 \mathrm{sec}$ and $5 \mathrm{~min}$. Higher mixing times resulted in lower final turbidities.

Figure 4.2 : Pre-treatment versus post-PŪR ${ }^{\circledR}$-treatment turbidities of prototypes mixed for between $30 \mathrm{sec}$ and $5 \mathrm{~min}$. Bag 1 was intentionally conducted with a lessthan-optimal mixing speed to accentuate resulting differences in performance. 64

Figure 4.3: Pre-treatment and post-treatment turbidities of prototypes mixed with either fluid or abrupt twisting rotations. This experiment was intentionally conducted with a less-than-optimal procedure (mixing time of $2 \mathrm{~min}$ ) to accentuate resulting differences in performance.

Figure 4.4: Pre-treatment and post-treatment turbidities for prototypes with a 0-min to 5-min delay between PŪR® addition and mixing start. 68

Figure 4.5: Pre-treatment and post-treatment turbidities for prototypes with different numbers of narrow baffles. Each baffle was a $5.1-\mathrm{cm}$ wide by $16.5-\mathrm{cm}$ long and was made from two layers of standard duct tape. This experiment was intentionally conducted with a less-than-optimal procedure (mixing time of 2.5 min at $40 \mathrm{bpm}$ ) to accentuate resulting differences in performance. 70

Figure 4.6: Turbidity over time for prototypes with different numbers of baffles. Initial (pre-treatment) turbidity values are not shown. This experiment was intentionally conducted with a less-than-optimal procedure (only 2.5 min of mixing at $40 \mathrm{bpm}$ ) to accentuate resulting differences in performance.

Figure 4.7: Pre-treatment and post-treatment turbidities for prototypes with varying baffle configurations. This experiment was intentionally conducted with a less-thanoptimal procedure (mixing time of $2.5 \mathrm{~min}$ ) to accentuate resulting differences in performance. 
Figure 4.8: Turbidity over time for prototypes with different types of baffles. Initial turbidity values are not shown. This experiment was intentionally conducted with a less-than-optimal procedure (mixing time of only $2.5 \mathrm{~min}$ ) to accentuate resulting differences in performance.

Figure 4.9: Wide baffle configuration selected for subsequent experiments. The dimensions are provided in Table 2.4 , above.

Figure 4.10: Initial (pre-treatment), 30-min post-treatment, and 3-hr post-treatment TOC measurements. Percentages indicate a percent of the $10 \mathrm{mg} / \mathrm{L}$ TOC required by the U.S. EPA Challenge Test (Test Water \#2) 76

Figure 4.11: Free chlorine residuals over time for prototypes containing a range of initial TOC concentrations. Percentages indicate the percent of the $10 \mathrm{mg} / \mathrm{L}$ TOC required by the U.S. EPA Challenge Test (Test Water \#2). Shaded area represents the recommended range of free chlorine residual desired for disaster relief water provision (WHO, 2006; Sphere Project, 2004). Time zero represents the point at which mixing stopped and the 30-min settling/disinfection period began.

Figure 4.12: Comparison of germicidal efficiency of hypochlorous acid, hypochlorite ion, and monochloramine for $99 \%$ destruction of $E$. coli at $2^{\circ} \mathrm{C}$ to $6^{\circ} \mathrm{C}$ (Tchobanoglous \& Schroeder, 1987; Bakhir et al., 2003). 80

Figure 4.13: Post-treatment turbidities over time for prototypes treated with different numbers of PŪR ${ }^{\circledR}$ sachets in the presence of $10 \mathrm{mg} / \mathrm{L}$ TOC from added humic acid. Bag 6 from Experiment C-1 is included for comparison purposes (test water conditions were similar for each experiment).

Figure 4.14: TOC concentrations over time for waterbags treated with different numbers of PŪR ${ }^{\circledR}$ sachets. Bag 6 from Experiment C-1 is included for comparison purposes (test water conditions were similar for each experiment).

Figure 4.15: Significant numbers of floating flocs occurred for Bag 3, the prototype treated with four PŪR ${ }^{\circledR}$ sachets. Floating flocs contributed to sporatic increases in turbidity during the 30-hour sampling period in Bag 3. 86

Figure 4.16: Pre-treatment, post-treatment, and post-filter turbidity measurements for prototypes treated with varying numbers of $\mathrm{PUR}^{\circledR}$ sachets under challenge conditions. 
Figure 4.17: Pre-treatment and post-filter TOC measurements for prototypes treated with varying numbers of PŪR ${ }^{\circledR}$ sachets under challenge conditions. Also, the TOC removed between the initial and post-filter conditions......................................... 89

Figure 4.18: TOC concentrations of samples collected by Cal Poly researchers during the U.S. EPA Challenge Water test at BioVir Laboratories. .

Figure 4.19: Turbidity of samples collected by Cal Poly researchers during the U.S. EPA Challenge Water test at BioVir Laboratories. 


\section{CHAPTER 1: INTRODUCTION}

Provision of drinking water and the means for adequate sanitation are critical determinants for survival in the initial stages of a disaster (The Sphere Project, 2004). Disaster survivors are generally very susceptible to illness and death from disease resulting from inadequate sanitation, inadequate water supplies, and poor hygiene (The Sphere Project, 2004). Thus, drinking water provision is a primary objective of responders such as governments and relief organizations like the Red Cross, UNICEF, USAID, and CARE. These responders generally have two options for provision of clean drinking water to disaster victims: (1) transport pretreated, clean drinking water in from an outside source, or (2) provide point-of-use (POU) drinking water treatment devices that treat onsite contaminated source water. When infrastructure is destroyed, transport of treated water into disaster zones in tanker trucks, 20L jerry cans, or small water bottles is inhibited. Alternatively, POU treatment devices are relatively compact and can allow disaster survivors to independently treat local water until longer term solutions are available. However, some POU methods are often costly or not effective for treating all the major classes of pathogens (Lantagne \& Clasen, 2009).

The Sphere Project and World Health Organization (WHO) have created universal minimum standards for humanitarian assistance to improve the quality of assistance provided to people affected by disasters (The Sphere Project, 2004). In addition, the United States Environmental Protection Agency (U.S. EPA) has developed a Guide Standard and Protocol for Testing Microbiological Water Purifiers (described in Section 2.4), which details pathogen removal requirements for U.S. EPA-approved microbiological treatment devices.

A common POU drinking water treatment method used for disaster relief is Procter \& Gamble's PŪR ${ }^{\circledast}$ Purifier of Water chemical sachets, which are used in combination with a 
two-bucket treatment method (Proctor \& Gamble, 2010). A PŪR ${ }^{\circledR}$ sachet is a four-gram waterproof sachet that contains coagulating, flocculating, and disinfecting chemicals that have been shown to provide pathogen removals similar to those required by the U.S. EPA Guide Standard and Protocol for Testing Microbiological Water Purifiers (Procter \& Gamble, 2010). Though the two-bucket treatment method is effective at treating contaminated water, the method has some drawbacks. For example, the method requires two 20 -L pails, a mixing implement, and a clean filter cloth (e.g., clean t-shirt material); disaster survivors may not have ready access to these implements. Additionally, storage in uncovered buckets provides the opportunity for recontamination.

An alternative to the standard $\mathrm{PU} \mathrm{R}^{\circledR}$ two-bucket method is a ten-liter plastic waterbag in development since 2007 at California Polytechnic State University, San Luis Obispo (Compas, 2009a). The waterbag, called the Polytech Waterbag or, commercially, the DayOne Waterbag ${ }^{\mathrm{TM}}$, uses PŪR ${ }^{\circledR}$ for treatment but also provides water collection, treatment, transport, and storage in a single unit. The Mark I version of the waterbag was developed through an iterative cycle of testing of the geometry, materials, usability, capacity, treatment method, and cost associated with the bag (Compas, 2009a). Ultimately, the Mark I version consistently met WHO emergency drinking water guidelines, but did not meet the pathogen reduction requirements of the U.S. EPA Guide Standard and Protocol for Testing Microbiological Water Purifiers (discussed in Section 2.3). A patent was issued for the design features of the Mark I waterbag (US PTO No. 7,514,006).

The purpose of the waterbag is to provide emergency relief organizations with an all-in-one water treatment device that can treat even highly contaminated water to meet disaster relief drinking water quality guidelines. In particular, the waterbag is meant to provide drinking 
water to disaster survivors in the gap period immediately following a disaster, but before high-capacity, pump-driven water treatment systems can be installed in a relief area.

The scope of this research was to optimize the prescribed treatment method and physical characteristics of the waterbag to provide the most effective treatment by removing water contaminants commonly found in local waters used for drinking water in emergency situations. Nine experiments were performed which, collectively, led to the examination of three critical variables: (1) optimization of mixing method, (2) optimization of baffle configuration, and (3) characterization of the waterbag's ability to treat challenging test water qualities. These three variables in particular comprised data gaps in Mark II development and needed to be researched for development purposes of the waterbag. Each experiment involved an evaluation of an operational or design variable in terms of water quality improvement, based on disaster relief objectives (see Section 2.1.2 for more detail). Results of each experiment helped to determine the objectives of subsequent experiments. Once optimization of the Mark II treatment protocol was complete, experiments were performed to develop a treatment scheme that could meet the pathogen removal requirements of the U.S. EPA Guide Standard and Protocol for Testing Microbiological Water Purifiers.

Research objectives were accomplished by the following:

1. Performance of optimization experiments to identify baffle configuration and treatment procedure of the Mark II waterbag that resulted in optimal post-treatment water qualities.

2. Identification of $\mathbf{P U} \mathbf{R}^{\circledR}$ sachet capabilities of treating test waters with high organic content, high turbidity, and elevated bacteria concentrations. 
3. Testing the optimized Mark II waterbag and treatment protocol against a U.S. EPA Guide Standard and Protocol for Testing Microbiological Water Purifiers to determine compliance with Safe Drinking Water Act requirements where POU systems may be needed in emergency (temporary) situations.

Due to the iterative nature of the experimental process of this research, each experiment incorporated different procedures, methods, and tested variables. As a result, much variability occurred in experimental results. A primary goal of this research was to identify aspects of the waterbag which were important to specify in the design of the final product. Determining the statistical significance of the variability in the results was not included in the scope of this work. 


\section{CHAPTER 2: BACKGROUND}

This chapter presents a summary of drinking water contaminants typically found in emergency and disaster relief situations. Water quality objectives and treatment options for emergency relief are discussed, with a primary focus on point-of-use (POU) drinking water treatment using Procter \& Gamble's PŪR ${ }^{\circledR}$ Purifier of Water. Previous investigations on the Mark I waterbag are described, followed by a review of the U.S. EPA Guide Standard and Protocol for Testing Microbiological Water Purifiers.

\subsection{Drinking Water Contamination during Emergencies}

Drinking water provision immediately following a natural disaster or emergency is a primary factor affecting the health of survivors (The Sphere Project, 2004). Natural disasters like earthquakes, hurricanes, monsoons, mudslides, and floods often damage water treatment and transportation infrastructure and lead to the contamination of drinking water sources. When infrastructure is destroyed, relief agencies must provide clean drinking water to emergency victims by transporting pre-treated drinking water in from an outside source, or treating water onsite.

Relief agencies take several factors into account when choosing the local water source to be treated for a population affected by a disaster. In particular, important issues are quantity, reliability, access, acceptability, required supplies for collection or storage, raw quality, contamination sources, and treatment requirements of the water source (WHO, 2006). In situations where conveyance and treatment infrastructure has been compromised, disaster victims should assume that all water available during emergencies is contaminated, especially if it is taken from surface waters such as lakes, ponds, rivers, or streams (UNHCR, 
2000). The following sections describe typical water contaminants, especially when surface water is the only water source available for POU treatment.

\subsubsection{Typical Characteristics of Source Water Contamination}

Two types of contamination are prevalent in surface water sources: microbiological and nonmicrobiological. Microbiological contamination includes waterborne pathogens such as bacteria, viruses, protozoa, and helminthes (MWH, 2005). Non-microbiological characteristics such as turbidity, natural organic matter, $\mathrm{pH}$, temperature, dissolved solids, and chemicals are also considered important to the health and water acceptability of water consumers. This brief review will discuss the microbiological contamination of drinking water due to bacteria, viruses, and protozoan cysts only, as well as non-microbiological contamination of surface water typically encountered in disaster relief.

\subsubsection{Microbiological Contamination: Pathogens}

Control of microbiological contamination is of paramount importance when considering treatment options for contaminated source water. According to the World Health Organization (WHO), "infectious diseases caused by pathogenic bacteria, viruses, and parasite (e.g. protozoa and helminthes) are the most common and widespread health risk associated with drinking-water" (WHO, 2006). Although pathogens are found in natural source waters all over the world, each pathogen exhibits varying significance to human health, persistence in water supplies, and resistance to chlorine disinfection (Table 2.1). 
Table 2.1: Waterborne pathogens and their significance in water supplies. Table adapted from World Health Organization Guidelines for Drinking-Water Quality, (2006).

\begin{tabular}{|c|c|c|c|}
\hline Pathogen & $\begin{array}{c}\text { Health } \\
\text { Significance }\end{array}$ & $\begin{array}{c}\text { Persistence in } \\
\text { Water Supplies }\end{array}$ & $\begin{array}{c}\text { Resistance to } \\
\text { Chlorine }^{2}\end{array}$ \\
\hline \multicolumn{4}{|l|}{ Bacteria: } \\
\hline Escherichia coli & high & moderate & low \\
\hline Salmonella typhi & high & moderate & low \\
\hline Vibrio chloerae & high & Short & low \\
\hline \multicolumn{4}{|l|}{ Viruses: } \\
\hline Adenoviruses & high & Long & moderate \\
\hline Poliovirus & high & Long & moderate \\
\hline Hepatitis A virus & high & Long & moderate \\
\hline Rotaviruses & high & Long & moderate \\
\hline \multicolumn{4}{|l|}{ Protozoa: } \\
\hline Cryptosporidium parvum & high & Long & high \\
\hline Giardia intestinalis & high & moderate & high \\
\hline
\end{tabular}

${ }^{1}$ Detection period for infective stage in water at $20^{\circ} \mathrm{C}$ : short, up to 1 week; moderate, 1 week to 1 month; long, over 1 month.

${ }^{2}$ When infective stage is freely suspended in water and treated at conventional doses and contact times. Moderate resistance, agent may not be completely destroyed.

In addition to the information in Table 2.1, other pathogen characteristics such as size and behavior in the environment are important to know so that an appropriate treatment method can be selected. The discussion on bacteria, viruses, and protozoa below presents characteristics which have a significant influence on prescribed treatment.

Bacteria - Water-borne pathogenic bacteria often cause diarrhea or other potentially life-threatening health effects $(\mathrm{MWH}, 2005)$. Bacteria typically range in size from 0.1 $\mu \mathrm{m}$ to $10 \mu \mathrm{m}(\mathrm{MWH}, 2005)$, and therefore cause varying challenges for removal by filtration. However, bacteria are susceptible to disinfection, and can be inactivated when exposed to a disinfectant like chlorine for an adequate period of time (discussed in Section 2.2). Indicator bacteria, like the fecal coliform bacteria E. coli, are 
important in characterizing the microbial quality of water. Presence of the indicator organism in water intended for human consumption means that the water source is contaminated and should be treated before consumption (WHO, 2006). The use of indicator organisms does have its limitations. For example, pathogens may be present in water even in the absence of indicator organisms (MWH, 2005).

Viruses - Viruses are ubiquitous in untreated surface waters around the world. Prevalent viruses include hepatitis A, rotaviruses, poliovirus, and other enteroviruses. When humans are exposed, pathogenic viruses may cause symptoms including fever, headache, vomiting, muscle pain, organ inflammation, and diarrhea, sometimes to a life-threatening degree. Some enteroviruses are resistant to disinfection (including disinfection by chlorine) and can remain pathogenic in a water source after treatment. Since viruses typically range in size from $0.02 \mu \mathrm{m}$ to $0.1 \mu \mathrm{m}$ (MWH, 2005), filtration is often not adequate for virus removal and must be accompanied by disinfection. Common indicator organisms used for virus detection are bacteriophages, which are viruses that infect bacterial cells and have similar environmental persistence to viruses (Shuler \& Kargi, 2002; WHO, 2006).

Protozoa - Protozoa are a group of non-photosynthetic, unicellular organisms that progress through a succession of life stages, including relatively resilient resting stages such as cysts, oocysts, and spores. It is in these resting forms that protozoa can survive outside a host and are fairly resistant to destruction, including inactivation by disinfection. Two of the most prevalent protozoan pathogens in drinking water treatment are Giardia lamblia and Cryptosporidium parvum, which both cause diarrhea in humans when ingested. Both of these protozoa are found worldwide, 
especially in areas with poor sanitation practices. Protozoa typically range in size from $3 \mu \mathrm{m}$ to $16 \mu \mathrm{m}$, with oocysts typically measuring $3 \mu \mathrm{m}$ to $5 \mu \mathrm{m}$ in diameter. Protozoa can remain pathogenic within a water source even after treatment by disinfection (MWH, 2005). Therefore, filtration of a water source contaminated with protozoan cysts is required to ensure minimal risk to human health. Microspheres (often fluorescent) can be used as a surrogate for protozoa in laboratory testing.

\subsubsection{Non-microbiological Contamination}

There are many non-microbiological characteristics of water that can threaten human health or the efficacy of drinking water treatment. Characterization of these constituents in a drinking water source is essential to the determination of an appropriate treatment method. For disaster relief scenarios, the most common concerns are the following:

Turbidity - Highly turbid waters indicate a high level of particulate solids in water, which can decrease the efficacy of disinfection and other treatment methods like filtration. Turbidity data are often used to monitor treatment system performance since the presence of turbidity indicates the presence of particles, which could include pathogens such as bacteria, Giardia cysts, and Cryptosporidium oocysts (MWH, 2005). In a study on the correlation between particle (turbidity) removals and Cryptosporidium removals, particle (turbidity) removal was shown to provide a conservative qualitative indication of Cryptosporidium removal capability (Huck, 2002). In addition, turbid water ( $>5 \mathrm{NTU}$ ) is often considered unacceptable or undrinkable by consumers and therefore can adversely affect public health (WHO, 2006). Formazin standards are typically used as the primary reference standards for 
turbidity, which is measured in nephelometric turbidity units (NTU) (Metcalf \& Eddy, 2003).

Natural Organic Matter - Natural organic matter (NOM) reacts with and consumes both disinfectants and coagulants, so the required dose to achieve effective disinfection or turbidity removal is higher in the presence of elevated NOM concentrations (MWH, 2005). In addition, high concentrations of NOM react with chemical disinfectants like chlorine to create disinfection byproducts (DBP), many of which are carcinogenic. Removal of NOM before disinfection helps avoid DBP formation (MWH, 2005).

$p H-\mathrm{pH}$ is an important water quality constituent of natural water sources because the concentration of many dissolved chemical constituents is dependent on the hydrogen-ion concentration (Metcalf \& Eddy, 2003). In addition, high alkaline (high $\mathrm{pH}$ ) water requires longer disinfection contact time or a higher free chlorine residual to ensure adequate disinfection; for most effective disinfection with chlorine, the $\mathrm{pH}$ of a source water should be less than 8 (WHO, 2006). The formation of some problem DBPs from disinfection with chlorine can be reduced by increasing or decreasing the $\mathrm{pH}$ during chlorination (MWH, 2005).

Temperature - Temperature affects chemical reactions and reaction rates and acceptability of the water to consumers (Metcalf \& Eddy, 2003; WHO, 2006). In general, higher temperatures result in faster chemical reaction rates $(\mathrm{MWH}, 2005)$. Therefore, chemical reactions like disinfection with chlorine and coagulation/flocculation are adversely affected in low-temperature water. However, 
high water temperature enhances microorganism growth and may increase taste, odor, color and corrosion problems in water systems (WHO, 2006).

Total Dissolved Solids - Total dissolved solids (TDS) concentrations (and the charges of the salt ions that usually comprise most of TDS) affect coagulation and flocculation. If TDS is high enough to cause taste or potential health problems, TDS removal would be desirable as part of drinking water treatment.

Chemicals - In natural disaster relief operations, chemicals are generally not of immediate concern for consumers because many chemicals in drinking water pose a risk only after extended exposure (WHO, 2006). In most disaster relief situations, consumption of a chemically-contaminated water source is temporary. Where water sources are likely to be used for extended periods of time, greater attention should be given to chemical constituent concentrations (WHO, 2006).

\subsubsection{Drinking Water Quality Objectives for Emergency Relief}

Minimum standards in core areas of humanitarian assistance have been created in an effort to standardize the quality of assistance provided to people affected by disasters. The Sphere Project, a program created in 1997 by a group of humanitarian non-governmental organizations (NGOs) and other relief agencies, has created the Humanitarian Charter and Minimum Standards in Disaster Response (2004). The charter and minimum standards advocate disaster assistance in five sectors of relief efforts: water supply and sanitation, nutrition, food aid, shelter, and health services (The Sphere Project, 2004). The water quality specifications in The Sphere Project's charter and minimum standards are a compilation of the drinking water quality conditions proposed by numerous prominent relief organizations. 
The WHO and U.S. EPA have also created emergency response guidelines and standards for drinking water quality. The WHO has published several documents regarding minimum standards for drinking water quality for disaster relief, including Guidelines for Drinkingwater Quality (2006) and Environmental Health in Emergencies and Disasters: A Practical Guide (2002). The U.S. EPA issued a Guide Standard and Protocol for Testing Microbiological Water Purifiers (1987) to standardize the evaluation of microbiological water purifiers (described in Section 2.4). The combined drinking water quality objectives of The Sphere Project, WHO, and U.S. EPA create a comprehensive guide for emergency relief efforts (Table 2.2).

Table 2.2: Drinking water quality objectives for emergency response, issued by the Sphere Project (2004), WHO (2006), and U.S. EPA (1987).

\begin{tabular}{ccc}
\hline Constituent & Objective Value & Issuing Agency \\
\hline E. coli & $<2$ CFU/100 mL & The Sphere Project (2004) \\
The Sphere Project (2004), & WHO (2006) \\
Turbidity & $0.2-0.5 \mathrm{mg} / \mathrm{L}$ & The Sphere Project (2004) \\
pH & $<5$ NTU & WHO (2006) \\
Bacteria & 6 to 8 & U.S. EPA (1987) \\
Viruses & 4-log removal $(99.9999 \%)$ & U.S. EPA (1987) \\
Protozoan Cysts & 3-log removal $(99.99 \%)$ & U.S. EPA (1987) \\
\hline
\end{tabular}

The primary focus of microbial treatment of drinking water should be on providing appropriate disinfection of a contaminated water source. The treatment goal for E. coli for all water supplies is zero E. coli per $100 \mathrm{~mL}$ of water. This goal should be the treatment objective for emergencies as well, though this may be difficult to achieve in immediate postdisaster circumstances (WHO, 2006). Since some pathogens are resistant to disinfection, 
residual chlorine (or other disinfectant) should be maintained in the distribution system for emergency situations. Minimum chlorine concentrations at point of delivery are $0.2 \mathrm{mg} / \mathrm{L}$ in normal circumstances and $0.5 \mathrm{mg} / \mathrm{L}$ in high-risk circumstances (WHO, 2006). Disinfectants should be allowed a contact time in the treated water of at least 30 minutes prior to consumption, and turbid waters should be clarified (by settling) and/or filtered before disinfection. Though disinfection in emergency situations may not eliminate the number of pathogens in drinking water, implementation of appropriate disinfection procedures will result in a decreased risk of illness to the consumer. A pre-disinfection turbidity of $<5$ NTU and an initial $\mathrm{pH}$ between 6 and 8 are required to prevent interference with disinfection (The Sphere Project, 2004; WHO, 2006). In addition, a turbidity of <5 NTU provides a low turbidity to allow for long filter runs before clogging. Bacteria, virus, and protozoan cysts removals are based on the requirements of U.S. EPA Guide Standard and Protocol for Testing Microbiological Water Purifiers (described in Section 2.4).

\subsection{Point-of-Use Drinking Water Treatment using PŪR ${ }^{\circledR}$ Purifier of Water}

The most appropriate water treatment technology for a population affected by disaster depends on existing water and sanitation conditions, water quality, cultural acceptability, implementation feasibility, and other conditions (CDC, 2008). In response to the need for a widely effective and universally-appropriate point-of-use (POU) treatment technology, Procter \& Gamble, in conjunction with the Centers for Disease Control (CDC), developed a combined flocculation and disinfection water treatment technology: PŪR ${ }^{\circledR}$ Purifier of Water (PŪR ${ }^{\circledR}$ ). PŪR ${ }^{\circledR}$ was designed to replicate the functions of a water treatment plant, incorporating several barrier processes of particulate removal followed by disinfection (CDC, 2008; Lantagne \& Clasen, 2009). When used appropriately, PŪR ${ }^{\circledR}$ has been proven to reduce 
numbers of bacteria, viruses, and protozoa even in turbid water, remove heavy metals and chemical contaminants like some pesticides, and provide residual protection against recontamination (CDC, 2008).

A drawback of flocculant/disinfectant powder combinations is that multiple steps are required to use the product, thereby increasing the potential of user-error and introducing the need for a demonstration before users can implement the technology. In addition, Procter \& Gamble's currently prescribed PŨR $^{\circledR}$ method-of-use requires several appurtenances, including two buckets, a stirring device, and clean filter cloth (CDC, 2008). To treat water using $\mathrm{PUT}^{\circledR}$, a user collects ten liters of contaminated water in a utility bucket or pail. Next, the user adds a single four-gram sachet to the water, and mixes $\mathrm{PU}^{\circledR}{ }^{\circledR}$ into the water for approximately five minutes with a stirring spoon. After letting the flocculated solids settle, the user decants the treated water through the filter cloth (such as a t-shirt or towel) into the second bucket. After approximately 30 minutes of disinfection time, the user can drink the treated water. Since PURR ${ }^{\circledR}$ is most appropriate where education can be provided to users on correct use of the product, independent operation of this two-bucket method with $\mathrm{PU}^{\circledR}{ }^{\circledR}$ may be problematic (CDC, 2008; Lantagne \& Clasen, 2009).

\subsubsection{Chemical Composition}

The PŪR ${ }^{\circledR}$ sachet contains four grams of a powdered chemical mixture including a coagulant (ferric sulfate), flocculants (polyacrylamide and chitosan), an alkaline agent (sodium carbonate), and chlorine disinfectant (calcium hypochlorite) (Table 2.3; Souter et al., 2003; CDC, 2008). The ingredients in $\mathrm{PU}^{\circledR}{ }^{\circledR}$ have been formulated to work quickly on small volumes of water by aggregating and facilitating the removal of suspended organic matter, bacteria, viruses, parasites, and heavy metals in treated water (Reller et al., 2003). The 
following sections describe the primary treatment mechanisms of $\mathrm{PU}^{\circledR}{ }^{\circledR}$ based on its ingredients listed in Table 2.3.

Table 2.3: $\mathbf{P} \overline{\mathbf{U}} \mathbf{R}^{\circledR}$ ingredients include an iron salt coagulant, disinfectants, and flocculants and flocculating aids (Souter, Cruickshank, \& Stoddart, 2007; Reller, et al., 2003; Compas, 2009a).

\begin{tabular}{ccc}
\hline Ingredient & Molecular Formula & Purpose \\
\hline Ferric sulfate & $\mathrm{Fe}_{2}\left(\mathrm{SO}_{4}\right)_{3}$ & Coagulant \\
Calcium hypochlorite & $\mathrm{Ca}(\mathrm{ClO})_{2}$ & Chlorine-based disinfectant \\
Sodium carbonate & $\mathrm{Na}_{2} \mathrm{CO}_{3}$ & Alkaline agent \\
Potassium & $\mathrm{KMnO}_{4}$ & Oxidant, acts as disinfectant \\
permanganate & & $\begin{array}{c}\text { Swelling clay (excellent colloidal } \\
\text { properties), flocculation aid }\end{array}$ \\
Bentonite & polymer & Flocculant \& flocculation aid \\
Polyacrylamide & $\left(-\mathrm{CH}_{2} \mathrm{CHCONH}_{2}\right)$ & Flocculant \& flocculation aid \\
Chitosan & &
\end{tabular}

\subsubsection{Coagulation, Flocculation, and Sedimentation}

$\mathrm{PUTR}^{\circledR}$ utilizes three primary means of particle removal: coagulation, flocculation, and sedimentation. Though each treatment mechanism is technically an independent reaction, the three methods are often combined to remove particles by means of aggregation (Metcalf \& Eddy, 2003).

\subsubsection{Coagulation}

Chemical coagulation is the process of destabilizing the surface charges of colloidal particles so that particle floc formation can occur. "In this process, colloidal particles such as clays, [which] do not readily settle in plain sedimentation, are encouraged to combine to form heavier particles that will settle by adding a chemical coagulant" (Wisner \& Adams, 2002). Colloids are $0.01 \mu \mathrm{m}$ to $1 \mu \mathrm{m}$ particles, typically with a net negative surface charge. The 
negative electrical surface charges of colloids cause a natural repulsion to one another, while Brownian motion (i.e. random movement) keeps the particles in suspension (Metcalf \& Eddy, 2003). To remove colloids from water, their surface charges must be neutralized to allow particle-on-particle collisions. Charge neutralization is accomplished by shrinking the electric double layer of colloidal particles (Figure 2.1).

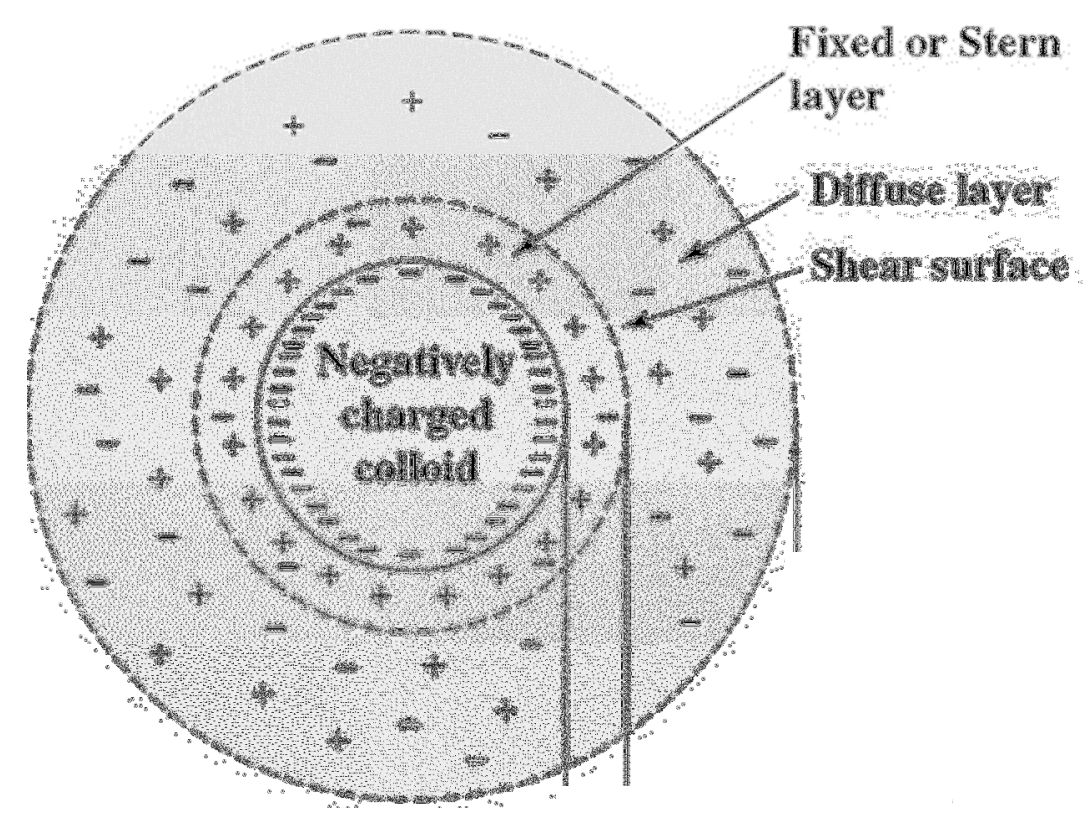

Figure 2.1: Electric double layer of a negatively charged colloid. Coagulation works by shrinking the double layer of a charged colloidal particle (Sawyer, McCarty, \& Parkin, 2003).

A colloid becomes charged when counterions (i.e. ions of the opposite charge) are attracted to and attach to the surface of the particle. The counterions form a fixed layer of oppositely charged ions, which are held in place through electrostatic and van der Waals forces. The attractive forces between the colloid and fixed first layer are strong enough to overcome the natural thermal agitation of the surrounding water. Surrounding this fixed layer is a second layer of diffusely scattered ions of both positive and negative charges. This diffuse layer is 
prevented from forming a compact layer (like the first layer of counterions) because of natural thermal agitation in the water (Metcalf \& Eddy, 2003).

To neutralize the charged colloidal surfaces, divalent metal cations (i.e. $\mathrm{Fe}^{3+}$ ) are introduced by the coagulant, such as the ferric sulfate $\left[\mathrm{Fe}_{2}\left(\mathrm{SO}_{4}\right)_{3}\right]$ coagulant in PŪR ${ }^{\circledR}$. The divalent cations are strongly attracted to the negatively-charge colloid, and subsequently cause the electric double layer to shrink. The shrinking of the double layer causes charge destabilization, and the colloidal particles can freely collide with one another without repulsive electrical forces.

\subsubsection{Flocculation}

Once the surface charges of colloidal particles have been neutralized by coagulation, the resulting collisions between destabilized particles cause particle sizes to increase through a process called flocculation. Flocculating chemicals are natural or synthetic polymers, which encourage particle aggregation through either Brownian motion or induced mixing in the fluid with colloidal particles requiring flocculation (Metcalf \& Eddy, 2003). By inducing velocity gradients in a fluid, particles can be forced to collide and stick to one another, forming larger particulate flocs. Even viruses $(0.1 \mu \mathrm{m}$ in size or smaller) can be adsorbed or enmeshed in larger flocs and be physically removed from water (Metcalf \& Eddy, 2003). $\mathrm{PUTR}^{\circledR}$ sachets contain a coagulating aid called bentonite, a swelling clay with colloidal properties (Table 2.3). The inclusion of bentonite aids in flocculation in source waters with low initial turbidities. PŪR ${ }^{\circledR}$ sachets include two flocculants: polyacrylamide and chitosan polymers. The inclusion of these flocculating agents increases floc formation and subsequent particle removal. 


\subsubsection{Sedimentation}

Once coagulation and flocculation have been executed, sedimentation occurs to permanently remove particulates from water. Sedimentation refers to the separation of suspended particles that are heavier than water by gravitational settling (Metcalf \& Eddy, 2003). Gravitational settling characteristics vary based on concentration and interaction of particles. In large-scale systems, settling generally depends on fluid density and viscosity, gravitational force, diameter and terminal settling velocity, and drag forces (Metcalf \& Eddy, 2003). For smallscale POU applications in emergency relief situations, sedimentation is accomplished given effective coagulation/flocculation, settling time, and a low-disturbance environment.

\subsubsection{Mixing}

Mixing is a critical step in successful particulate removal with coagulation and flocculation. Mixing imparts kinetic energy to the water through physical action, and induces velocity gradients in the fluid to be treated, which results in particle interactions with coagulating and flocculating chemicals as well as collisions with other particles. Mixing is required to homogenize the contents of a contaminated water source once products like PŪR ${ }^{\circledR}$ have been added for treatment. In the case of coagulation, immediate, rapid mixing prevents metal salt coagulants from hydrolyzing with water (Metcalf \& Eddy, 2003). For flocculation, continuous gentle mixing is required to induce particle-particle collisions and interaction with the long-chained polymer flocculants, and encourages the formation of large, heavy flocs which subsequently settle quickly. Rapid mixing during flocculation is undesirable because high mixing velocities cause the flocs to break apart (Lundquist, 2009a).

For coagulation/flocculation with $\mathrm{PU}^{\circledR}{ }^{\circledR}$, a mixing time of five minutes is required for complete homogenization, chemical distribution, and to achieve sufficient turbulence for 
complete coagulation and flocculation to occur. The power input (i.e. energy input per time) required to achieve adequate mixing depends on the volume of water to be treated, fluid viscosity, and the average velocity gradient established in the fluid with mixing. The power input for a given volume of water can be used as a rough measure of mixing effectiveness because, in general, greater power input creates greater turbulence, and greater turbulence results in better mixing (Metcalf \& Eddy, 2003). In the context of PŪR ${ }^{\circledR}$, the users provide the energy input and turbulence.

\subsubsection{Chlorine Disinfection}

Reducing microbiological contamination is accomplished by either removing microorganisms from water or through inactivation of the organisms. Inactivated organisms may be still present in a water source, but, generally, they can no longer reproduce and cause illness to consumers (MWH, 2005). Residual disinfection capacity is important to ensure that treated water is protected from recontamination during storage, distribution, or transport (CDC, 2005). Common chemical disinfectants include chlorine, combined chlorine, chlorine dioxide, and ozone (MWH, 2005).

After chlorine is added to drinking water it proceeds through a series of reactions affected by the water chemistry (temperature, $\mathrm{pH}$, ammonia content, organic content, etc.). First, some of the chlorine reacts with organic materials and metals in water and is not considered available for disinfection; this consumed chlorine is described as the chlorine demand of the water. In particular, the presence of oxidizable compounds such as humic acid, iron, and manganese consume chlorine, making chlorine unavailable for inactivation of microorganisms ( $\mathrm{MWH}$, 2005). The remaining chlorine is considered the total chlorine, which is the sum of the combined chlorine residual and the free chlorine residual. When ammonia is present in 
water, chlorine reacts successively with ammonia to form combined chlorine (or chloramines) (CDC, 2005; MWH, 2005). Free chlorine is the sum of hypochlorous acid $(\mathrm{HOCl})$ and hypochlorite ions $\left(\mathrm{OCl}^{-}\right)$, which are both more effective disinfectants than chloramines. The relative distribution of $\mathrm{HOCl}$ and $\mathrm{OCl}^{-}$in treated water is affected by temperature and $\mathrm{pH}$. Though both species have good disinfection capabilities, $\mathrm{HOCl}$ is a more effective disinfectant; therefore, characterization of species distribution is important to predicting disinfection performance (Tchobanoglous \& Schroeder, 1987). Figure 2.2 illustrates the distribution of $\mathrm{HOCl}$ and $\mathrm{OCl}^{-}$as a function of temperature and $\mathrm{pH}$.

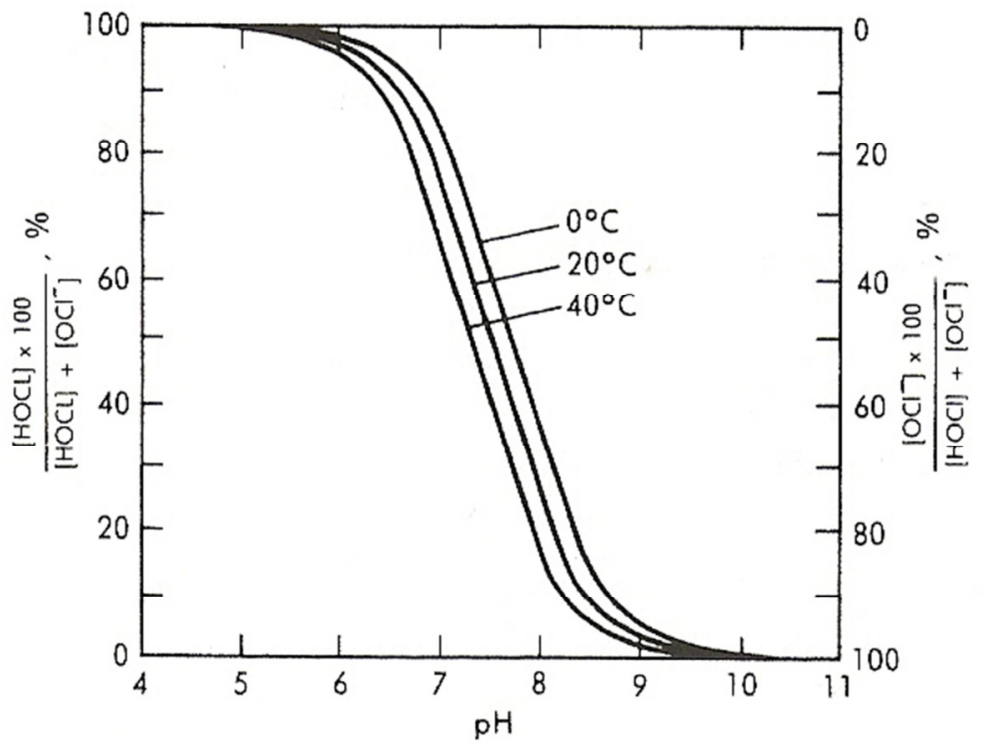

Figure 2.2: Distribution of $\mathrm{HOCl}$ and $\mathrm{OCl}$ - as a function of $\mathrm{pH}$ and temperature (Tchobanoglous \& Schroeder, 1987).

To ensure adequate chlorine dosage, the amount of total chlorine added to a water source for disinfection is typically greater than the estimated amount of free chlorine required to inactivate pathogens $(\mathrm{CDC}, 2005)$. $\mathrm{PU}^{\circledR}{ }^{\circledR}$ sachets include calcium hypochlorite $\left[\mathrm{Ca}(\mathrm{OCl})_{2}\right]$, which disassociates in water to produce disinfecting hypochlorite ions $\left(\mathrm{OCl}^{-}\right)$and contributes to the amount of free chlorine available for disinfection. Depending on source water quality, the free chlorine contained in a single PŪR ${ }^{\circledR}$ sachet may be an under- or over-estimate of the 
free chlorine required to provide adequate disinfection. To ensure that the free chlorine contained in a single four-gram sachet is enough, $P \mathrm{PUR}^{\circledR}$ also contains potassium permanganate $\left(\mathrm{KMnO}_{4}\right)$, which is a strong oxidant and disinfecting aid. The strong oxidizing capacity of $\mathrm{KMnO}_{4}$ helps destroy organic matter to remove chlorine demand and allocate more free chlorine for disinfection.

Chlorine inactivates most pathogens found in contaminated water sources, but each pathogen exhibits varying resistances to chlorine disinfection (CDC, 2007). The kinetics of most chemical disinfectants are complex, and they are influenced by the chemistry of disinfectant as well as the susceptibility of the organism to disinfection (MWH, 2005). However, an empirical disinfection parameter, $\mathrm{Ct}$, can be established for the inactivation efficiency for a given organism using a disinfectant residual concentration (C) multiplied by the disinfection contact time (t) (Table 2.4; MWH, 2005). The Ct factor is used to compare the efficacy of chlorine disinfection of various pathogens. The $\mathrm{Ct}$ value needed to achieve a given disinfection efficiency (e.g., 99\% inactivation) will be high if the organism is highly resistant to chlorine (CDC, 2007). 
Table 2.4: Centers for Disasease Control Safe Water System summary on chlorine inactivation of selected pathogens (CDC, 2007).

\begin{tabular}{|c|c|c|c|c|c|c|}
\hline \multirow{2}{*}{ Pathogen } & \multirow{2}{*}{$\begin{array}{c}\mathrm{C} \\
(\mathrm{mg} / \mathrm{L})\end{array}$} & \multirow{2}{*}{$\mathbf{t}(\min )$} & \multirow{2}{*}{$\begin{array}{c}\mathbf{C t} \\
\text { Factor }\end{array}$} & \multirow{2}{*}{$\begin{array}{c}\text { Inactivation } \\
(\%)\end{array}$} & \multicolumn{2}{|c|}{$\begin{array}{c}\text { Variables Affecting } \\
\text { Ct Factor }\end{array}$} \\
\hline & & & & & $\begin{array}{c}\text { Temperature } \\
\left({ }^{\circ} \mathrm{C}\right)\end{array}$ & pH \\
\hline \multicolumn{7}{|l|}{ Bacteria: } \\
\hline E. coli & 0.5 & $<0.5$ & $<0.25$ & 99.999999 & 23.0 & 7.0 \\
\hline Salmonella typhi & 0.05 & 20 & 1 & 99.2 & $20.0-25.0$ & 7.0 \\
\hline Vibrio cholerae & 0.5 & $<1$ & $<0.5$ & 100 & 20.0 & 7.0 \\
\hline \multicolumn{7}{|l|}{ Viruses: } \\
\hline Hepatitis A & 0.41 & $<1$ & $<0.41$ & 99.99 & 25.0 & 8.0 \\
\hline Poliovirus & 0.5 & 12.72 & 6.36 & 99.99 & 5.0 & 6.0 \\
\hline Rotavirus & 0.2 & 0.25 & 0.05 & 99.99 & 4.0 & 7.0 \\
\hline \multicolumn{7}{|l|}{ Protozoa: } \\
\hline Giardia lamblia & 1.5 & 10 & 15 & 99.9 & 25.0 & 7.0 \\
\hline \multicolumn{7}{|l|}{ Cryptosporidium } \\
\hline parvum & 80 & 90 & 7200 & 99 & 25.0 & 7.0 \\
\hline
\end{tabular}

For most bacteria and viruses, chlorine disinfection is effective. But for certain protozoa like Cryptosporidium oocysts, chlorine disinfection is not effective at practical $\mathrm{Ct}$ values (CDC, 2007). Since the discovery of the chlorine-resistance of organisms like Giardia and Cryptosporidium, some regulatory agencies only recognize removal, not inactivation, as an effective method for controlling pathogens in drinking water (MWH, 2005). Chlorine alone should not be expected to inactivate Cryptosporidium in drinking water treatment plants (CDC, 2007); therefore, filtration is often recommended to physically remove pathogens resistant to disinfection.

\subsubsection{Disinfection Efficacy}

Five important factors affect the disinfection with chlorine compounds in drinking water: (1) initial mixing, (2) chemical constituents of the water, (3) particles in water, (4) presence of 
coliforms within particles, and (5) characteristics of microorganisms (Metcalf \& Eddy, 2003). Initial mixing after chlorine addition is imperative to achieving high inactivation rates. In fact, the application of chlorine into highly turbulent conditions (Reynolds number greater than $10^{4}$ ) will result in inactivations two orders of magnitude greater than when chlorine is added into more laminar conditions (Metcalf \& Eddy, 2003). The chemical characteristics of a water source also affect the efficacy of chlorine disinfection. Organic compounds exert an immediate chlorine demand with higher or lower interferences based on their functional groups. Suspended solids in water affect disinfection by interfering with pathogen-chlorine contact. High suspended solids (higher turbidity) create increased interference with disinfection, while low suspended solids have little interference with disinfection. When particles contain significant numbers of coliform bacteria, embedded organisms are protected by other organisms, thereby shielding them from inactivation by chlorine. Pathogen characteristics like number, type, and age affect the disinfection capacity of chlorine, and chlorine dosages should be adjusted based on the characteristics of the source water (Table 2.4; Metcalf \& Eddy, 2003).

\subsection{Waterbag Alternative for Drinking Water Treatment using PŪR ${ }^{\circledR}$}

$\mathrm{PU}^{\circledR}{ }^{\circledR}$ is an effective means of POU drinking water treatment, especially in disaster relief or emergency response applications. However, the currently-prescribed treatment method using $\mathrm{PU}^{\circledR}{ }^{\circledR}$ has drawbacks. For example, the requirement of two buckets, a mixing implement, and a clean filter cloth may prevent widespread use of $P \bar{U} R^{\circledR}$ for disaster survivors who do not have access to those appurtenances. In addition, once drinking water has been treated using PŪR ${ }^{\circledR}$, storage of drinking water in potentially uncovered buckets allows for the recontamination of water. Finally, the filter cloth used to separate treated water from settled 
solids introduces some risk to the user; if reused incorrectly, users risk ingesting pathogens like Cryptosporidium that are resistant to disinfection.

Researchers at Cal Poly State University in San Luis Obispo have developed an alternative treatment method using PŪR ${ }^{\circledR}$, hereafter called the waterbag (Compas, 2009a; US Patent $7,514,006)$. Instead of requiring multiple supplies to treat water, the waterbag incorporates collection, treatment, transport, and storage in a single unit. With PŪR ${ }^{\circledR}$, each waterbag treats ten liters of water at a time, collected from local contaminated water sources like rivers, lakes, streams, or even puddles. Waterbags users treat the collected ten liters of water with the four-gram PŪR ${ }^{\circledR}$ sachets (described in Section 2.2), along with a filter for cyst removal. The treatment steps for the waterbag are similar to the $\overline{P U R}^{\circledR}$ two-bucket method and include the following: (1) rapid mixing of $\mathrm{PU}^{\circledR}{ }^{\circledR}$ into ten liters of contaminated water to facilitate coagulation and flocculation, (2) sedimentation of flocculated particles, (3) 30 minutes of disinfection time, and (4) filtration to separate flocculated solids from treated water. The main difference between the waterbag and two-bucket method is that the waterbag method leaves the sediment in contact with the water during the 30-min disinfection period. In addition, waterbags are to be shipped in a kit with multiple PŪR ${ }^{\circledR}$ sachets for a potential reuse of at least ten times. The all-in-one features of the waterbags can help ensure immediate provision of drinking water following a natural disaster, with the potential for long-term use if needed (Lundquist, 2009b).

From 2008 to 2009, Tricia Compas performed an investigation of the Mark I version of the waterbag, including experiments related to product optimization, filter selection, and baseline water quality requirements. In addition, Compas' research involved testing the Mark I waterbag design against the U.S. EPA Guide Standard and Protocol for Testing 
Microbiological Water Purifiers (described in Section 2.4). In her optimization experiments, Compas identified the optimal mixing time and method that resulted in lowest final turbidities and highest bacterial removals. Compas also performed a detailed investigation of filters including filter material, pore size, flow rates, and configuration. She performed several tests to determine the waterbag's efficacy in treating drinking water with variables such as low to high organic content, low to high turbidities, normal to high $\mathrm{pH}$, low to normal temperature, and high TDS concentrations. Although the Mark I waterbag consistently met WHO emergency drinking water guidelines for turbidity, chlorine residual, and pH, the U.S. EPA Challenge Water test results did not meet U.S. EPA minimum microorganism reductions (Compas, 2009a).

The research described herein focused on the optimization of the Mark II waterbag, an improved version of the Mark I treatment device that was developed prior to the start of the present thesis research. A U.S. continuation patent is pending on the Mark II design. Many of the materials and methods used during this research period (described in Chapter 3) are derived from the materials and methods of Compas' research on the Mark I bag.

The primary differences between the Mark I and Mark II waterbags are in the physical construction of the bags, as well as prescribed mixing method. In both aspects, the Mark II design improved the ease of use. While the Mark I bag had a 4:1 height-to-width ratio, the Mark II bag used a 2.5:1 height-to-width ratio to be more compact. In addition, the Mark II version includes one or two internal mixing baffles for increased turbulence and therefore better particulate removals and disinfection qualities. Finally, the Mark II mixing method requires the user to hold the bag vertically to the side or to hang the bag from a post or tree, and mix by twisting the bag from side to side. The inclusion of a mixing baffle increases the 
amount of turbulence in the waterbag without requiring substantial additional mixing intensity from the user. The Mark I version required vigorous vertical and horizontal mixing, a process that may have been difficult for fatigued users.

The optimization experiments and U.S. EPA Challenge Water experiments performed during this research period were conducting using the Mark II waterbag. Optimization experiments were performed to determine optimal operating conditions of the waterbag to produce sufficient water quality for disaster relief. Primarily, the results of the optimization experiments were used to prescribe an optimal treatment protocol to be used and repeated by users in disaster relief situations. Testing of the waterbag against U.S. EPA Guide Standard and Protocol for Testing Microbiological Water Purifiers (described in Section 2.4) was performed to determine compliance with temporary POU drinking water standards, and to characterize the performance of the waterbag treatment protocol against challenging test water conditions.

\subsection{U.S. EPA Guide Standard and Protocol for Testing Microbiological Water Purifiers}

Based on the Safe Drinking Water Act requirements where POU treatment units may be needed to temporarily treat contaminated water supplies, the U.S. EPA has developed a Guide Standard and Protocol for Testing Microbiological Water Purifiers as a guide for regulation compliance. The guide applies to microbiological water purification units that "remove, kill or inactivate all types of disease-causing microorganisms from the water, including bacteria, viruses and protozoan cysts so as to render the processed water safe for drinking" (U.S. EPA, 1987). The U.S. EPA Guide Standard and Protocol for Testing Microbiological Water Purifiers describes three general types of microbiological water 
purification units to which the standard applies: (1) ceramic filter, (2) halogenated disinfectants (chemical disinfection and filtration), and (3) ultraviolet irradiation (U.S. EPA, 1987). Halogenated disinfectants (i.e. $P \bar{U}^{\circledR}{ }^{\circledR}$ ) refer to chemical compounds containing a halogen element, most commonly chlorine, iodine, or bromine (Metcalf \& Eddy, 2003).

The U.S. EPA Guide Standard and Protocol for Testing Microbiological Water Purifiers contains the basic framework for the testing and evaluation of microbiological water purifiers. The document provides protocols using "challenge waters" formulated to represent a realistic worst-case scenario for the treatment unit under study (U.S. EPA, 1987; BioVir, not dated). In order meet the standard, microbiological water treatment units must provide sufficient removals of the challenge organisms specified by the standard (Table 2.5). Included in the U.S. EPA Challenge Water are three types of organisms: (1) coliform bacteria, (2) viruses, and (3) protozoan cysts. The U.S. EPA chose these pathogens for the testing protocol because of their widespread occurrence in contaminated water sources and for their high resistance to a variety of treatment processes (U.S. EPA, 1987). 
Table 2.5: U.S. EPA initial challenge organisms, initial challenge concentrations, and reduction requirements for microbiological water purifiers.

\begin{tabular}{|c|c|c|c|}
\hline \multirow[t]{2}{*}{ Organism } & \multirow{2}{*}{$\begin{array}{c}\text { Initial } \\
\text { Challenge }^{1}\end{array}$} & \multicolumn{2}{|c|}{$\begin{array}{l}\text { Minimum Required } \\
\text { Reduction }\end{array}$} \\
\hline & & $\log$ & $\%$ \\
\hline \multicolumn{4}{|l|}{ Bacteria: } \\
\hline Klebsiella terrigena & $10^{7} / 100 \mathrm{~mL}$ & 6 & 99.9999 \\
\hline \multicolumn{4}{|l|}{ Virus: } \\
\hline $\begin{array}{r}\text { Poliovirus } 1 \\
\text { Rotavirus }\end{array}$ & $\begin{array}{l}10^{7} / \mathrm{L} \\
10^{7} / \mathrm{L}\end{array}$ & 4 & $99.99^{2}$ \\
\hline \multicolumn{4}{|l|}{ Protozoan Cyst: } \\
\hline Giardia muris or G. lamblia & $10^{6} / \mathrm{L}$ & 3 & 99.9 \\
\hline $\begin{array}{r}\text { Particles or microspheres } 4-6 \\
\mu \mathrm{m}\end{array}$ & $10^{7} / \mathrm{L}$ & 3 & 99.9 \\
\hline
\end{tabular}

1 "Influent challenges may constitute greater concentrations than would be anticipated in source waters, but these are necessary to properly test, analyze, and quantitatively determine the indicated log reductions." (U.S. EPA 1987)

${ }^{2}$ A combined 4-log reduction between both virus types listed is acceptable.

The specified initial challenge concentrations of these organisms are based on concentrations observed in surface waters or storm waters, which may be the only water source available during emergency situations. For example, the initial concentration of coliform bacteria required has been observed in highly polluted stream waters. The initial concentration for viruses is based on the estimated concentration of viruses that would be found in natural waters contaminated with raw sewage. And although concentrations of Giardia in natural source waters are typically low, the initial concentration of protozoan cysts was determined based on conservative estimates of historical Giardia removals by filtration. The target log reductions for each microorganism (and subsequent effluent concentrations) are based on the requirements of either (1) the National Primary Drinking Water Regulations (coliform 
bacteria) or (2) the EPA health-based recommended maximum contaminant level (viruses and cysts) (U.S. EPA, 1987).

\subsubsection{Microbiological Water Purifier Test Protocol}

The testing protocol for the U.S. EPA Guide Standard and Protocol for Testing Microbiological Water Purifiers was established to identify the capability of the treatment unit under study to meet both microbiological and physical challenges of contaminated source water. Along with the pathogen removals in Table 2.5, standardized test waters include chemical and physical augmentation challenges (Table 2.6). The U.S. EPA specifies five test waters, each with characteristics based on the type of treatment unit to be tested. This research presented herein focuses on Challenge Test Water \#2, meant to challenge units using halogen disinfectants (U.S. EPA 1987).

Table 2.6: U.S. EPA Challenge Test Water characteristics for Test Water \#2 for units using halogen disinfection.

\begin{tabular}{ccc}
\hline Constituent & Challenge Value & $\begin{array}{c}\text { Recommended Materials } \\
\text { for Adjustment of Test } \\
\text { Water Characteristics }\end{array}$ \\
\hline Chlorine residual & none & deionized water \\
pH & $9.0 \pm 0.2$ & HCl or NaOH \\
TOC & not less than $10 \mathrm{mg} / \mathrm{L}$ & humic acids \\
Turbidity & not less than $30 \mathrm{NTU}$ & fine test dust $1^{1}$ \\
Temperature & $4^{\circ} \mathrm{C} \pm 0.1^{\circ} \mathrm{C}$ & refrigeration/ice \\
TDS & $1500 \pm 150 \mathrm{mg} / \mathrm{L}$ & sea salts \\
\hline
\end{tabular}

${ }^{1}$ Fine test dust recommended was A2 Fine Test Dust ISO 12103-1.

The augmented water characteristics in Test Water \#2 provide challenges to water treatment using halogen (specifically chlorine) disinfection. For example, high $\mathrm{pH}$ can negatively affect the disinfection capacity of chlorine; the specified $\mathrm{pH}$ of $9.0 \pm 0.2$ is high, but is still within 
the range seen in some natural water sources (U.S. EPA, 1987). Organic carbon (quantified above as TOC) interferes with coagulation and with chlorine disinfection because it exerts a chlorine demand; the degree of interference is dependent on the chemical composition of the organic carbon present in the water source (Metcalf \& Eddy, 2003). The inclusion of humic acid as a carbon source additionally reduces the "effectiveness of chlorine by forming chlorinated organic compounds that are measured as chlorine residual but are not effective for disinfection" (Metcalf \& Eddy, 2003). High turbidities can shield microorganisms and decrease the efficacy of the disinfectant on treating the contaminated water. For Challenge Test Water \#2, the U.S. EPA recommends a turbidity of not less than 30 NTU because "this level is found in many surface waters, especially during periods of heavy rainfall and snow melt" (U.S. EPA, 1987). With chemical disinfection, decreases in temperature generally decrease the rate of kill of microorganisms; $4^{\circ} \mathrm{C}$ or colder is a common low temperature in some natural waters (U.S. EPA, 1987). High concentrations of TDS interfere with adsorptive processes in water treatment; the recommended TDS concentration of $1500 \mathrm{mg} / \mathrm{L}$ represents a realistic concentration often found in drinking water supply sources. The inclusion of these augmented variables in the U.S. EPA Challenge Water constitutes a challenging treatment scenario for microbiological water purifiers. 


\section{CHAPTER 3: MATERIALS AND METHODS}

This section describes Mark II prototype construction, experimental design of the optimization experiments and U.S. EPA Challenge Water experiments, water quality measurement variables considered, and quality control efforts used during experimentation.

\subsection{Mark II Prototype Construction}

The Mark II prototype, used for all experiments conducted for this research, includes several key design features which contribute to water treatment (Figure 3.1). First, the wide-mouth opening of the bag allows for users to fill the bag in shallow puddles or streams in the absence of a substantial current. The integrated dry-bag closure creates a tight seal which prevents water in the waterbag from being re-contaminated after treatment. The tapered bottom of the waterbag creates a funnel which guides settling solids to the bottom, below the outlet valve. In addition, the tapered design of the bag increases water yield compared to a bag with straight sides along its entire length. Based on sediment accumulation after treatment, the outlet valve is located approximately $10.2 \mathrm{~cm}$ above the sediment. The internal mixing baffle(s) help create turbulence in the waterbag during mixing. When mixing, the user turns the bag from side-to-side; the baffle creates a cutting effect through the water, creating eddy currents and helping to promote homogenization after PŪR ${ }^{\circledR}$ addition. Both the original Mark I and the current Mark II design were created by Tricia Compas and Dr. Tryg Lundquist at Cal Poly State University in San Luis Obispo, Calif. 


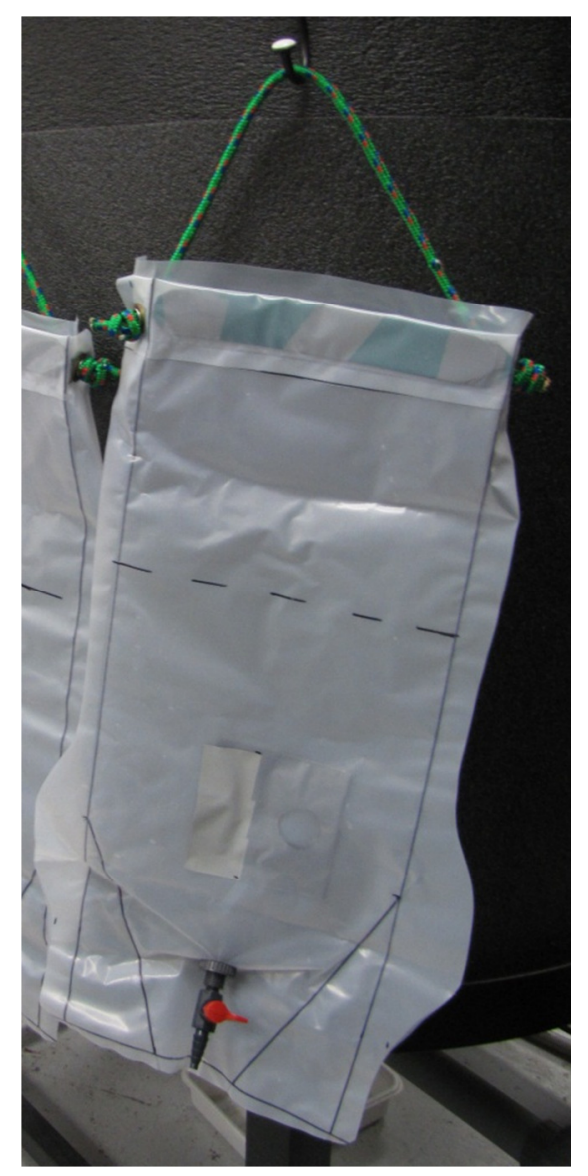

Figure 3.1: An empty Mark II waterbag. Note key design features such as wide-mouth opening, dry-bag closure, tapered bottom, outlet vale position, and internal baffles.

The prototypes were constructed of two sheets of 6-mil low density polyethylene (LDPE) plastic, sealed together with a ULINE ${ }^{\circledR}$ impulse sealer. The 6-mil LPDE plastic sheeting was purchased from Plastic Sheeting Supply (IPS Packaging) in 1.83-m by 30.48-m rolls (Compas, 2009a). To begin construction, bag dimensions (Figure 3.2) were drawn manually on the plastic sheeting before impulse-sealing the bag along the desired seams. 

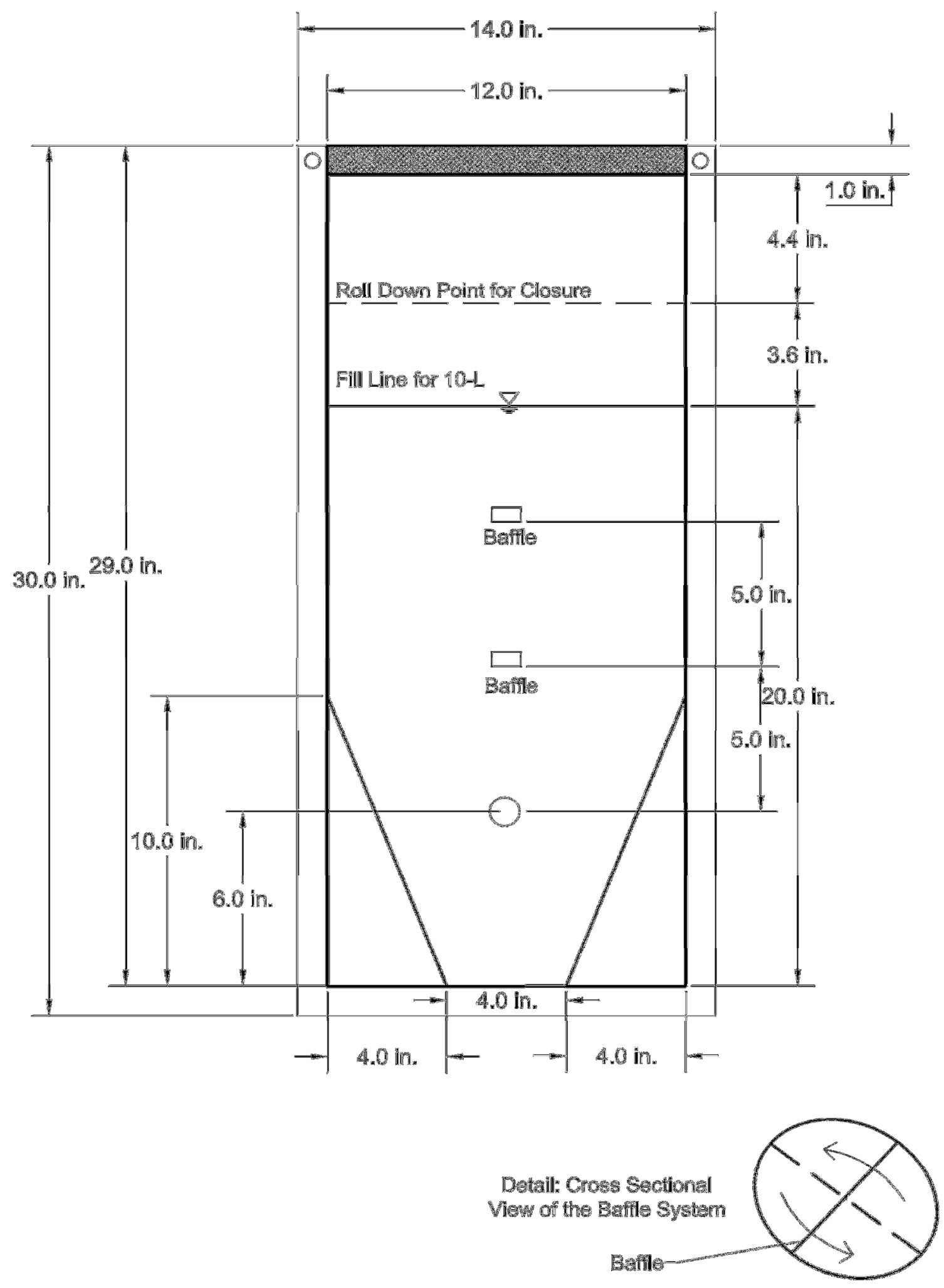

Figure 3.2: Dimensions of Mark II prototype (Compas, 2009b). 
Once partially sealed, a bulkhead fitting was attached near the bottom of the prototype through a hole made in the plastic sheeting. The bulkhead fitting had a nominal $0.635-\mathrm{cm}$ diameter. A plastic stopcock valve was threaded into the bulkhead fitting. At the top of the prototype, a piece of flexible, $1.5-\mathrm{mm}$ thick plastic was inserted into a hem to stiffen the drybag style closure. At this point, the remaining seams on the bag were sealed, and the bag handle and dry-bag closure were completed. Standard (2.54-cm wide) black heavy nylon webbing was cut into two $15.24-\mathrm{cm}$ long strips, and attached to each side of the top of the bag using $1.27-\mathrm{cm}$ diameter grommets and associated tools. Quick release buckles $(2.54-\mathrm{cm}$ wide) were attached to the nylon webbing as the snap closure method for the dry-bag closure. Braided nylon rope $(0.95 \mathrm{~cm}$-wide) was used as the bag handle, which was attached through the grommet holes on either side of the bag (Figure 3.3).
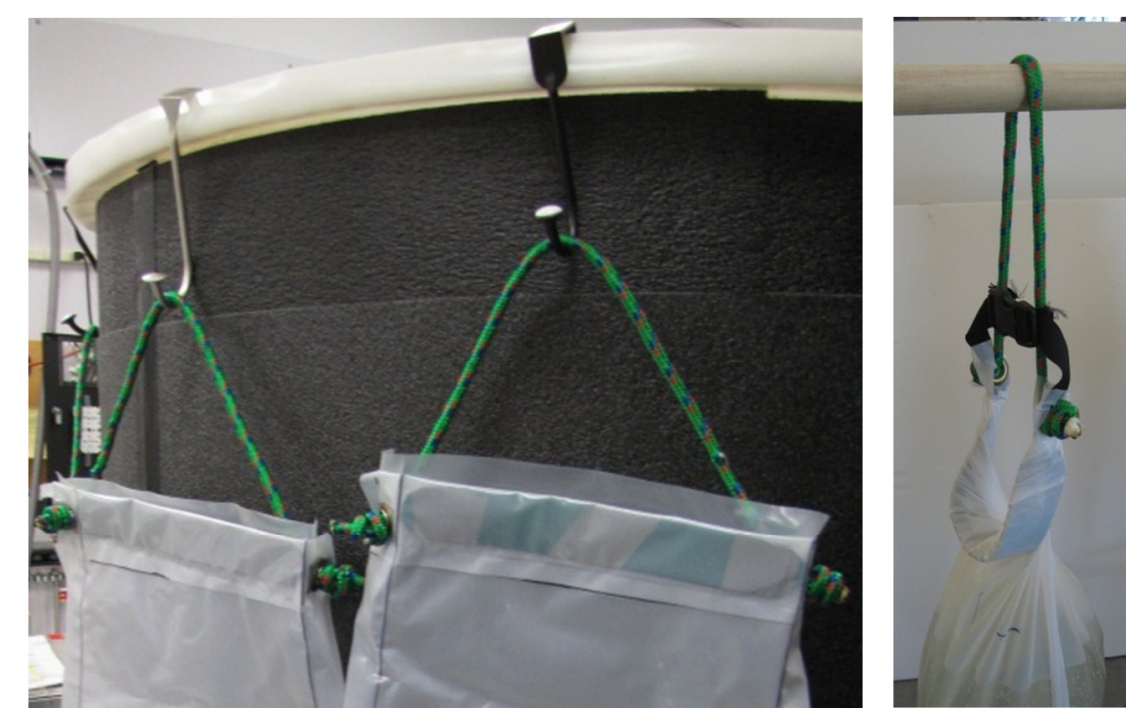

Figure 3.3: Braided rope handle attached to the prototype with grommets; dry-bag closure with plastic reinforcement.

The Mark II prototype included internal mixing baffles for increased turbulence during mixing. The baffles were made of duct tape and the type of baffle used varied throughout the optimization experiments (described in Section 3.2). 


\subsection{Experimental Design}

Two primary types of experiments were conducted: (1) optimization experiments - to identify the most advantageous mixing procedure of the bag, optimal baffle configuration, and chlorine residual performance against elevated, differing TOC concentrations, and (2) U.S. EPA Challenge Water experiments - to test the performance of the Mark II bag against the microbiological testing protocol for Test Water \#2. The following sections describe the objectives of the experimental design, test water conditions and preparations, and experimental procedures for each type of experiment. Section 3.3 describes water quality measurement procedures utilized throughout this research period. The naming convention used for the experiments are detailed in Figure 3.4.

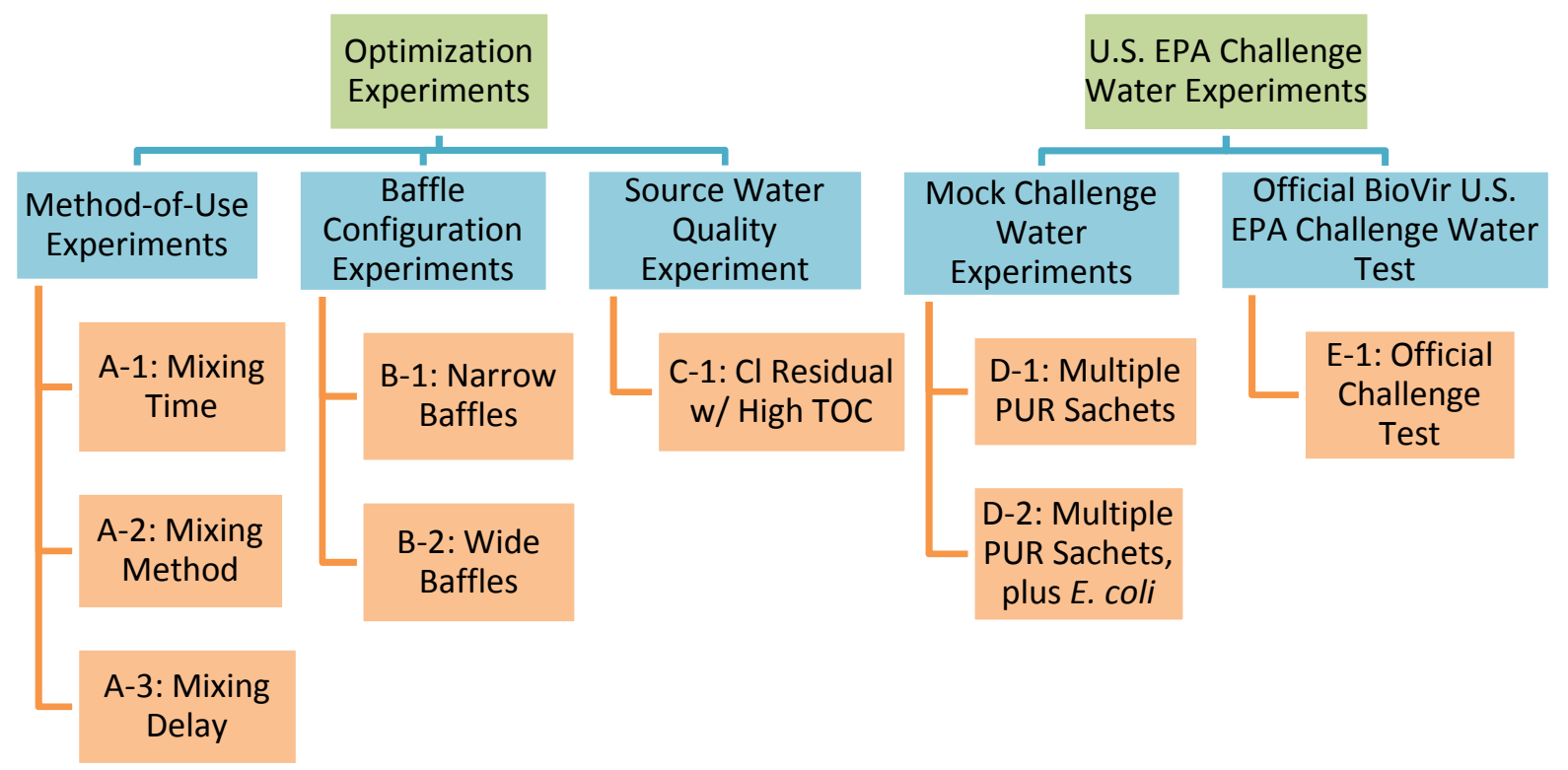

Figure 3.4: Experiment naming convention. 


\subsubsection{Experimental Objectives}

The nine experiments discussed in this research were determined from an iterative design process of the Mark II prototype. Specifically, there were optimization data gaps which were investigated so that a final Mark II waterbag design could be commercially fabricated. The procedural operation data gaps included determination of optimal mixing time to prescribe to users, establishment of optimal mixing method (vigor), and characterization of the effect of a delay between PŪR ${ }^{\circledR}$ addition and mixing start. All procedural experiments (A-1 through A3) were designed to standardize mixing procedure for subsequent experiments and to determine a mixing procedure for field use. As a primary physical feature of the Mark II waterbag, baffle experiments (B-1 and B-2) were performed to investigate the optimal configuration of internal baffle, one which provided best turbidity removal in comparison to others. An additional optimization data gap included the ability of the waterbag to maintain a free chlorine residual in the presence of high TOC within the range prescribed by the WHO/Sphere Project for disaster relief. Characterization of the ability of the waterbag to maintain a desired free chlorine residual was important in determining its appropriateness in treating challenging source waters.

The U.S. EPA Challenge water experiments were performed to test the ability of the optimized Mark II treatment protocol and baffle configuration to meet the pathogen removals required by the U.S. EPA Guide Standard and Protocol for Testing Microbiological Water Purifiers. Experiments D-1 and D-2 involved testing multiple PŪR ${ }^{\circledR}$ sachets against the U.S. EPA Challenge Test Water \#2 recipe. The motivation for testing multiple PŪR ${ }^{\circledR}$ sachets against the challenge recipe was the previous waterbag U.S. EPA Challenge Water experiment performed in July 2009 (Compas, 2009a). Two of the three Mark I prototypes 
tested with one $\mathrm{P} \overline{\mathrm{U}} \mathrm{R}^{\circledR}$ sachet against the challenge recipe during that experiment were not successful in achieving the pathogen reductions required by the test. Therefore, once the appropriate number of PŪR ${ }^{\circledR}$ sachets was determined, the optimized Mark II prototype was taken to BioVir Laboratories for the official Challenge Test.

User conditions were taken into account in the development of each experiment. For example, Experiment A-1 included the testing of a "worse-case" scenario prototype, with a waterbag mixed for a short amount of time at a slow mixing speed. This bag was meant to characterize a situation which may be encountered in reality, where a user might not mix the waterbag for as long or with as much vigor as prescribed. In other cases, some of the experiments performed were intentionally conducted using less-than-optimal procedures (like mixing time, mixing speed, and/or mixing method) to accentuate the differences in the results caused by the design features of the bag. Complete characterization of the treatment abilities of the waterbag helped to develop a waterbag that operated well despite sub-optimal treatment operations. However, general water preparation and experimental procedures (described in the following section) were followed for most of experiments in Figure 3.4.

Though filtration is a required treatment step in waterbag treatment protocol, development of an appropriate filter was not included in the scope of this research. Therefore, filtration was not used consistently for all experiments. Rather, pre-filter results were used and compared to the disaster relief objectives described in Section 2.1.2. Filtration was used in Experiment D2 and Experiment E-1 for the reasons described in Section 3.5.

The Mark II design was unchanged throughout testing, except for the baffle configuration change that was implemented mid-way through this research period. Experiments A-1 and A- 
2 used the first iteration of baffle design, which included two separate, 16.51-cm long baffles located $27.94 \mathrm{~cm}$ and $40.64 \mathrm{~cm}$ above the bottom seam (Figure 3.2, Figure 3.5). Experiments B-1 and B-2 tested the effectiveness of a variety of baffle configurations, including the use of wide baffles instead of narrow ones. From these results, an optimum baffle configuration (Figure 3.6) was determined, which was used for the remaining Experiments A-3, and C-1 through E-3. The baffle configuration was changed from two separate baffles to a single, wider baffle with two holes meant to increase turbulence. Use of a single baffle, rather than two, was thought to facilitate commercial fabrication.

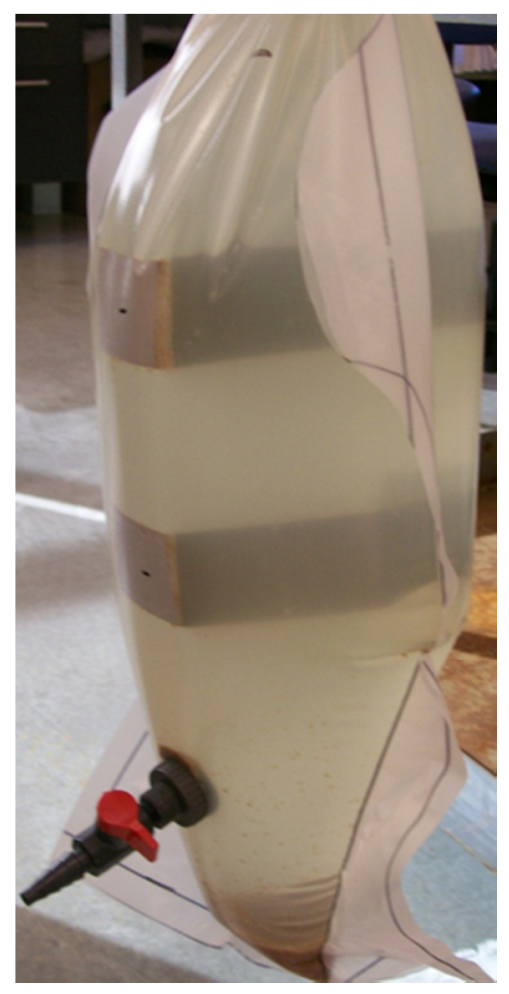

Figure 3.5: Mark II waterbag with two $16.51 \mathrm{~cm}$-long narrow internal mixing baffles. 


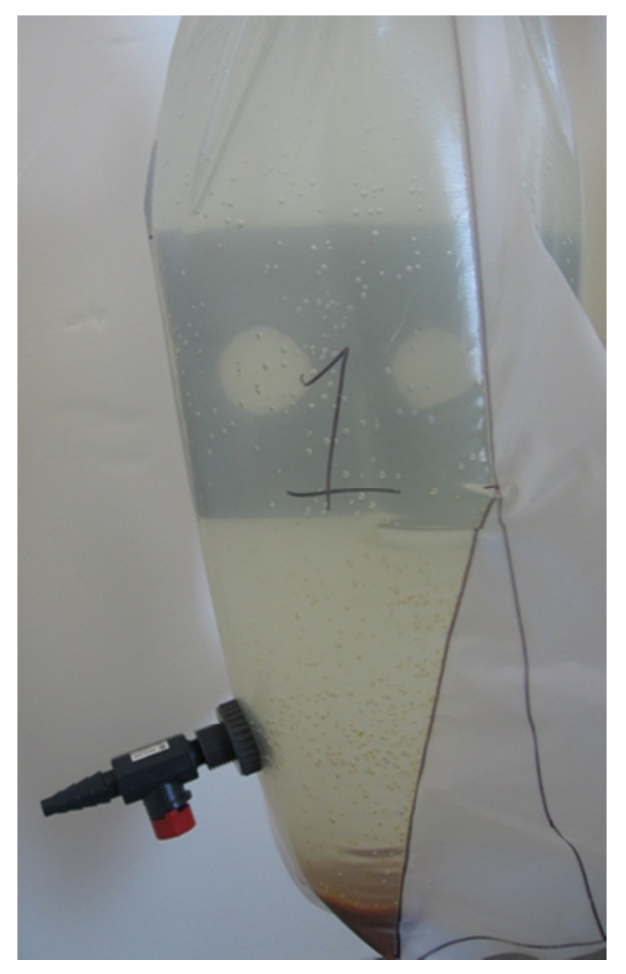

Figure 3.6: Final baffle configuration chosen for Experiments A-3, and C-1 through E3. This $12.7 \mathrm{~cm}$-wide baffle was chosen over two separate, narrow baffles because of the results obtained in Experiments B-1 and B-2.

\subsubsection{Water Preparation}

Adjustments were made to the recipe of the water mixture to be treated depending on experimental objectives. For Experiments A-1, A-2, and B-1, baseline source water was Drumm Reservoir water, which contained runoff from the pasture and sage brush areas above the Cal Poly campus. Water was collected in 20-L buckets from an outlet point near the practice irrigation fields at Cal Poly and then stored overnight in the testing lab to equilibrate to room temperature. For Experiments A-3 and B-2, tap water was collected and used immediately afterwards for test water preparation. Non-aerated tap water was used when chlorine residual was not a variable chemical constituent monitored in the experiments. When chlorine residual was a pertinent constituent in an experiment (in Experiment C-1), tap water was aerated overnight with an aquarium air stone before use. Aeration of tap water was 
performed to promote volatilization of the chlorine from the water to remove any initial free chlorine that could interfere with the experimental results.

The ingredients used for all experiments were A2 Fine Test Dust (ISO 12103-1; purchased from Powder Technology, Inc., Burnsville, MN) to create turbidity, sea salts (Instant Ocean, Cincinnati, OH) to adjust total dissolved solids (TDS), and humic acid (Alfa Aesar, Ward Hill, Mass., Stock \#41747, Lot \#D25S004) to increase total organic carbon (TOC). These specific ingredients are recommended for U.S. EPA Challenge Water recipes by the U.S. EPA (U.S. EPA, 1987). A turbidity-dust and TOC-humic acid concentration correlation had been established previously (Compas, 2009a; Appendix A). The turbidity of the test water differed based on experimental objectives. Experiments A-1, A-2, A-3, B-1, and B-2 had initial test water turbidities typically between 350 NTU and 500 NTU. Experiments C-1, D-1, D-2, and E-1 had initial test water turbidities of approximately $100 \mathrm{NTU}$; this $100 \mathrm{NTU}$ turbidity met the $>30$ NTU requirement of the U.S. EPA Challenge Test Water \#2 recipe and, with less available particles as nucleation sites for flocculation, provided more of a treatment challenge than the 350-500 NTU test waters.

Once the source water was collected, it was added to a 75 -liter RubberMaid ${ }^{\circledR}$ refuse container (hereafter "large drum") with a ball-valve outlet (Figure 3.7). A Flotec ${ }^{\circledR}$ submersible sump pump (model FP0S2450A-08, 1/3 HP; Figure 3.8) was used to homogenize the test water mixture. Before addition to the source water in the large drum, pre-determined measured amounts of specified ingredients were blended with one liter of source water using an Osterizer $^{\circledR}$ glass blender (on pulse setting) for approximately 30 seconds. Use of the blender prevented clumping of the powdered ingredients. The sump pump was then turned on in the drum, and the blended ingredient-source water mixture was added to the large drum and 
allowed to mix with the sump pump for at least five minutes. Once mixing was complete, the appropriate number of Mark II prototypes were filled consecutively and hung vertically from hooks around the laboratory space. If there was a significant delay ( $>3$ minutes) between filling the prototypes, the sump pump was turned on and the test water was re-mixed.

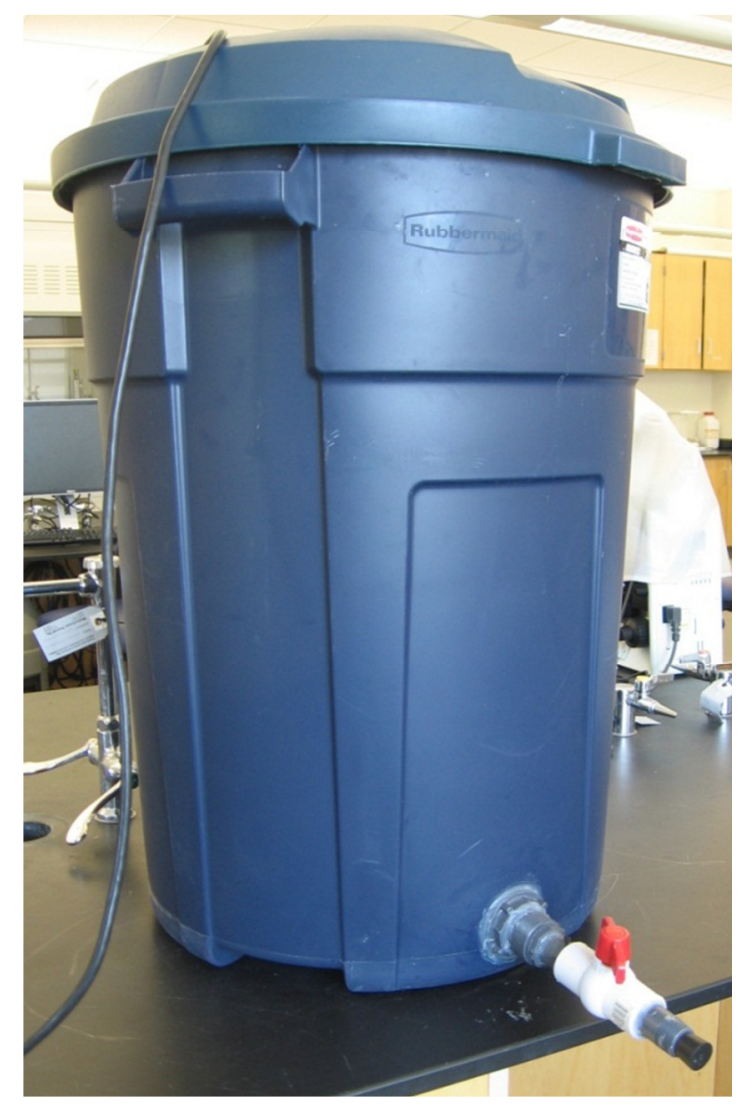

Figure 3.7: 75-liter RubberMaid ${ }^{\circledR}$ refuse container ("large drum") with a ball-valve outlet containing a Flotec ${ }^{\circledR}$ submersible sump pump (model FP0S2450A-08, 1/3 HP). 


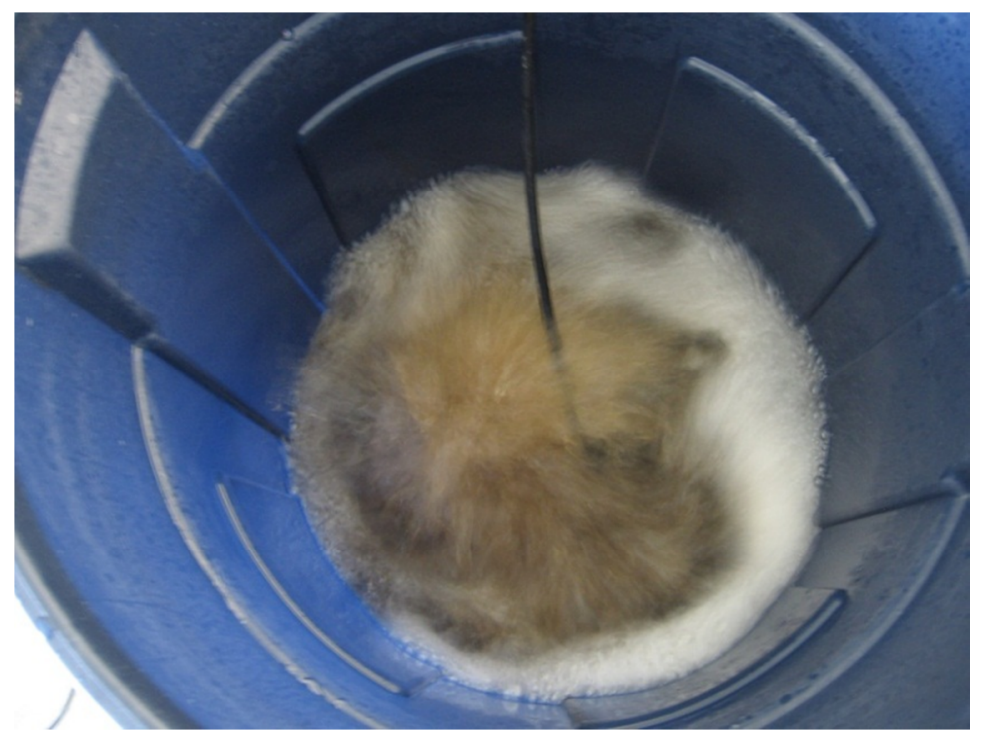

Figure 3.8: Interior of the large drum used to prepare and store the test water for each experiment. A submersible sump pump was used to homogenize the test water before distribution into prototypes.

In some cases, experiments required different amounts of constituent for each prototype. For Experiment C-1, different amounts of humic acid were used in each bag. To achieve this, a $2.0 \mathrm{~g} / \mathrm{L}$ humic acid solution was created. Bags with no humic acid were filled first. For the first bag that required humic acid concentration, a pre-determined amount of the $2.0 \mathrm{~g} / \mathrm{L}$ humic acid solution (mixed before use) was added to the large drum, and the sump pump was allowed to run for five minutes. The first Mark II prototype was filled with ten liters of water. Additional humic acid solution was added to the large drum and the sump pump was run for five minutes. Additional prototypes were filled. This process continued for each prototype to achieve the variable amounts of humic acid required. The temperature of the water in the drum was monitored to ensure that the sump pump did not increase the temperature of the water above the target temperature over the course for the test. 


\subsubsection{Experimental Testing Procedures}

Once the prototypes were filled with test water from the large drum, a PŪR ${ }^{\circledR}$ sachet was added to the untreated water, the bag was closed, and each bag was mixed using a standardized mixing method. For specific lot numbers of PŪR ${ }^{\circledR}$ used in each experiment, see Appendix E. To mix, bags were hung from a beam or from an over-the-door hanger and were twisted $180^{\circ}$ from side-to-side for the specified mixing time (Figure 3.9).

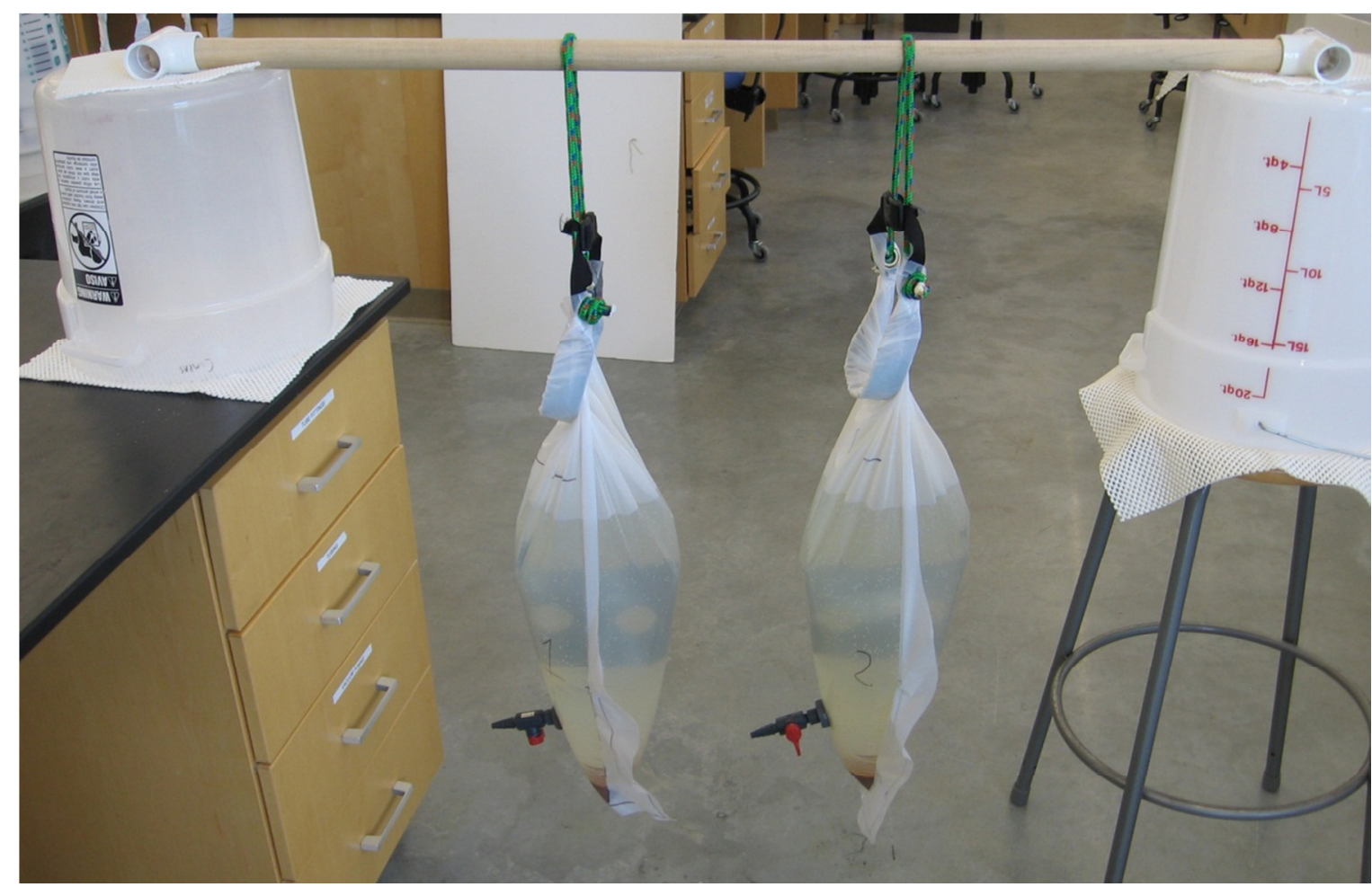

Figure 3.9: For mixing, waterbags were hung from a horizontal post and twisted from side-to-side $\left(\mathbf{1 8 0}^{\circ}\right)$. Mixing speeds were different based on experiment and were standardized using a metronome.

A metronome was used to achieve consistent mixing: 70 beats per minute (bpm) was determined to represent a medium mixing effort, $40 \mathrm{bpm}$ represented slow mixing, and 100 bpm represented very fast mixing. For most experiments, a medium mixing speed of $70 \mathrm{bpm}$ was used to mix every prototype because, upon visual observation, $70 \mathrm{bpm}$ was determined 
to represent the mixing intensity that would be exerted by an average user of the bag. In terms of bag rotation, one beat represented a complete $180^{\circ}$ twist.

Different mixing times were used depending on the objectives of the individual experiments. For example, Experiment A-1 tested the post-treatment turbidities of prototypes mixed over a range of reasonable mixing times, from thirty seconds to five minutes. In some cases, lower mixing times were used to accentuate differences in post-treatment water quality between prototypes with variable design or testing features.

Samples were taken at pre-determined times during experiments, generally at 10, 15, 20, 25, and 30 minutes after mixing was performed on each bag. Since the required chlorine contact time for PŨR ${ }^{\circledR}$ is 30 minutes, the 30 minute samples reflect "post-treatment" conditions. The purpose of taking $10,15,20$, and 25 minute intermediate samples was to monitor the measured water quality constituents over the critical 30 minute settling period. As an exception, Experiments C-1 and D-1 were performed over an extended period of time (24 to 30 hours) to determine ability to maintain a free chlorine residual over time.

\subsection{Water Quality Measurements}

The water quality variables measured for the aforementioned experiments included nonmicrobiological and microbiological constituents. The following section describes the measurement methods used to monitor pertinent constituents.

\subsubsection{Non-Microbiological Variables}

Non-microbiological water quality variables included turbidity, $\mathrm{pH}$, temperature, chlorine residual, and TOC. 


\subsubsection{Turbidity}

Turbidity was measured with a HACH 2100P Portable Turbidimeter (Catalog \#46500-00, Lot \#L7002). The turbidity meter was periodically calibrated with StablCal ${ }^{\circledR}$ Stabilized Formazin Turbidity Standards (sealed vials of $<0.1$ NTU, 20 NTU, 100NTU, and 800 NTU). During experiments, a sample was collected in a turbidimeter vial, and the vial was capped and its exterior dried with a soft cloth. The turbidity of each sample was read with the turbidimeter three times, and the average of the three resulting turbidity values was used in results and analysis of the experiment. Typically, the variance among the three readings was less than $10-15 \%$. After analysis, the vials were rinsed with deionized water and either reused for another sample or allowed to air-dry before storage. This turbidity measurement method meets the U.S. EPA Method 180.1 criteria for reporting drinking water analysis (HACH Company 2010).

\subsubsection{Temperature and $p H$}

Temperature and $\mathrm{pH}$ were measured with a Mettler Toledo Seven Easy $\mathrm{pH}$ meter (with a pH range from 0 to 14 and a resolution of 0.01 ), which includes a thermocouple. The $\mathrm{pH}$ meter was calibrated periodically using Fisher Scientific $\mathrm{pH} \mathrm{4,} \mathrm{7,} \mathrm{and} 10$ buffer solutions. Temperature and $\mathrm{pH}$ samples were collected in $250 \mathrm{~mL}$ beakers. Temperature measurements were read immediately after sampling, while $\mathrm{pH}$ measurements were allowed to equilibrate before readings were recorded.

\subsubsection{Chlorine Residual}

Free chlorine residual was measured with a HACH DR/890 Colorimeter (Catalog \#4847000) in combination with HACH DPD Free Chlorine Reagent powder pillows for $10 \mathrm{~mL}$ samples (Catalog \#2105569). Ten milliliter samples were collected in glass sample vials, and a single 
reagent pillow packet was added to the sample. Vials were mixed by continuous swirling and inversions for approximately 20 seconds, and analyzed immediately after mixing. The HACH Colorimeter analysis program used was Program 9, which has a method detection limit of $0.02 \mathrm{mg} / \mathrm{L}$ and a readable chlorine residual range of 0 to $2.00 \mathrm{mg} / \mathrm{L}$. This method is accepted by the U.S. EPA for reporting drinking water analysis (HACH Company 2010), and is equivalent to Standard Method 4500-Cl G (HACH Colorimeter Manual, not dated). A calibration curve and matrix spikes were established using $\mathrm{HACH}$ Chlorine Standard Solution PourRite Ampules, 25-30 mg/L as $\mathrm{Cl}_{2}$ (Catalog \#2630020). See Appendix D for more information on the implementation of matrix spikes and the use of the calibration curve in experimental analysis.

\subsubsection{Total Organic Carbon (TOC)}

TOC was measured as non-purgable organic carbon (NPOC) using a Shimadzu TOC-V CSH Total Organic Carbon (Model ASI-V) analyzer. To sample for TOC, a $100 \mathrm{~mL}$ sample was collected in a glass beaker and treated with a $10 \mathrm{mg}$ sodium thiosulfate tablet to neutralize chlorine present. Once the sodium thiosulfate tablets had dissolved, several drops of concentrated sulfuric acid were added to the sample to decrease the $\mathrm{pH}$ to 2 for preservation purposes and the samples stored at $4^{\circ} \mathrm{C}$. The acidification of the samples and sparging by the instrument stripped dissolved inorganic carbon from the water prior to NPOC measurement.

\subsubsection{Microbiological Variables}

The microbiological constituents measured in Experiment D-2 were total coliform bacteria and E. coli. Both total coliform bacteria and E. coli were measured using IDEXX Colilert ${ }^{\circledR}$ 24-hour coliform/E. coli reagent and Quanti-Tray ${ }^{\circledR} / 2000$ methods. Pre- and post-treatment samples were collected in sterile glass beakers and diluted with sterile DI water to be in the 
concentration range of the Colilert method. Samples were then transferred to $100 \mathrm{~mL}$ sterile polypropylene plastic bottles each containing one $10 \mathrm{mg}$ sodium thiosulfate tablet. Once the sodium thiosulfate dissolved, a single Colilert ${ }^{\circledR}$ snap pack (specifically for $100 \mathrm{~mL}$ water samples) was added to the sample and shaken gently to dissolve. Each sample plus Colilert ${ }^{\circledR}$ reagent was poured into an IDEXX Quanti-Tray ${ }^{\circledR} / 2000$, sealed with a Quanti-Tray ${ }^{\circledR}$ sealer, and incubated at $37^{\circ} \mathrm{C}$ for 24 hours. After 24 hours, the trays were removed from the incubator and examined for positive tray cells. Yellow cells indicated positive results for total coliform bacteria, and yellow and fluorescent cells indicated positive results for $E$. coli. Fluorescence was determined using a portable long-wave UV light apparatus (Blak-Ray Lamp, Model UVL-21, Serial \#3418). Finally, the most probable number (MPN) of bacteria was determined using a Colilert ${ }^{\circledR}$ MPN table, based on the number of positive cells observed (IDEXX, 2010).

\subsection{Optimization Experiments}

Optimization experiments included seven individual experiments which tested three general areas: (1) method-of-use, (2) baffle configuration, and (3) ability to maintain sufficient chlorine residual in the presence of high initial TOC. The primary objective of most of these experiments was to identify optimal operation and treatment procedure of the bag that resulted in a final post-treated turbidity of $<5$ NTU, meeting The Sphere Project standard. Additionally, the objective of Experiment C-1 was to determine performance against varying initial test water TOC concentrations, which was evaluated by maintenance of a free chlorine residual between 0.2 and $0.5 \mathrm{mg} / \mathrm{L}$. 


\subsubsection{Water Preparation for Optimization Experiments}

The optimization experiments followed the general water preparation procedures detailed in Section 3.2. Table 3.1 describes the test variables and information for the optimization experiments. 
Table 3.1: Optimization experiment information including test water variables, source water types, ingredient amounts, mixing speeds, and mixing times.

\begin{tabular}{|c|c|c|c|c|c|c|c|c|c|}
\hline $\begin{array}{l}\text { Experi- } \\
\text { ment }\end{array}$ & $\begin{array}{c}\text { Number of } \\
\text { Prototypes } \\
\text { Tested }\end{array}$ & $\begin{array}{l}\text { Primary } \\
\text { Variable }\end{array}$ & $\begin{array}{c}\text { Type of } \\
\text { Baffle(s) }\end{array}$ & $\begin{array}{l}\text { Source } \\
\text { Water }\end{array}$ & $\begin{array}{c}\text { A2 Fine } \\
\text { Test Dust } \\
\text { Amount } \\
\text { Added to } \\
10 \mathrm{~L}\end{array}$ & $\begin{array}{c}\text { Instant } \\
\text { Ocean } \\
\text { Amount } \\
\text { Added to } \\
10 \text { L }\end{array}$ & $\begin{array}{l}\text { Humic } \\
\text { Acid } \\
\text { Amount } \\
\text { Added } \\
\text { to } 10 \text { L }\end{array}$ & $\begin{array}{l}\text { Mixing } \\
\text { Speed } \\
\text { (beats per } \\
\text { minute) }\end{array}$ & $\begin{array}{l}\text { Mixing } \\
\text { Time(s) }\end{array}$ \\
\hline A-1 & 6 & Mixing time & $\begin{array}{l}\text { Two narrow } \\
\text { baffles }\end{array}$ & $\begin{array}{l}\text { Drumm } \\
\text { Reservoir }\end{array}$ & $5 \mathrm{~g}$ & $10 \mathrm{~g}$ & None & $\begin{array}{l}40 \mathrm{bpm}, \\
70 \mathrm{bpm}\end{array}$ & $\begin{array}{c}30 \mathrm{sec}, 1 \mathrm{~min}, \\
1.5 \mathrm{~min}, 2 \\
\min , 3 \mathrm{~min}, 5 \\
\min \end{array}$ \\
\hline A-2 & 4 & $\begin{array}{l}\text { Mixing method } \\
\text { (abrupt vs fluid } \\
\text { motion) }\end{array}$ & $\begin{array}{l}\text { Two narrow } \\
\text { baffles }\end{array}$ & $\begin{array}{l}\text { Drumm } \\
\text { Reservoir }\end{array}$ & $5 \mathrm{~g}$ & $10 \mathrm{~g}$ & None & 70 bpm & $2 \min$ \\
\hline A-3 & 4 & $\begin{array}{c}\text { Delay between } \\
\text { PŪR }^{\circledR} \text { sachet } \\
\text { addition and } \\
\text { mixing }\end{array}$ & $\begin{array}{c}\text { Single wide } \\
\text { baffle with side- } \\
\text { by-side circular } \\
\text { holes }\end{array}$ & Tap water & $5 \mathrm{~g}$ & $10 \mathrm{~g}$ & None & 70 bpm & $5 \mathrm{~min}$ \\
\hline B-1 & 5 & $\begin{array}{c}\text { Number of } \\
\text { narrow baffles }\end{array}$ & Variable & $\begin{array}{l}\text { Drumm } \\
\text { Reservoir }\end{array}$ & $5 \mathrm{~g}$ & $10 \mathrm{~g}$ & None & $40 \mathrm{bpm}$ & $2.5 \mathrm{~min}$ \\
\hline B-2 & 4 & $\begin{array}{c}\text { Baffle } \\
\text { configuration, } \\
\text { including wide } \\
\text { baffles }\end{array}$ & Variable & Tap water & $5 \mathrm{~g}$ & $10 \mathrm{~g}$ & None & 40 bpm & $2.5 \mathrm{~min}$ \\
\hline $\mathrm{C}-1$ & 6 & $\begin{array}{l}\text { Humic acid } \\
\text { concentration }\end{array}$ & $\begin{array}{c}\text { Single wide } \\
\text { baffle with side- } \\
\text { by-side circular } \\
\text { holes }\end{array}$ & $\begin{array}{l}\text { Aerated } \\
\text { tap water }\end{array}$ & $1.5 \mathrm{~g}$ & $15 \mathrm{~g}$ & Variable & 70 bpm & $5 \mathrm{~min}$ \\
\hline
\end{tabular}




\subsubsection{Experimental Procedures for the Optimization Experiments}

The water quality constituents measured during each experiment are listed in Table 3.2. Turbidity, $\mathrm{pH}$, and temperature were measured during all of the optimization experiments. Free chlorine residual and TOC were measured during Experiment $\mathrm{C}-1$ only, and no optimization experiments included the measurement of microbiological constituents.

Table 3.2: Variables measured during the optimization experiments. The variables measured during each experiment depended on the objectives of the individual experiment.

\begin{tabular}{|c|c|c|c|c|c|}
\hline \multirow[b]{2}{*}{ Experiment } & \multicolumn{5}{|c|}{ Variables Measured } \\
\hline & Turbidity & $\begin{array}{l}\text { Free Chlorine } \\
\text { Residual }\end{array}$ & $\mathbf{p H}$ & Temperature & TOC \\
\hline A-1 & $\mathrm{X}$ & & $\mathrm{X}$ & $\mathrm{X}$ & \\
\hline A-2 & $\mathrm{X}$ & & $X$ & $\mathrm{X}$ & \\
\hline A-3 & $X$ & & $X$ & $\mathrm{X}$ & \\
\hline B-1 & $\mathrm{X}$ & & $\mathrm{X}$ & $\mathrm{X}$ & \\
\hline B-2 & $\mathrm{X}$ & & $X$ & $\mathrm{X}$ & \\
\hline $\mathrm{C}-1$ & $X$ & $X$ & $\mathrm{X}$ & $X$ & $X$ \\
\hline
\end{tabular}

\subsection{U.S. EPA Challenge Water Experiments}

After determining optimal operating use and physical characteristics, the next step was to test the Mark II prototype against the U.S. EPA Challenge Water (Test Water \#2). Three experiments tested the performance of the waterbag against the U.S. EPA Challenge Water recipe. The first two experiments performed, Experiments D-1 and D-2, tested different numbers of PŪR ${ }^{\circledR}$ sachets per each bag to determine the number needed to pass the U.S. EPA Challenge Water tests in preparation for the third U.S. EPA Challenge Water experiment (E1) conducted in a commercial laboratory (BioVir Laboratories, Benicia, Calif.). The objective of Experiment E-1 was to confirm that waterbag treatment protocol would 
successfully treat the pathogen removals required by the U.S. EPA Challenge Water (Test Water \#2).

\subsubsection{Water Preparation for Experiments D-1 and D-2}

The ingredients used for the test water preparation of the U.S EPA Challenge Water experiments were the same as those used in the optimization experiments. The U.S. EPA Challenge Test (Test Water \#2) test water required additional modifications, including a pH adjustment to 9 , temperature adjustment to $4{ }^{\circ} \mathrm{C}$, and the addition of microorganisms (Table 2.6). Concentrated $\mathrm{NaOH}$ was added to the large drum of test water to achieve a $\mathrm{pH}$ of 9 . The temperature of the test water was lowered by storing the test water overnight in a $5.5^{\circ} \mathrm{C}$ refrigerator. Once chilled in the refrigerator and taken back to the lab, the water was transferred to the large drum for ingredient addition and mixing. Ice cubes were added to the large drum to drop the temperature to approximately $4^{\circ} \mathrm{C}$.

While Experiment D-1 did not include the use of microorganisms, Experiment D-2 did include E. coli to mimic the Challenge Test Water \#2 recipe specific by U.S. EPA Guide Standard and Protocol for Testing Microbiological Water Purifiers. For preparation to work with microorganisms, all associated glassware and dilution water was sterilized by autoclaving prior to use and new Mark II waterbags were made. All associated valve equipment was pre-soaked in a bleach/tap water solution for one hour and then rinsed with tap water. Approximately $100 \mathrm{~mL}$ stock solution of K12 E. coli was prepared for addition to the large drum of test water after all other ingredients and adjustments were made. K12 E. coli stock culture was received from Alice Hamrick in the Biological Sciences Department at Cal Poly (A. Hamrick, personal communication, June 23, 2010). K12 E. coli was grown in an LD liquid growth media and stored in an incubator to promote exponential growth for 
approximately four hours before the Experiment D-2 was performed. The initial E. coli concentration of the stock solution was estimated by measuring the optical density of the solution using a UV/V spectrophotometer. From this estimated concentration, an appropriate volume of $E$. coli solution was added to the large drum of test water to meet the $10^{7} / 100 \mathrm{~mL}$ bacterial initial challenge concentration. Ingredient addition and mixing followed the same procedure as that described in the general methods section. Table $\mathbf{3 . 3}$ describes the experiment variables and information for the U.S. EPA Challenge Water tests. 
Table 3.3: U.S. EPA Challenge Water experiment information including test water variables, source water types, ingredient amounts, mixing speeds, and mixing lengths.

\begin{tabular}{|c|c|c|c|c|c|c|c|c|c|}
\hline $\begin{array}{l}\text { Experi- } \\
\text { ment }\end{array}$ & $\begin{array}{c}\text { Number of } \\
\text { Prototypes } \\
\text { Tested }\end{array}$ & $\begin{array}{l}\text { Primary } \\
\text { Variable }\end{array}$ & $\begin{array}{l}\text { Types of } \\
\text { Baffle(s) }\end{array}$ & $\begin{array}{l}\text { Source } \\
\text { Water }\end{array}$ & $\begin{array}{c}\text { A2 Fine } \\
\text { Test Dust } \\
\text { Amount } \\
\text { Added to } \\
10 \text { L } \\
\end{array}$ & $\begin{array}{c}\text { Instant } \\
\text { Ocean } \\
\text { Amount } \\
\text { Added to } \\
10 \text { L } \\
\end{array}$ & $\begin{array}{c}\text { Humic } \\
\text { Acid } \\
\text { Amount } \\
\text { Added to } \\
10 \text { L } \\
\end{array}$ & $\begin{array}{l}\text { Mixing } \\
\text { Speed } \\
\text { (beats per } \\
\text { minute) }\end{array}$ & $\begin{array}{l}\text { Mixing } \\
\text { Time(s) }\end{array}$ \\
\hline D-1 & 3 & $\begin{array}{c}\text { Number of } \\
\text { PŪR }{ }^{\circledR} \\
\text { sachets }\end{array}$ & $\begin{array}{c}\text { Single wide } \\
\text { baffle with side- } \\
\text { by-side circular } \\
\text { holes }\end{array}$ & $\begin{array}{l}\text { Aerated } \\
\text { tap water }\end{array}$ & $1.5 \mathrm{~g}$ & $15 \mathrm{~g}$ & $0.4 \mathrm{~g}$ & $70 \mathrm{bpm}$ & $5 \mathrm{~min}$ \\
\hline E-1 & 3 & None & $\begin{array}{c}\text { Single wide } \\
\text { baffle with side- } \\
\text { by-side circular } \\
\text { holes }\end{array}$ & \multicolumn{6}{|c|}{ Source water and ingredients prepared by BioVir Laboratories, Inc. } \\
\hline
\end{tabular}




\subsubsection{Experimental Procedure for Experiments D-1 and D-2}

The primary goal of Experiments D-1 and D-2 was to determine the optimum number of PŪR ${ }^{\circledR}$ sachets that would meet the pathogen removals required by the U.S. EPA Guide Standard and Protocol for Testing Microbiological Water Purifiers (Table 2.5). Once the U.S. EPA Challenge Water (Test Water \#2) was prepared in the large drum (Table 2.6), prototypes were filled with ten liters of test water. Once the appropriate number of $\mathrm{PU}^{\circledR}{ }^{\circledR}$ sachets was added to each bag, the mixing procedure employed was the general experimental procedures.

The constituents measured in Experiments D-1 and D-2 include additional variables than those measured for the optimization experiments (Table 3.4). In Experiment D-1, three prototypes were tested and sampled for turbidity, TOC, $\mathrm{pH}$, and temperature were measured over time, up to thirty hours after mixing. E. coli was not added to the test water for Experiment D-1, and was therefore not measured. In Experiment D-2, four bags were tested and sampled for turbidity, TOC, $\mathrm{pH}$, and temperature as well as E. coli and total coliforms. Since the primary constituent-of-concern in Experiment D-2 was E. coli and total coliforms (not chlorine residual over time), sampling was not extended longer than the 30-minute settling and disinfection period. 
Table 3.4: Variables measured during U.S. EPA Challenge Water experiments. The constituents measured during each experiment depended on the objectives of the individual experiment.

\begin{tabular}{cccccc}
\hline \multirow{2}{*}{ Experiment } & \multicolumn{2}{c}{ Non-Microbiological Variables } & \multicolumn{2}{c}{ Microbiological Variables } \\
\cline { 2 - 6 } & Turbidity & pH & Temperature & $\begin{array}{c}\text { Total } \\
\text { Coliform }\end{array}$ & E. coli \\
\hline D-1 & X & X & X & & \\
D-2 & X & X & X & X & X \\
E-1 & X & & & X & X \\
\hline
\end{tabular}

A clamshell filter with polypropylene filter pad was used for the collection of the posttreatment (30 minutes after mixing) sample for Experiments D-2 and E-1 (Figure 3.10). The clamshell filter was developed by Tricia Compas and her research partners in the previous investigations of the Mark I waterbag (see Section 2.3). The filter material used was one micron nominally-rated polypropylene felt cloth (Rosedale Products of California, Inc., order code: PO-1, non-glazed finish). In Experiment D-2, the filter was attached to the effluent valve at the bottom of the bag (Figure 3.11) via $1.58 \mathrm{~cm}$ vinyl tubing. Then, $100 \mathrm{~mL}$ was passed through the clamshell filter prior to post-treatment sample collection for bacterial analysis. Notches printed on the side of the stopcock valve were used to regulate flow through the filter and for sample collection. The purpose of the filter in this case was to prevent $E$. coli bound to errant flocs flocs from interfering with TOC and bacterial testing of the 30-minute post-treatment sample. In addition, filtration is a required step in the formal waterbag treatment method; therefore, the use of the filter in this experiment helped to prepare for the use of the filter during Experiment E-1 at the official Challenge Test at BioVir. 


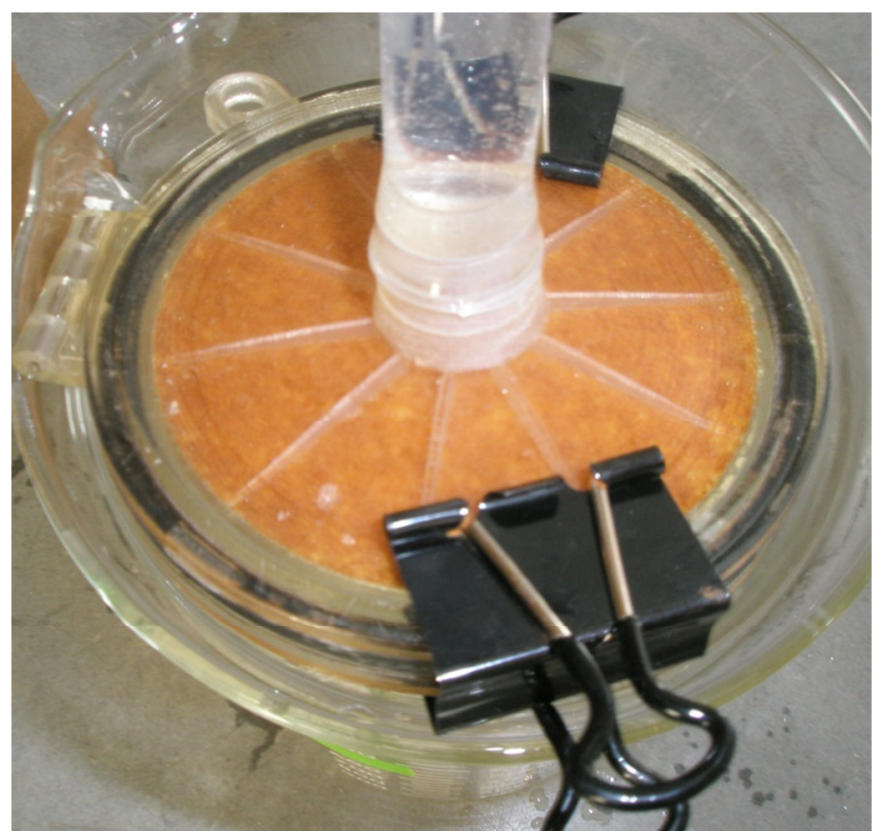

Figure 3.10: Clamshell filter from Experiment D-1 with $1 \mu \mathrm{m}$ nominally-rated polypropylene filter pad. The filter is inundated with solids after treatment of the high humic test water of the U.S. EPA Challenge Water Test with four PŪR ${ }^{\circledR}$ sachets.

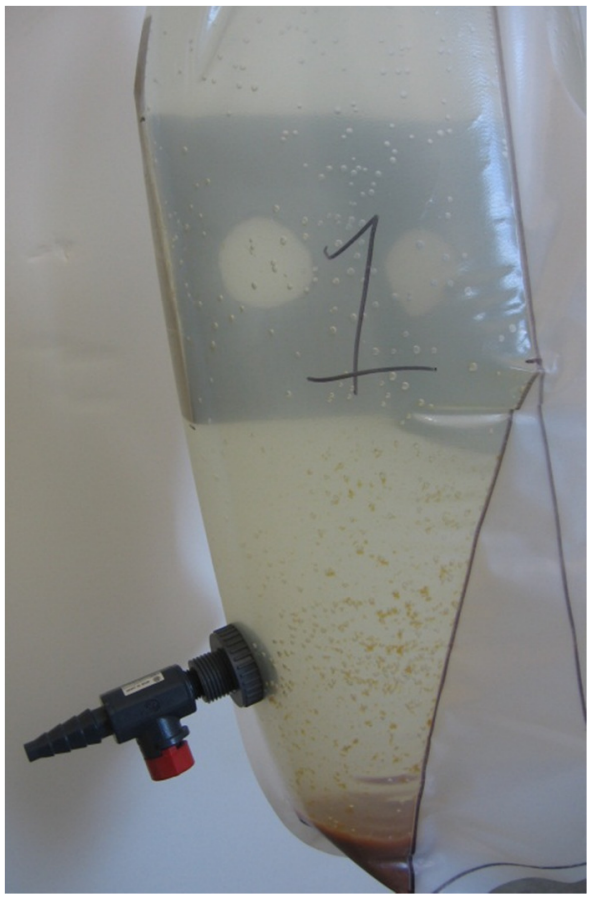

Figure 3.11: Effluent valve attached $12.7 \mathrm{~cm}$ above the bottom seam of the prototype. Filter tubing was attached directly to the valve. Notch marks on the valve were used to regulate and standardize the flow from all the bags tested. 


\subsubsection{Water Preparation at BioVir for Experiment E-1}

A 40-L batch of U.S. EPA Challenge Test Water \#2 was prepared by BioVir staff with the characteristics listed in Table 3.5.

Table 3.5: Characteristics of the U.S. EPA Challenge Water prepared by BioVir staff

\begin{tabular}{cc}
\hline Variable & Value \\
\hline Volume & $40 \mathrm{~L}$ \\
pH & 8.3 \\
Chlorine & Non-Detect \\
TDS & $1570 \mathrm{mg} / \mathrm{L}$ \\
Turbidity & $>30 \mathrm{NTU}$ \\
TOC & $11.6 \mathrm{mg} / \mathrm{L}$ \\
Temperature & $4^{\circ} \mathrm{C}$ \\
\hline
\end{tabular}

Prior to filling the prototypes, the Challenge Test Water was inoculated with challenge microorganisms and fluorescent microspheres. The microorganisms were the bacterium Escherichia coli (ATCC 11229), MS2 (ATCC 15597-B1) and fr coliphage (ATCC 15767B1). The fluorescent microspheres, surrogates for Cryptosporidium oocysts, were $3.1 \mu \mathrm{m}$ in diameter. After ingredient addition, the test water was stirred continuously with a magnetic stir bar atop a large stir plate. The U.S. EPA Challenge Water was stirred continuously through Experiment E-1 to ensure homogenization of the Test Water \#2 before filling each prototype.

\subsubsection{Experimental Procedure at BioVir for Experiment E-1}

Triplicate prototypes were tested in Experiment E-1. The mixing procedure, mixing times, settling and disinfection times, filtration methods, and sampling procedures were the same for all three prototypes. Once the test water was prepared and mixed by BioVir staff, the waterbags were filled and treated in staggered fashion to allow continued mixing to preserve 
the homogeny and temperature of the test water for each prototype. Two PŪR ${ }^{\circledR}$ sachets were added to the filled prototype, the bag was closed via the dry-bag closure, and was hung from a hook on the side of a large indoor tank (Figure 3.12). Two sachets were used because the results of Experiments D-1 and D-2 showed that two PŪR ${ }^{\circledR}$ sachets provided sufficient pathogen removals as required by U.S. EPA Guide Standard and Protocol for Testing Microbiological Water Purifiers. Each prototype was mixed for five minutes at $70 \mathrm{bpm}$ (Table 3.3), and then allowed to settle and disinfect for 30 minutes before filtration through the two filters used in this experiment.

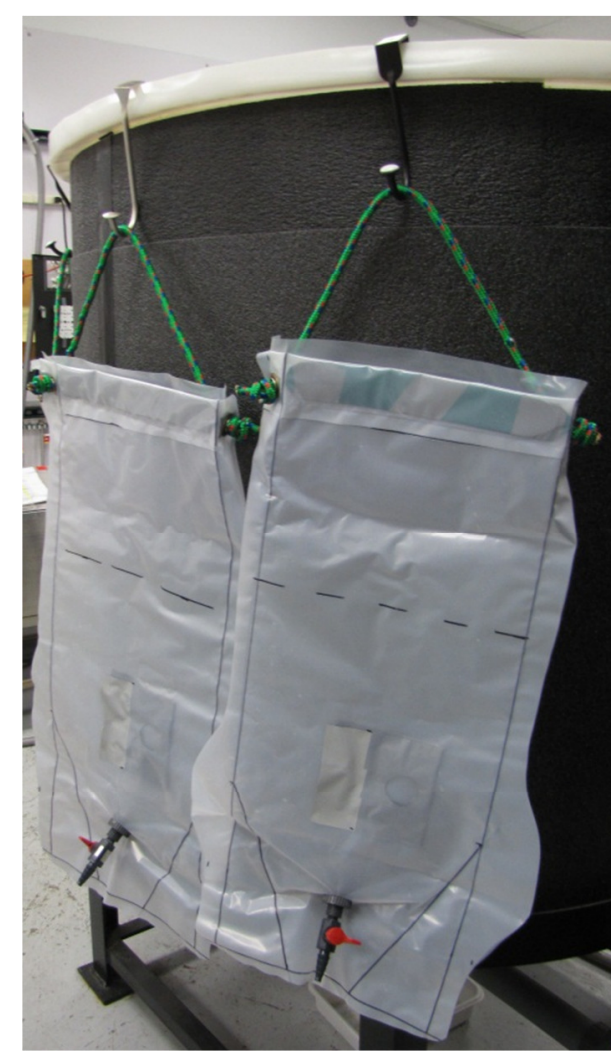

Figure 3.12: Empty Mark II prototypes hanging against an indoor mixing tank. This was the where the prototypes were hung during treatment, mixing, and sampling.

Each prototype was sampled at three points: a pre-treatment initial test water sample, a postpad-filter sample, and a post-microfilter sample. The first filter was the clamshell filter with a 
$1-\mu \mathrm{m}$ nominally-rated polypropylene filter pad (Figure 3.10). The second filter was a $0.2-\mu \mathrm{m}$ absolute-rated hollow fiber microfilter (Figure 3.13; MSR $^{\circledR}$ AutoFlow $^{\mathrm{TM}}$ Gravity Microfilter, Cascade Designs, Inc., Seattle, Wash.). The 0.2- $\mu \mathrm{m}$ microfilter had a filter rating higher than necessary to remove protozoa (typically $3 \mu \mathrm{m}$ in diameter). The microfilter was used in Experiment E-1 to ensure that the pathogen removal requirements would be met for at least one sample point (post-microfilter) during the experiment. The pad filter and microfilter were connected in series with vinyl tubing.

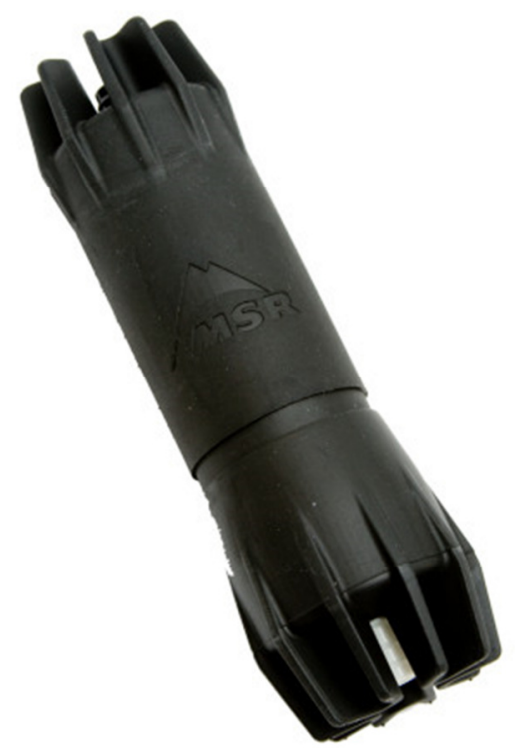

Figure 3.13: 0.2- $\mu \mathrm{m}$ absolute-rated $\mathrm{MSR}^{\circledR}$ AutoFlow $^{\mathrm{TM}}$ Microfilter (microfilter), provided by Cascade Designs, Inc. (Backcountry.com, 2010).

After treatment with $\mathrm{PU}^{\circledR}, 2 \mathrm{~L}$ of treated water was passed through both filters in series. Next, a 1.5-L sample was collected after filtering through the clamshell plus microfilter; this sample was considered the post-microfilter sample. Then, a 1.5-L sample was collected after filtering through the clamshell filter only; this sample was considered the post-pad-filter sample. All post-treatment samples were filtered through the clamshell filter, though only some (a different sample set) were filtered through the microfilter. Before reuse between 
prototypes, the clamshell filters were rinsed with DI water and 70\% isopropyl alcohol, which was then allowed to evaporate, and a new $1-\mu \mathrm{m}$ polypropylene filter pad was used. A new microfilter was used for each prototype.

All samples were collected in sterile plastic screw-top bottles containing sodium thiosulfate to neutralize any residual chlorine that may have been present in the sample (Dr. Robert Cooper, BioVir, 2010). The BioVir test report (Appendix B) described the sample handing and processing: "The influent and product water samples were kept refrigerated until assayed, a period of no more than 3 hours. The E. coli assays were performed using the membrane filter method and employing $\mathrm{mFC}$ agar incubated for 20 to 24 hours at $44.5^{\circ} \mathrm{C}$; the results being reported as colony forming units (Cfu) per $300 \mathrm{~mL}$. The combined bacteriophage were assayed using the Adams Double Agar overlay method and reported as plaque forming units $(\mathrm{Pfu})$ per $\mathrm{mL}$. The microspheres were enumerated by direct microscopic count using epi-fluorescent microscopy and reported as spheres per L" (Dr. Robert Cooper, BioVir, 2010).

\subsection{Quality Control}

Quality control (QC) procedures were incorporated into several experiments to establish repeatability and precision of results. QC procedures included the testing of duplicate prototypes within a single experiment, testing of duplicate prototypes between two experiments, taking multiple (split) constituent readings, taking duplicate samples, calibration using a standard, matrix spikes for chlorine residual, and use of developed calibration curves. 
Experiments B-1 and B-2 incorporated the testing of a duplicate prototype over the course of two experiments. One bag from each experiment contained the same two-baffle configuration. The initial water qualities of both experiments were theoretically the same, so the results from the two bags could be compared to determine repeatability of prototype performance. Experiment A-2, C-1, D-2, and E-1 each incorporated the testing of duplicate prototypes within the single experiment. The purpose of testing two identical prototypes was to ensure repeatability of performance and to compare results to evaluate variability of the treatment process. In most cases, duplicate bags performed similarly. However, several duplicate runs had inconsistent results from which procedural discussions and conclusions were drawn (see Chapter 4).

In terms of water quality, QC procedures were incorporated into turbidity and chlorine residual measurements. For example, every turbidity sample taken was read a total of three times by the turbidimeter and the measured values averaged for use in data analysis. The use of an averaged turbidity measurement ensured that outlying turbidity values did not significantly affect the turbidity trends in the prototype. Typically, the variance among the three readings was less than $10-15 \%$. For experiments in which chlorine residual was measured, a standard with known free chlorine residual concentration was used to develop a matrix spike for each prototype. Spikes were performed on every bag tested, and recovery values determined on the data recording sheets (see Appendix E). The free chlorine standard was also used to develop a calibration curve to be used with the colorimeter. The use of these QC procedures throughout experimental testing helped to confirm design and treatment conclusions made for the waterbag prototype. 


\section{CHAPTER 4: RESULTS AND DISCUSSION}

This chapter presents the results and discussion on the two types of experiments performed: 1) optimization experiments and 2) U.S. EPA Challenge Water experiments.

\subsection{Optimization Experiments}

The primary objective of the optimization experiments was to determine the optimal operational and physical characteristics of the waterbag required to meet the WHO/Sphere Project emergency guidelines for water treatment. The guidelines state that treated water turbidity should be $<5 \mathrm{NTU}$ and that free chlorine residual should be between 0.2 and 0.5 mg/L (The Sphere Project, 2004; WHO, 2006). Three types of optimization experiments were performed: (1) experiments with various methods-of-use of the waterbag, including mixing time, mixing motion, and mixing start time after PŪR ${ }^{\circledR}$ addition; (2) experiments with different baffle numbers and designs; and (3) an experiment with challenging initial water conditions including high organic carbon concentration, low temperature, high $\mathrm{pH}$, and high dissolved solids.

\subsubsection{Experiment A-1: Mixing Times}

Several mixing times were tested to determine the minimum mixing time required to achieve a post-PŪR ${ }^{\circledR}$-treatment, pre-filtration turbidity of $<5$ NTU. A primary purpose of this experiment was to establish a standard mixing time to use for future experiments by comparing post-treatment turbidities. Six prototype waterbags were (1) filled with $10 \mathrm{~L}$ of water, (2) treated with one $\mathrm{PU}^{\circledR}{ }^{\circledR}$ sachet, (3) mixed with standard $180^{\circ}$ twisting rotations at a rate of $40 \mathrm{bpm}$ or $70 \mathrm{bpm}$, and (4) settled and disinfected for $30 \mathrm{~min}$. A medium mixing speed of $70 \mathrm{bpm}$ was used for all of the prototypes mixed except for Bag 1, which was mixed 
at a speed of $40 \mathrm{bpm}$; Bag 1 represented a potential worst-case mixing scenario. The six prototypes were mixed for $30 \mathrm{sec}, 1 \mathrm{~min}, 1.5 \mathrm{~min}, 2 \mathrm{~min}, 3 \mathrm{~min}$, and $5 \mathrm{~min}$, respectively. Although all initial water conditions were meant to be identical, the initial conditions were somewhat different. Initial turbidities varied from 374 to $457 \mathrm{NTU}$, pH varied from 7.72 to 8.23, and temperatures of $23.1^{\circ} \mathrm{C}$ to $26.1^{\circ} \mathrm{C}$.

Turbidity decreased for all prototypes over the course of the 30 min settling period and that longer mixing times resulted in much lower post-treatment turbidities (Figure 4.1). The mixing time of 5 min (Bag 6) resulted in the lowest final turbidity of all six prototypes tested, and it was the only mixing time that produced a final turbidity $<5$ NTU (Figure 4.2).

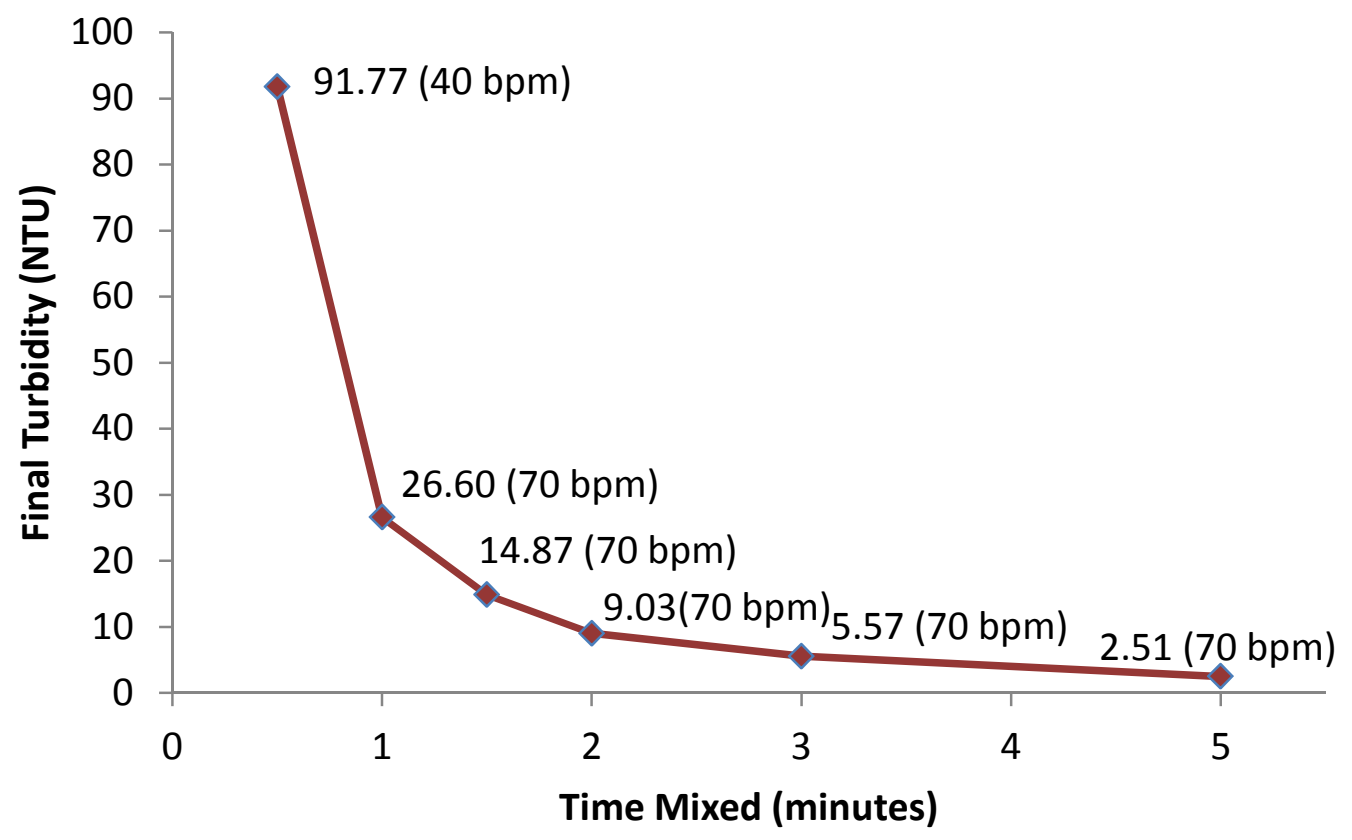

Figure 4.1: Final turbidities of prototypes mixed for between $30 \mathrm{sec}$ and $5 \mathrm{~min}$. Higher mixing times resulted in lower final turbidities. 


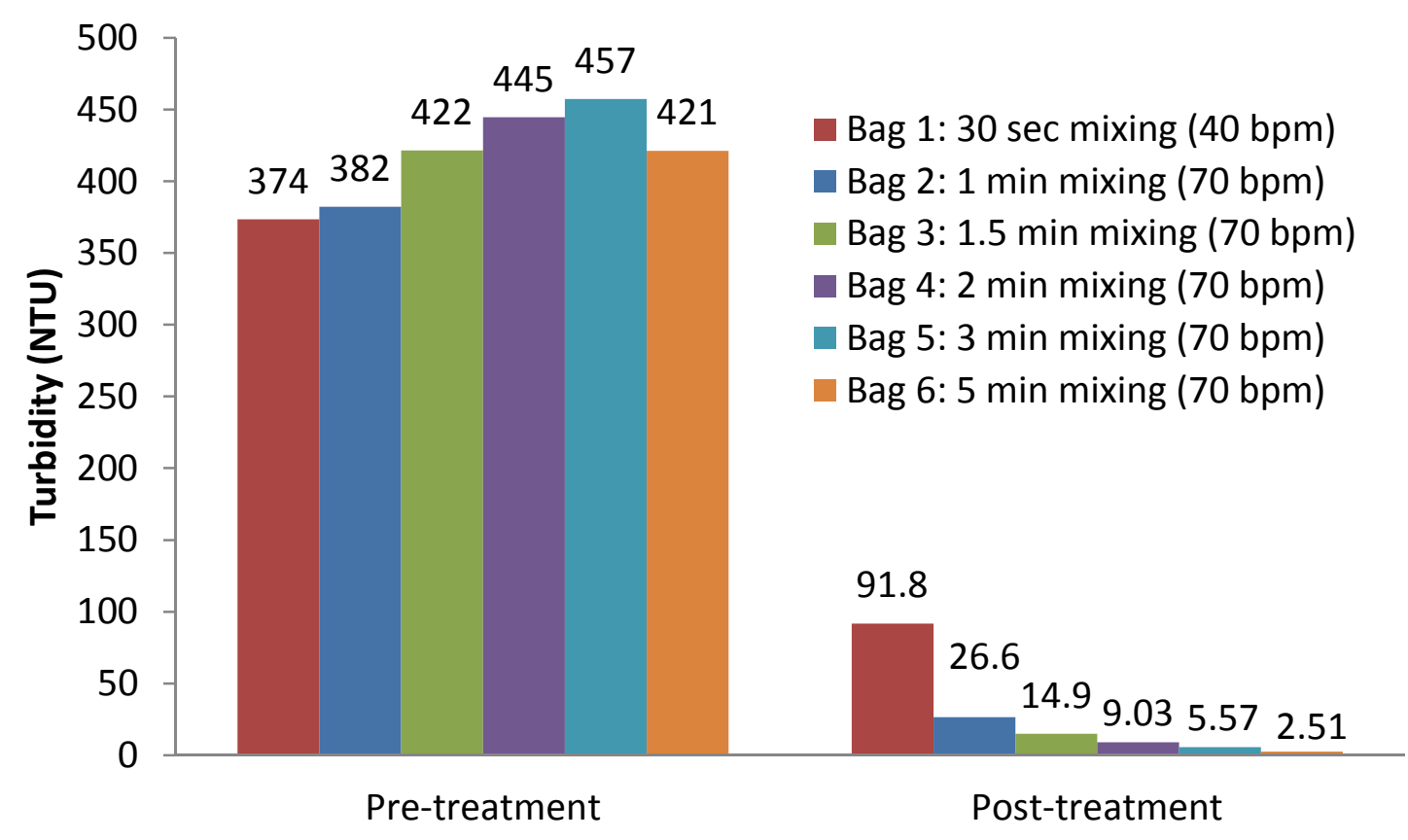

Figure 4.2 : Pre-treatment versus post-PŪ $R^{\circledR}$-treatment turbidities of prototypes mixed for between 30 sec and 5 min. Bag 1 was intentionally conducted with a less-thanoptimal mixing speed to accentuate resulting differences in performance.

Experiment A-1 showed that sufficient mixing time is important to achieving low posttreatment turbidities. Although all tested prototypes had some floc formation, floc sizes and water clarity increased with longer mixing times. The water in Bag 1 remained significantly orange (probably flocculated ferric ions from the $\mathrm{PU}^{\circledR}{ }^{\circledR}$ ferric sulfate coagulant) and turbid, while Bags 2 through 6 showed progressively less orange color and less turbidity, with Bags 5 and 6 showing virtually no residual orange and significant floc formation and settling. The slow mixing $(40 \mathrm{bpm})$ for Bag 1 resulted in a high post-treatment turbidity of $91.8 \mathrm{NTU}$, a very high turbidity that could impede chlorine disinfection. Even Bag 2 (26.6 NTU), Bag 3 (14.9 NTU), and Bag 4 (9.03 NTU) had post-treatment turbidities that might inhibit disinfection kinetics. 
Through interpolation, it might be concluded that a bag mixed for 4 min at $70 \mathrm{bpm}$ could achieve the $<5$ NTU standard. However, for the instructions provided to users, a conservative mixing time of five minutes would provide a safety factor. Based on these results, a mixing time of 5 min at $70 \mathrm{bpm}$ was chosen as the optimal mixing time to achieve sufficient solids removal.

\subsubsection{Experiment A-2: Mixing Method - Abrupt Motion vs. Fluid Motion}

Two different mixing method were tested to determine if minor variations in the twisting motion affected the overall final turbidity. The two mixing motions included $180^{\circ}$ twists with either (1) abrupt changes in rotation direction (jerking movements between turns) or (2) fluid direction changes (smooth, gentle motions). The primary purpose of this experiment was to standardize the mixing procedure for future experiments. Four prototypes were tested with the two mixing methods. Bags 1 and 2 employed the abrupt-motion mixing, while Bags 3 and 4 employed the fluid-motion mixing. All four prototype waterbags were (1) filled with $10 \mathrm{~L}$ of test water, (2) treated with one PŪR ${ }^{\circledR}$ sachet, (3) mixed for 2 min at a rate of $70 \mathrm{bpm}$, and (4) allowed to settle and disinfect for $30 \mathrm{~min}$. A mixing time of only 2 min was used in an attempt to accentuate any differences in final turbidities between the two mixing methods. Initial turbidities varied from 443 to $503, \mathrm{pH}$ varied from 7.21 to 7.61 , and the temperature was $24.5^{\circ} \mathrm{C}$ to $25.0^{\circ} \mathrm{C}$. Abrupt-motion mixing resulted in lower final turbidities than fluidmotion mixing (Figure 4.3). 


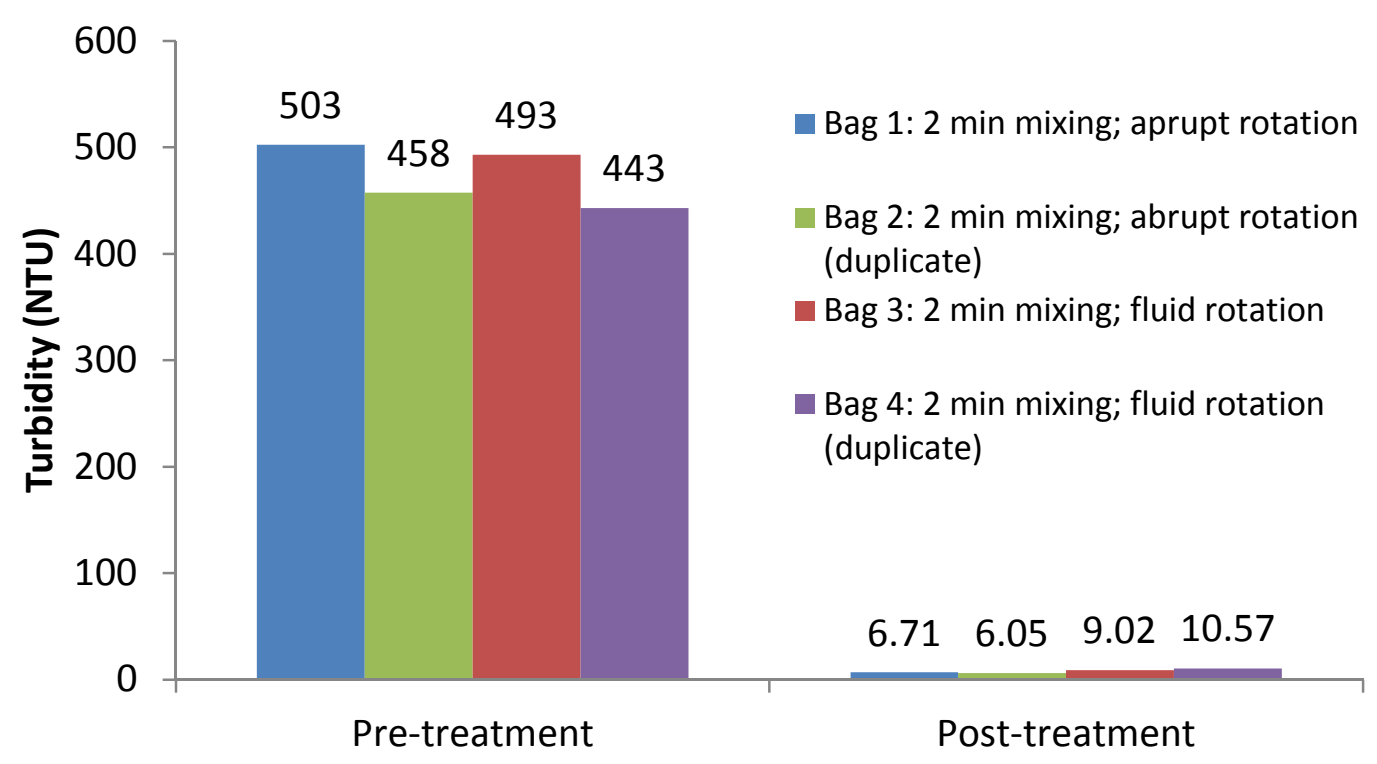

Figure 4.3: Pre-treatment and post-treatment turbidities of prototypes mixed with either fluid or abrupt twisting rotations. This experiment was intentionally conducted with a less-than-optimal procedure (mixing time of $2 \mathrm{~min}$ ) to accentuate resulting differences in performance.

Experiment A-2 showed that minor variations in twisting motion affect post-treatment turbidities. Rapid twisting rotations (with quick turning movements) resulted in lower posttreatment turbidities than fluid (controlled, calm turns) rotations. Since lower final turbidities were achieved with rapid mixing motions in this experiment, rapid mixing was used in all subsequent experiments.

Upon visual observation, the abrupt rotations performed on Bags 1 and 2 resulted in higher turbulence and sloshing at the top of the bags than observed with fluid rotations (Bags 3 and 4). The sloshing that was observed from abrupt twisting provided a visual cue that the water is being mixed; therefore, users might intuitively mix the waterbag with the more vigorous abrupt method. Even if a user does not employ consistently abrupt twisting rotations, the longer-than-necessary 5-min mixing time to be specified in the instructions would counteract less vigorous mixing. None of the prototypes tested in this experiment met the $<5$ NTU post- 
treatment guideline due to the short mixing time. The high final turbidities of the fluid twisting motion (Bags 3 and 4) are similar to Bag 4 from Experiment A-1, which was also mixed for $2 \mathrm{~min}$. A mixing time of $5 \mathrm{~min}$ might decrease the negative effect of gentle mixing.

\subsubsection{Experiment A-3: Delayed Mixing Start after $\mathbf{P} \overline{\mathbf{U}}{ }^{\circledR}$ Addition}

Some untrained users might require several minutes to roll-down and close the waterbag after PŨR ${ }^{\circledR}$ addition. Though much of the $\overline{P U R}^{\circledR}$ powder floats on the water surface before mixing begins, some of the treatment chemicals start to react with the contaminated water under lessthan-ideal conditions in the absence of immediate mixing. The effect of delay time between $\mathrm{PUR}^{\circledR}$ addition and mixing start was investigated to determine if a mixing delay affected the final turbidity of post-treatment water. In this experiment, Bag 1 had "no delay" between $\mathrm{PUR}^{\circledR}$ addition and mixing start, though the $\overline{P U R}^{\circledR}$ addition and bag closing process took 20$25 \mathrm{sec}$ before mixing began. Bags 2 through 4 had intentional delays between PŪR ${ }^{\circledR}$ addition and mixing start of one, two, and five min, respectively. Four prototype waterbags were (1) filled with $10 \mathrm{~L}$ of test water, (2) received one $\mathrm{PU}^{\circledR}{ }^{\circledR}$ sachet and were closed via dry-bag closure, (3) hung vertically and delayed for the specified amount of time, (4) mixed for 5 min at a rate of $70 \mathrm{bpm}$, and (5) allowed to settle and disinfect for $30 \mathrm{~min}$. Initial turbidities varied from $361 \mathrm{NTU}$ to $444 \mathrm{NTU}, \mathrm{pH}$ varied from 8.18 to 8.33 , and temperatures were $21.3^{\circ} \mathrm{C}$ to $22.3^{\circ} \mathrm{C}$.

With 5 min mixing time, a delay between $\mathrm{PUTR}^{\circledR}$ addition and mixing start did not have an appreciable impact on post-treatment turbidities (Figure 4.4). Subsequent experiments employed a "no mixing delay" treatment practice. 


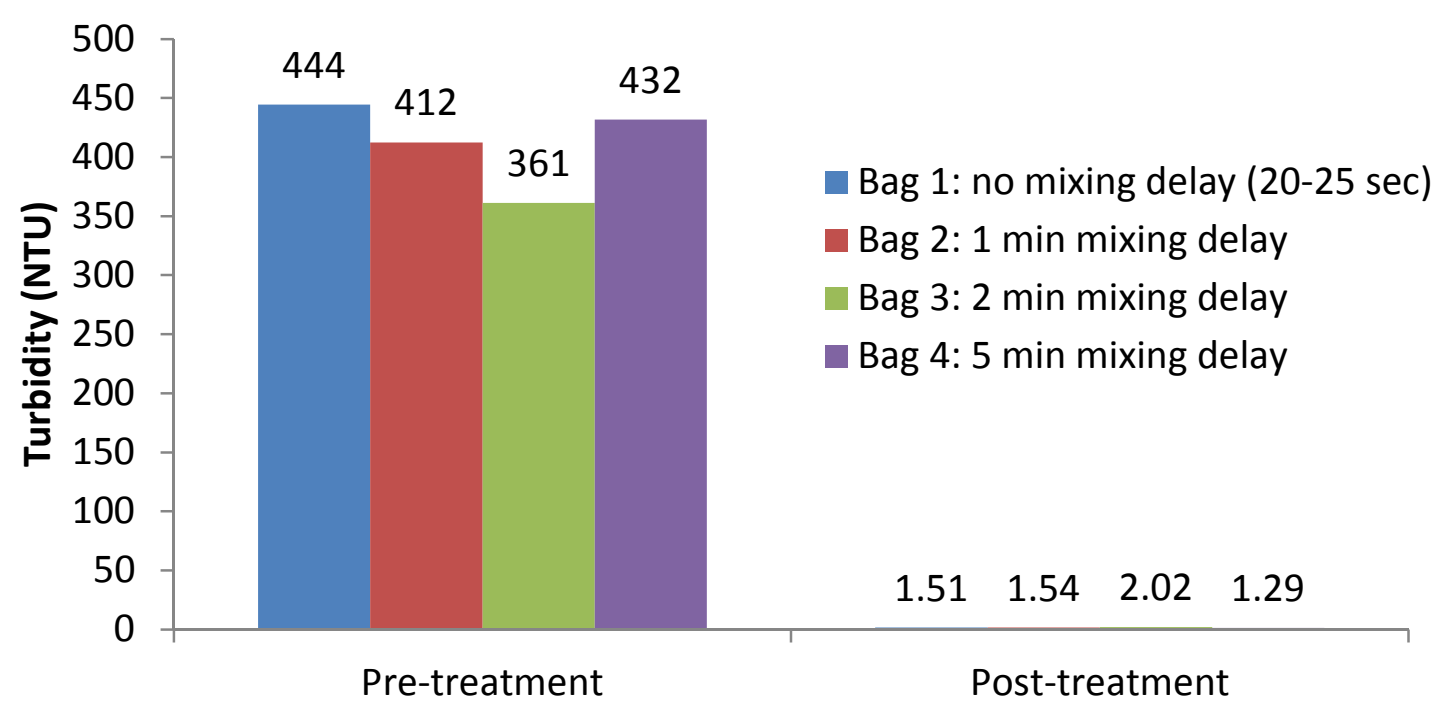

Figure 4.4: Pre-treatment and post-treatment turbidities for prototypes with a 0-min to 5-min delay between PŪR® addition and mixing start.

Experiment A-3 showed that a delay between PŪR ${ }^{\circledR}$ addition and mixing start did not have an appreciable effect on post-treatment turbidities. The range in final turbidities observed is not significant in the overall treatment scheme. The results from this experiment diverge from mixing theory. In general, immediate, rapid mixing is required for successful coagulation to occur (MWH, 2005). Immediate mixing ensures that treatment chemicals react with constituents in the water as intended, and do not hydrolyze with water and form unwanted compounds. It would be expected that a delay between $\mathrm{PU}^{\circledR}$ addition and mixing would result in inadequate chemical homogenization and floc formation. But, at least with 5 min mixing, a short mixing delay did not affect floc formation and sedimentation, as indicated by supernatant turbidity.

\subsubsection{Experiment B-1: Baffle Configuration, Part I - Narrow Baffles}

The number of internal narrow baffles was varied to determine which number resulted in lowest post-treatment turbidities. Four prototype waterbags were tested with varying 
numbers of 5.1-cm wide, $16.5-\mathrm{cm}$ long baffles made from standard duct tape. Baffles were attached internally in the locations detailed in Table 4.1.

Table 4.1: Locations of narrow baffles within each prototype for Experiment B-1.

\begin{tabular}{ccc}
\hline Bag & $\begin{array}{c}\text { Number } \\
\text { of Baffles }\end{array}$ & Location in Prototype \\
\hline 1 & 0 & N/A \\
2 & 1 & $15.2 \mathrm{~cm}$ above nozzle \\
3 & 2 & $\begin{array}{c}12.7 \mathrm{~cm} \text { above nozzle, } 12.7 \mathrm{~cm} \\
\text { above } 1 \mathrm{st} \text { baffle }\end{array}$ \\
4 & 3 & $\begin{array}{c}7.6 \mathrm{~cm} \text { above nozzle, } 7.6 \mathrm{~cm} \text { above } \\
1 \mathrm{st} \text { baffle, } 7.6 \mathrm{~cm} \text { above } 2 \mathrm{nd} \text { baffle }\end{array}$ \\
\hline
\end{tabular}

Each prototype waterbag was (1) filled with $10 \mathrm{~L}$ of test water, (2) dosed with one PŪR ${ }^{\circledR}$ sachet, (3) mixed for $2.5 \mathrm{~min}$ at a rate of $40 \mathrm{bpm}$, and (4) allowed to settle and disinfect for $30 \mathrm{~min}$. A mixing time of $2.5 \mathrm{~min}$ and a mixing speed of $40 \mathrm{bpm}$ were used to magnify the differences in final turbidities between the prototypes tested. Initial turbidities varied from $477 \mathrm{NTU}$ to $497 \mathrm{NTU}, \mathrm{pH}$ varied from 8.03 to 8.07 , and temperatures were $22.5^{\circ} \mathrm{C}$ to $23.6^{\circ} \mathrm{C}$. Addition of baffles resulted in lower final turbidities (Figure 4.5, Figure 4.6). Final turbidity with zero baffles was 28.2 NTU, but turbidity decreased to 5.60 NTU in Bag 4 with three baffles. 


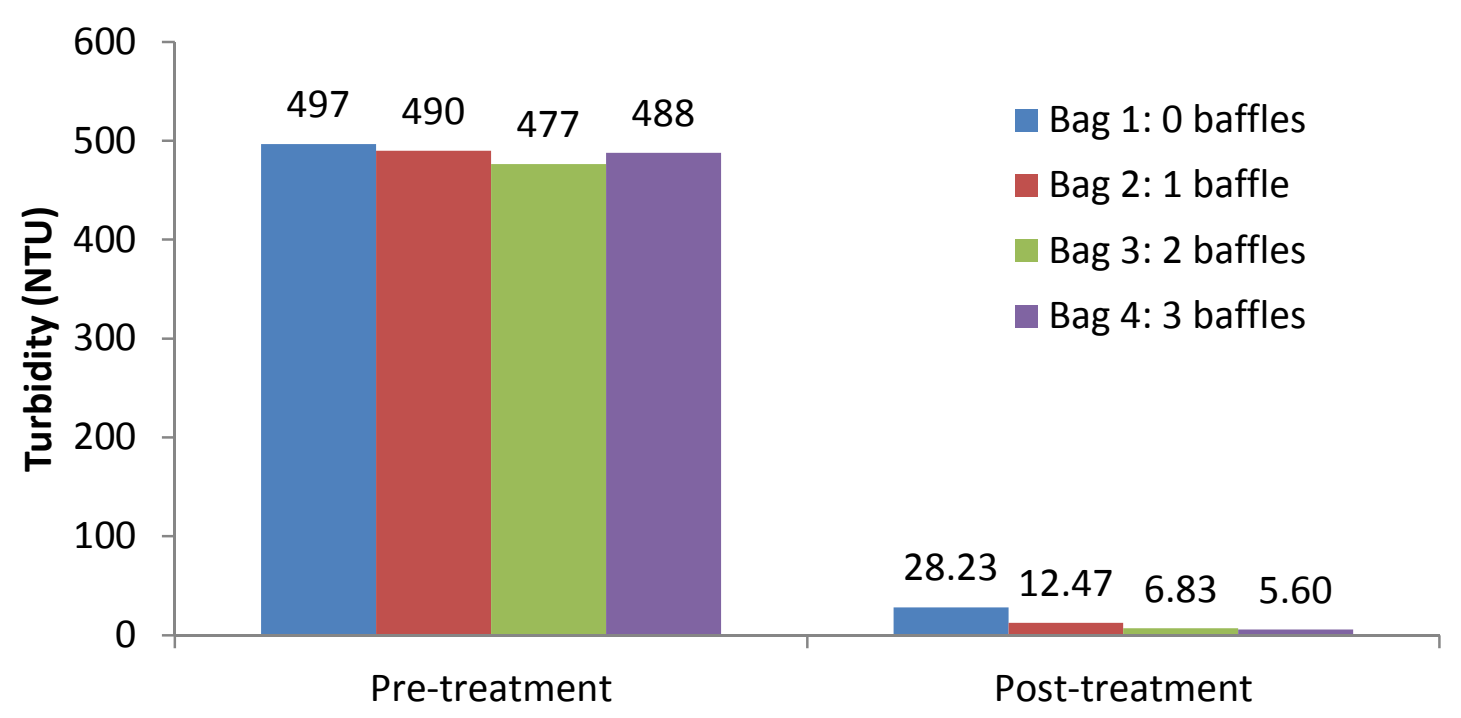

Figure 4.5: Pre-treatment and post-treatment turbidities for prototypes with different numbers of narrow baffles. Each baffle was a $5.1-\mathrm{cm}$ wide by $16.5-\mathrm{cm}$ long and was made from two layers of standard duct tape. This experiment was intentionally conducted with a less-than-optimal procedure (mixing time of $2.5 \mathrm{~min}$ at $40 \mathrm{bpm}$ ) to accentuate resulting differences in performance.

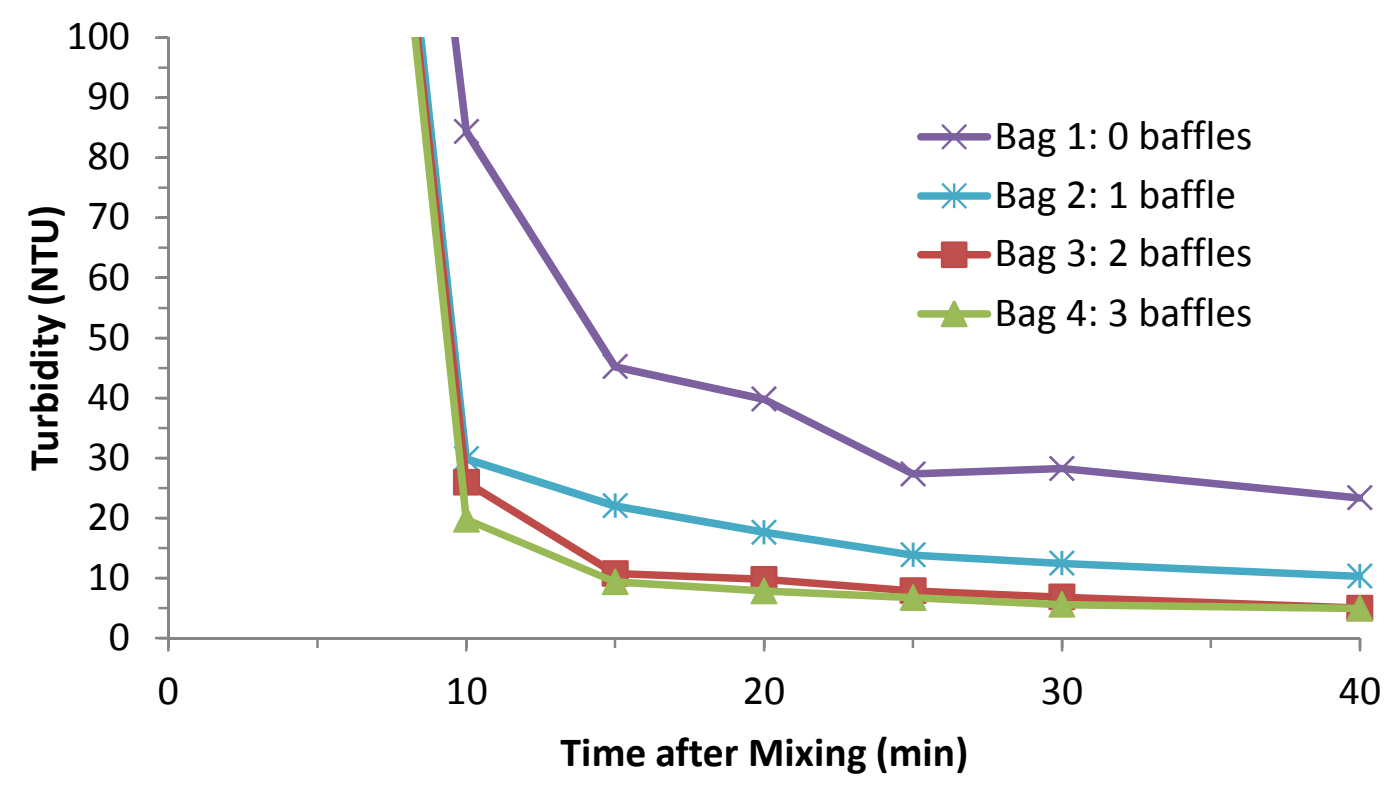

Figure 4.6: Turbidity over time for prototypes with different numbers of baffles. Initial (pre-treatment) turbidity values are not shown. This experiment was intentionally conducted with a less-than-optimal procedure (only 2.5 min of mixing at $40 \mathrm{bpm}$ ) to accentuate resulting differences in performance. 
Experiment B-1 showed that the number of baffles has a significant effect on post-treatment turbidities. Increased numbers of baffles led to lower final turbidity values, while no baffle resulted in a significantly elevated post-treatment turbidity. Therefore, when using the prescribed mixing method of $180^{\circ}$ rapid motion twists and a limited mixing time, a baffle is necessary to achieve low post-treatment turbidities. Though Bags 3 and 4 had relatively low post-treatment turbidities, none of the bags met the Sphere Project guideline of $<5$ NTU. However, all four prototypes were mixed for only $2.5 \mathrm{~min}$ at speed of $40 \mathrm{bpm}$ in an effort to accentuate the effect of the baffles. A 5 min mixing time would likely have resulted in lower turbidity values, some of which may have met the $<5$ NTU standard.

Since the turbidity difference between two and three baffles was minimal, even at only 2.5 min of mixing, it was decided that two baffles was sufficient. In addition, three baffles might increase the overall cost of production of the bag. Two baffles have the similar manufacturing drawback when compared to the use of a single baffle. Therefore, Experiment B-2 was designed to test single, wide baffles to determine if a wider baffle could produce similar or better results than the use of two narrow baffles. For a given mixing energy input, even one internal baffle greatly improves the treatment performance over a no-baffle design.

\subsubsection{Experiment B-2: Baffle Configuration, Part II - Wide Baffles}

After determining the effect on final turbidity from different numbers of narrow baffles in Experiment B-1, Experiment B-2 tested the same effect with wider baffles. Three prototypes (Bags 2 through 4) were tested with different configurations of wide baffles (Table 4.2), while one prototype (Bag 1) contained two narrow baffles for comparison. 
Table 4.2: Description and location of baffles within prototypes for Experiment B-2.

\begin{tabular}{cccc}
\hline Bag & $\begin{array}{c}\text { Number of } \\
\text { Baffles }\end{array}$ & Description of Baffle(s) & Location in Prototype \\
\hline 1 & 2 & 2 narrow baffles & $\begin{array}{c}12.7 \mathrm{~cm} \text { above nozzle, } \\
1.7 \mathrm{~cm} \text { above } 1 \mathrm{st} \text { baffle }\end{array}$ \\
2 & 1 & $\begin{array}{c}12.7-\mathrm{cm} \text { wide baffle with two side- } \\
\text { by-side circular (3.8-cm diameter) } \\
\text { holes }\end{array}$ & $\begin{array}{c}\text { Starting } 25.4 \mathrm{~cm} \text { above } \\
\text { bottom seam of bag }\end{array}$ \\
3 & 1 & $\begin{array}{c}\text { 12.7-cm wide baffle with two } \\
\text { circular (3.8-cm diameter) holes set } \\
\text { diagonally from each other } \\
\text { 12.7-cm wide baffle with two } \\
\text { rectangular holes across top and } \\
\text { bottom of baffle, respectively }\end{array}$ & $\begin{array}{c}\text { Starting } 25.4 \mathrm{~cm} \text { above } \\
\text { bottom seam of bag }\end{array}$ \\
bottom seam of bag \\
\hline
\end{tabular}

Each prototype waterbag was (1) filled with $10 \mathrm{~L}$ of test water, (2) dosed with one PŪR ${ }^{\circledR}$ sachet, (3) mixed for $2.5 \mathrm{~min}$ at a rate of $40 \mathrm{bpm}$, and (4) allowed to settle and disinfect for $30 \mathrm{~min}$. A mixing time of $2.5 \mathrm{~min}$ and a mixing speed of $40 \mathrm{bpm}$ were used to accentuate the differences in final turbidities between the prototypes tested. Initial turbidities varied from $422 \mathrm{NTU}$ to $452 \mathrm{NTU}, \mathrm{pH}$ varied from 8.08 to 8.19 , and temperatures were $22.2^{\circ} \mathrm{C}$ to $23.7^{\circ} \mathrm{C}$.

The variation in baffle configuration did not have an appreciable effect on post-treatment turbidities when mixed for 2.5 min (Figure 4.7, Figure 4.8). All baffle configurations had post-treatment turbidities between 7 NTU and 8 NTU. 


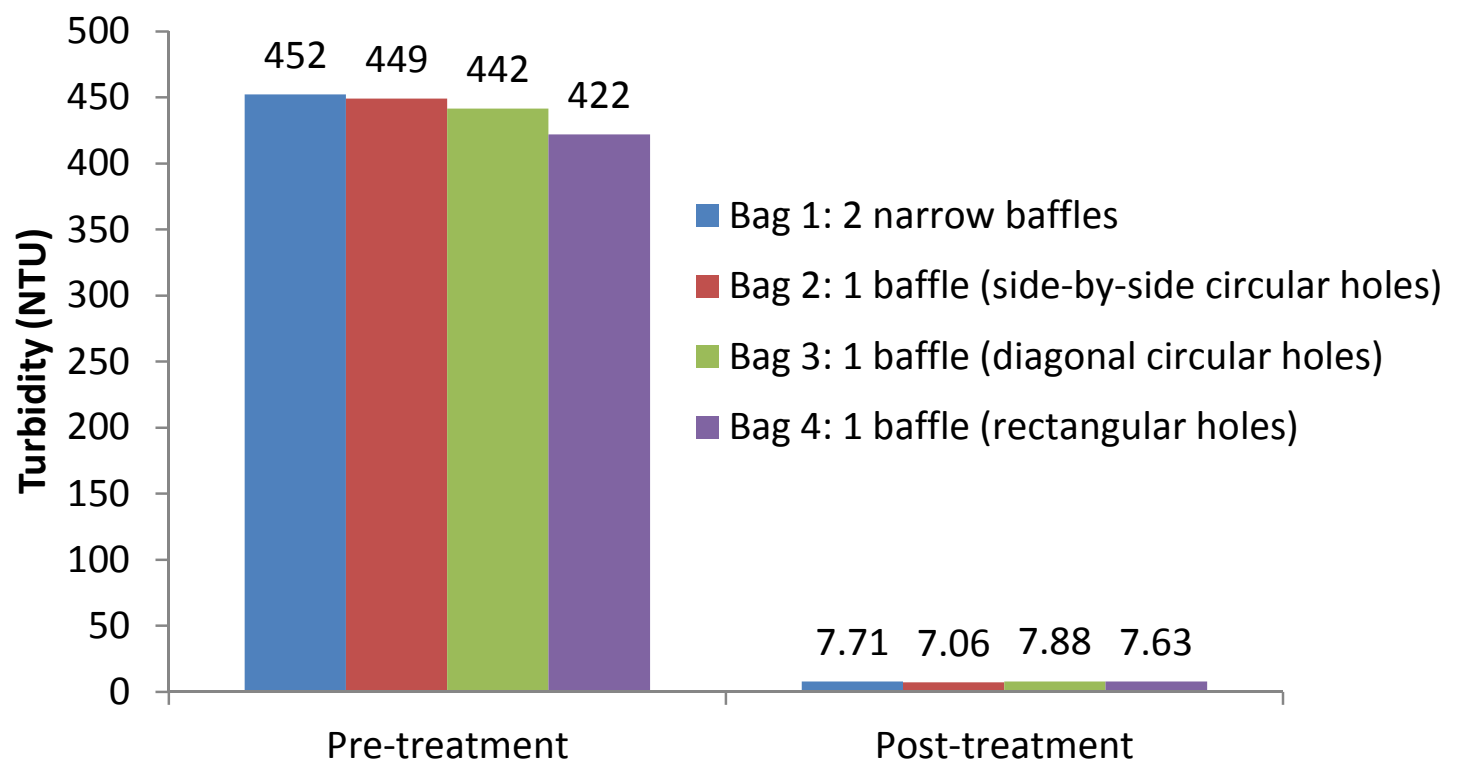

Figure 4.7: Pre-treatment and post-treatment turbidities for prototypes with varying baffle configurations. This experiment was intentionally conducted with a less-thanoptimal procedure (mixing time of $\mathbf{2 . 5} \mathbf{~ m i n}$ ) to accentuate resulting differences in performance.

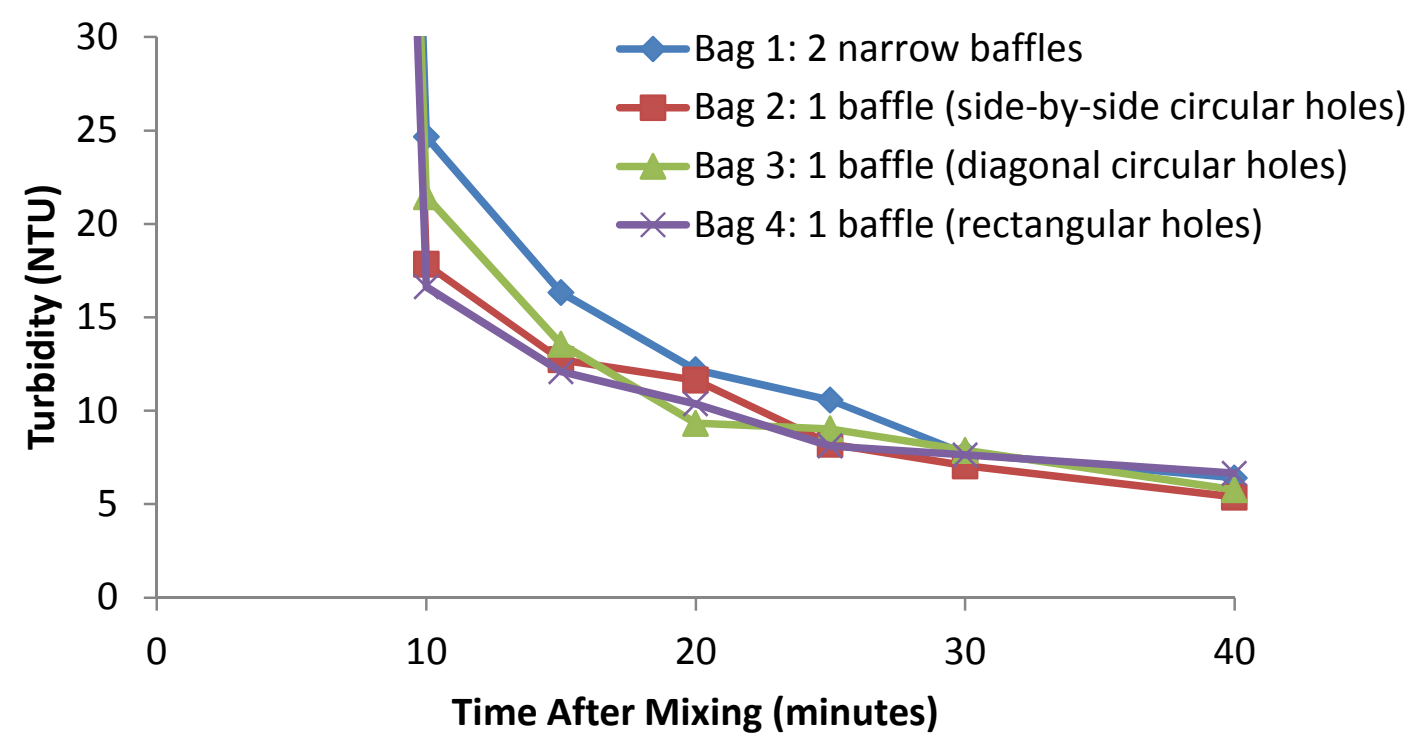

Figure 4.8: Turbidity over time for prototypes with different types of baffles. Initial turbidity values are not shown. This experiment was intentionally conducted with a less-than-optimal procedure (mixing time of only $2.5 \mathrm{~min}$ ) to accentuate resulting differences in performance. 
Experiment B-2 showed no important difference in post-treatment turbidities based on configuration of wide baffles tested. Based on these results, the final selection of baffle type and configuration was somewhat arbitrary in terms of treatment performance. Each wide baffle tested had either two circular holes or two rectangular holes cut through it. The purpose of the holes cut within the baffles was to promote turbulence during mixing. As the bags were twisted, water flowing through the holes and over the sharp edges of the baffle created turbulent eddies that improved mixing vigor. The optimal baffle configuration chosen for use in subsequent experiments was the wide baffle design with side-by-side circular holes, as used in Bag 2 of Experiment B-2 (Figure 4.9). The wide baffle design simplifies manufacturing by requiring only two internal welds, instead of the four internal welds required with two separate narrow baffles.

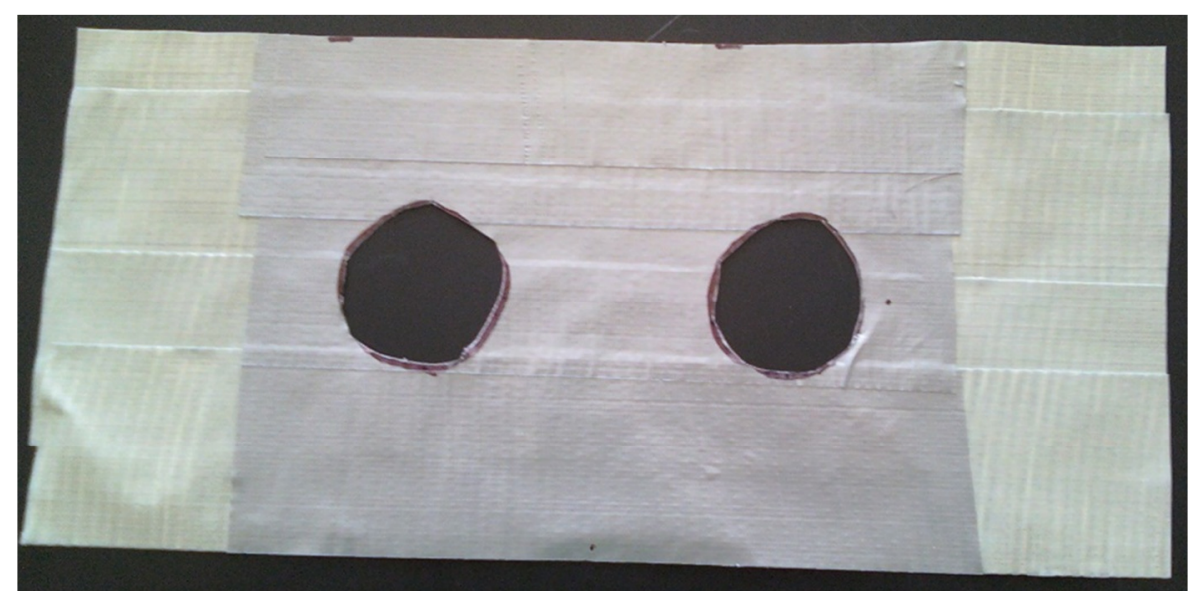

Figure 4.9: Wide baffle configuration selected for subsequent experiments. The dimensions are provided in Table 2.4, above. 


\subsubsection{Experiment C-1: Chlorine Residual Over Time with Various Initial TOC Concentrations}

Maintenance of a chlorine residual in treated water is generally recommended to help prevent reactivation of pathogens, but TOC consumes such residual chlorine. Since natural source waters can contain a wide range of TOC concentrations, it was important to identify how long the minimum free chlorine standard could be upheld in the presence of various TOC concentrations. The purpose of the experiment was to determine how long after treatment a free chlorine residual would persist within the desired range of $0.2 \mathrm{mg} / \mathrm{L}$ to $0.5 \mathrm{mg} / \mathrm{L}$ recommended by the WHO Guidelines for Drinking-water Quality (2006) and The Sphere Project Humanitarian Charter and Minimum Standards in Disaster Response (2004). For Experiment C-1, the temperature (approximately $4^{\circ} \mathrm{C}$ ) and concentrations of A2 Fine Test Dust and TDS were those used in U.S. EPA Test Water \#2. TOC concentrations were expressed in terms of percentages of the $10 \mathrm{mg} / \mathrm{L}$ TOC requirement of the U.S. EPA Challenge Water \#2. The correlation of humic acid to TOC in Appendix A was used to determine the humic acid dose. Six prototypes were tested in Experiment C-1 with a range of initial humic acid concentrations: no added TOC, 5\%, 10\% (duplicates), 25\%, and 100\% of the $10 \mathrm{mg} / \mathrm{L}$ maximum TOC concentration.

The humic acid was added to Bags 2 through 6 in the target dosages via a $2 \mathrm{~g} / \mathrm{L}$ humic acid stock solution prepared with DI water. A predetermined amount of the humic acid solution was added to the large drum and mixed for at least 5 min with the sump pump before the prototype was filled. All six prototype waterbags were (1) filled with $10 \mathrm{~L}$ of their respective initial test water types, (2) dosed with one PŪR ${ }^{\circledR}$ sachet, (3) mixed for 5 min at $70 \mathrm{bpm}$, and (4) allowed to settle and disinfect for 30 min. Bag 1 (with no added TOC) had an initial 
turbidity of $91.2 \mathrm{NTU}$, temperature of $4.5^{\circ} \mathrm{C}, \mathrm{pH}$ value of 9.01 , and TOC concentration of $3.85 \mathrm{mg} / \mathrm{L}$, apparently from the Instant Ocean salt formulation. Instant Ocean salts were added to all prototypes tested. Initial water quality characteristics of Bags 2 through 6 included turbidities varying from 79.2 NTU to 81.6 NTU, pH varying from 8.87 to 8.98 , temperatures were $3.4^{\circ} \mathrm{C}$ to $4.8^{\circ} \mathrm{C}$, and TOC varying from $4.51 \mathrm{mg} / \mathrm{L}$ to $13.39 \mathrm{mg} / \mathrm{L}$, as determined by the NPOC analysis described in Section 3.3. Initial TOC concentrations are shown in Figure 4.10.

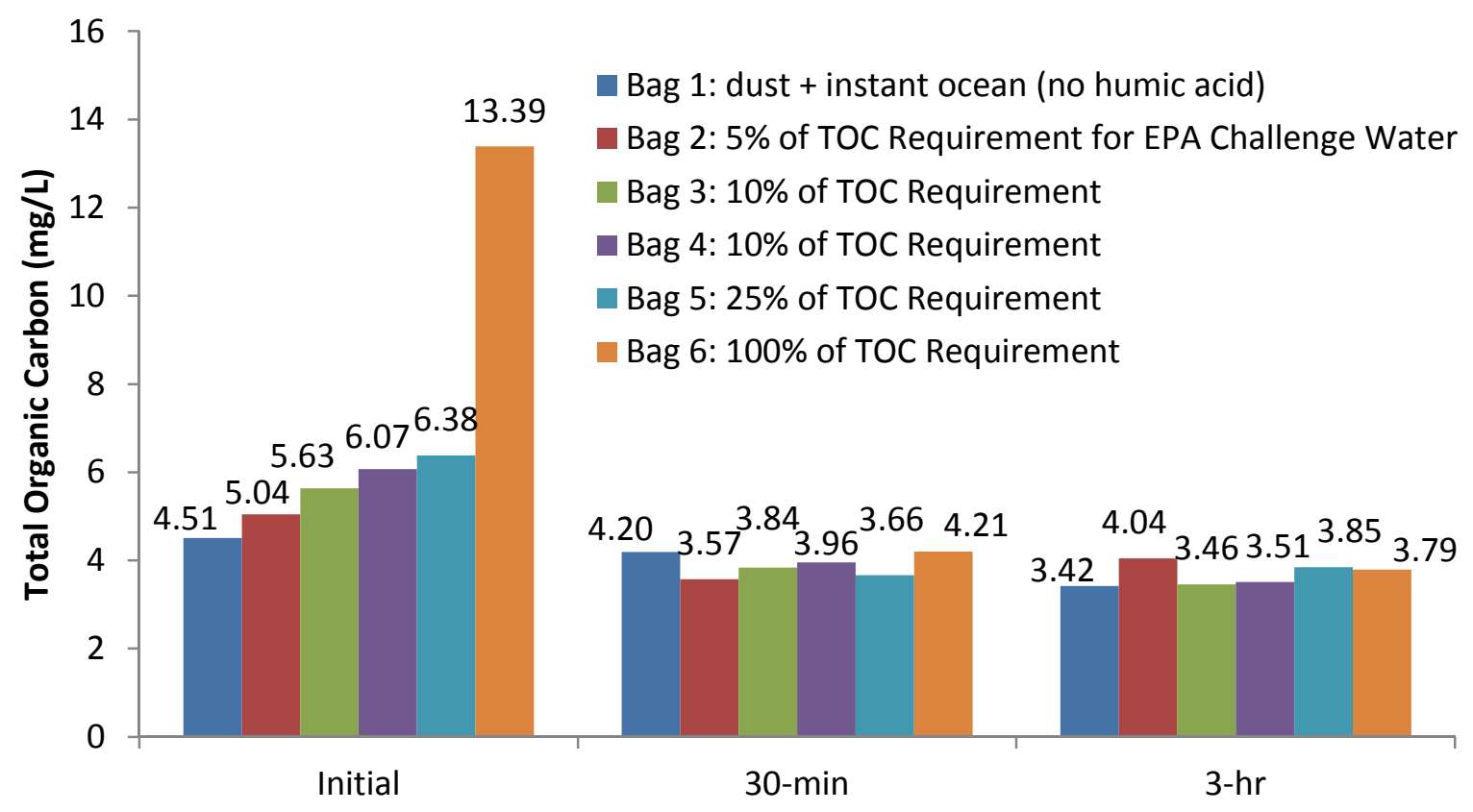

Figure 4.10: Initial (pre-treatment), 30-min post-treatment, and 3-hr post-treatment TOC measurements. Percentages indicate a percent of the $10 \mathrm{mg} / \mathrm{L}$ TOC required by the U.S. EPA Challenge Test (Test Water \#2).

Initial TOC values for Bags 1 through 6 followed a general upward tendency, but did not match expected TOC values of the desired percentages of the $10 \mathrm{mg} / \mathrm{L}$ TOC from the U.S. EPA Challenge Water (Figure 4.10). Even Bag 1, which did not contain any added humic acid, reportedly had an initial TOC concentration of $4.51 \mathrm{mg} / \mathrm{L}$. The blank, standard, and split samples indicate that the TOC analyzer was operating with reasonable repeatability 
( $0.5 \%$ to $4 \%$ differences between original and split samples). Therefore, the unexpected range and values of initial TOC concentrations might be due to an interference in the test water with the analytical method used to measure TOC. For example, if the value of 4.51 $\mathrm{mg} / \mathrm{L}$ TOC from Bag 1 (the sample blank, with no added humic acid) is subtracted from the initial TOC concentrations of Bags 2 through 6, the resulting concentrations nearly match expected results. Regardless, the chlorine residual behavior observed during this experiment still reflects the relationship expected in the presence of high vs. low TOC concentrations.

All six prototypes exhibited loss of chlorine residual over time (Figure 4.11). As expected, bags with lower initial TOC concentrations maintained the minimum standard for more time compared to bags with higher TOC concentrations. Bags 1 through 4 had initial posttreatment chorine residuals greater than the upper $0.5 \mathrm{mg} / \mathrm{L}$ standard, but eventually dropped below the $0.2 \mathrm{mg} / \mathrm{L}$ standard. Bag 6 , with the highest amount of initial TOC, dropped below the $0.2 \mathrm{mg} / \mathrm{L}$ standard in less than 20 minutes after mixing; this latter chlorine residual duration would be expected in the U.S. EPA Test Water \#2 challenge tests (Experiments D-1, D-2, and E-1). 


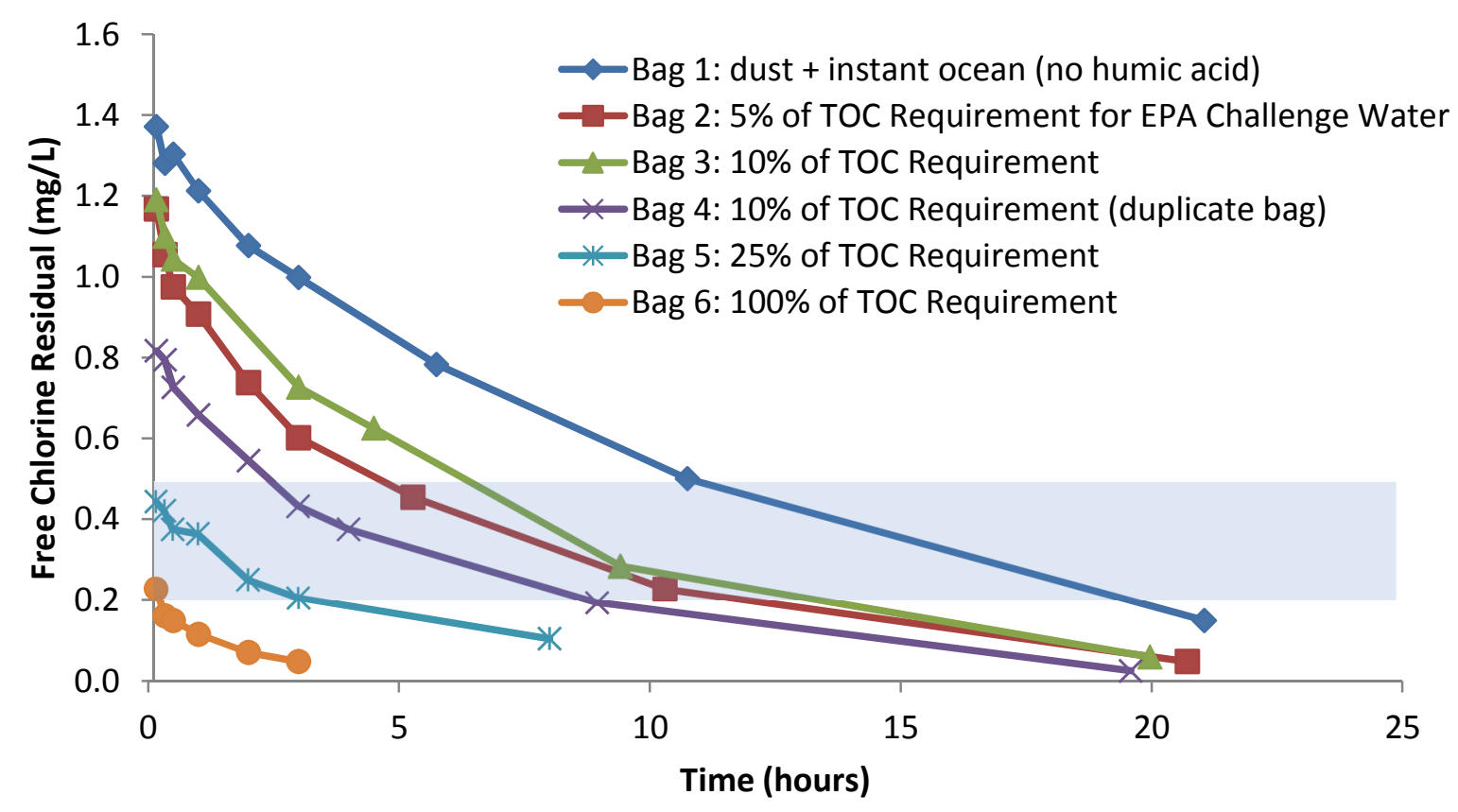

Figure 4.11: Free chlorine residuals over time for prototypes containing a range of initial TOC concentrations. Percentages indicate the percent of the $10 \mathrm{mg} / \mathrm{L} \mathrm{TOC}$ required by the U.S. EPA Challenge Test (Test Water \#2). Shaded area represents the recommended range of free chlorine residual desired for disaster relief water provision (WHO, 2006; Sphere Project, 2004). Time zero represents the point at which mixing stopped and the 30-min settling/disinfection period began.

The chlorine residual results shown in Figure 4.11 represent values that were adjusted from measured results using a calibration curve and linear equation created specifically for the HACH colorimeter used in Experiment C-1. See Appendix D for more information on the method, development, and use of the calibration curve.

Included in this experiment were duplicate bags with $10 \%$ of the TOC required for the EPA Challenge Test (Bags 3 and 4). Though the chlorine residuals for Bag 4 followed expected trends between the Bag $2(5 \%)$ and Bag 5 (25\%), Bag 3 displayed unexpected results. Figure 4.11 shows that Bag 3 exhibited chlorine residuals that were consistently higher than Bag 2, which had only 5\% of the TOC challenge level. In other words, although Bag 3 and Bag 4 were technically duplicate bags, tested under the same initial test water conditions and mixed 
identically, the bags displayed different results for chlorine residual over time. This shows some experimental variability of results under these testing conditions.

Experiment C-1 showed that high TOC concentrations in source water reduce free chlorine residuals over time, as expected. The results indicate the trends in chlorine degradation over time in the presence of low to high TOC concentrations, as well as identify the maximum TOC that can exist in source water for a single PŪR ${ }^{\circledR}$ sachet to still achieve the minimum free chlorine standard. If possible, relief agencies should test contaminated source waters before use to determine expected organic content. From this information, relief workers could advise waterbag users on the maximum length of time their treated water should be stored before the possibility of recontamination occurs. Alternately, relief agencies could advise waterbag users to use more than one PŪR ${ }^{\circledR}$ sachet to achieve desired free chlorine residuals.

The primary purpose of maintaining free chlorine residual in drinking water is to provide continual pathogen disinfection capabilities of the treated water. As discussed in Chapter 2 of this report, pathogen inactivation can be accomplished by exposing the microorganisms to chlorine for a specified contact time. Because pathogen susceptibility to chlorine disinfection varies, numerical $\mathrm{Ct}$ values have been established to achieve a degree of inactivation of specific organisms using specific disinfectants (MWH, 2005; Table 2.4). Although microorganisms were not a measured constituent in this experiment, the chlorine residual results can be interpreted to determine if sufficient $\mathrm{Ct}$ values were attained to achieve hypothetical pathogen inactivation. Figure 4.12 illustrates the required contact time to inactivate E. coli under varying free chlorine concentrations, at temperatures from $2^{\circ} \mathrm{C}$ to $6^{\circ} \mathrm{C}$. The contact time to achieve inactivation is highly dependent on the distribution of 
chlorine species in the water. Using Figure 2.2, the chlorine species distribution posttreatment (at a $\mathrm{pH}$ of 7) was determined to be approximately $85 \% \mathrm{HOCl}$ and $15 \% \mathrm{OCl}^{-}$. From this, the required contact time with varying chlorine residuals can be compared to the chlorine residuals measured in Experiment C-1.

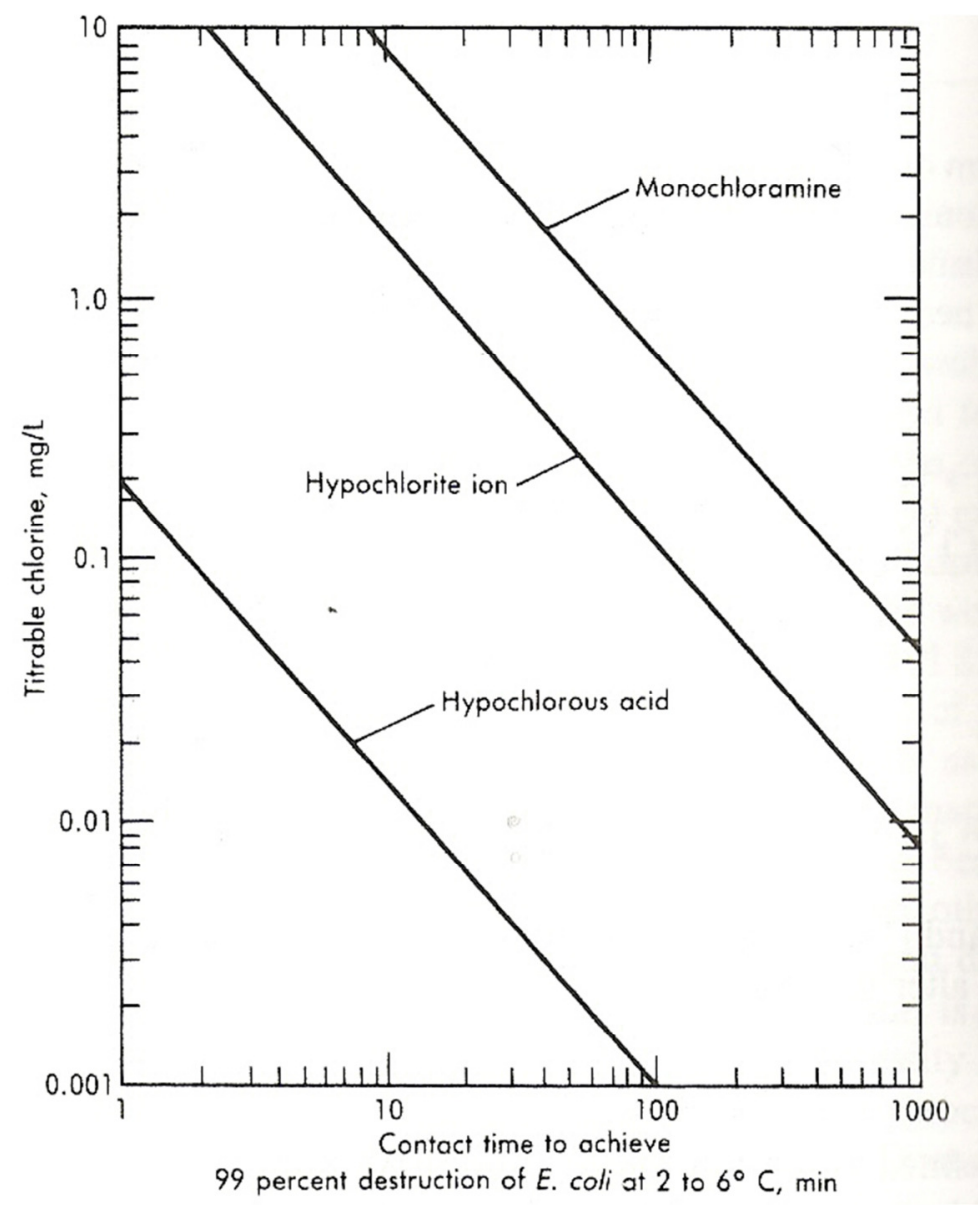

Figure 4.12: Comparison of germicidal efficiency of hypochlorous acid, hypochlorite ion, and monochloramine for $99 \%$ destruction of $E$. coli at $2^{\circ} \mathrm{C}$ to $6^{\circ} \mathrm{C}$ (Tchobanoglous \& Schroeder, 1987; Bakhir et al., 2003).

Under the temperature and $\mathrm{pH}$ conditions of this experiment (with $85 \% \mathrm{HOCl}$ and $15 \%$ $\mathrm{OCl}^{-}$), according to Figure 4.12, a free chlorine concentration of about $0.01 \mathrm{mg} / \mathrm{L}$ is required with a 30-min contact time to achieve $99 \%$ destruction of $E$. coli. With a 10-min contact time, $0.05 \mathrm{mg} / \mathrm{L}$ free chlorine residual is required to achieve $99 \%$ destruction of $E$. coli. As 
Figure 4.11 indicates, all six prototypes tested in this experiment met the required $\mathrm{Ct}$ value (concentration and contact time) to achieve 99\% inactivation of E. coli. Even Bag 6, with $13.4 \mathrm{mg} / \mathrm{L}$ initial TOC, held a free chlorine residual that would have provided sufficient kill capacity for protection against recontamination of treated water for at least three hours post-

treatment. Maintenance of a chlorine residual higher than the recommended standard provides additional protection against recontamination or reactivation of organisms in treated water. The low $\mathrm{Ct}$ values shown in Table 2.4 indicate that most bacteria and viruses types would have been inactivated under the conditions of this experiment as well. Therefore, though high TOC concentrations negatively affect the length of time that treated water maintains the $\mathrm{WHO} /$ Sphere Project chlorine residual standard, a single $\mathrm{PU}^{\circledR}{ }^{\circledR}$ sachet does have the ability to achieve pathogen inactivation within a reasonable contact time frame under the conditions posed in this experiment.

\subsection{U.S. EPA Challenge Water Experiments}

Final experiments focused on identifying the ability of the waterbag to treat the U.S. EPA Challenge Water (Test Water \#2). The first step was to determine if multiple PŪR ${ }^{\circledR}$ sachets could remove TOC and turbidity while still providing the pathogen removals specified by the U.S. EPA Guide Standard and Protocol for Testing Microbiological Water Purifiers. Once the appropriate number of PÜR ${ }^{\circledR}$ sachets was determined, the full U.S. EPA Challenge Test was conducted at BioVir Laboratories in Benicia, Calif.

\subsubsection{Experiment D-1: PŪR ${ }^{\circledR}$ Dose Needed with High TOC, Part I}

Different numbers of $\mathrm{PUT}^{\circledR}$ sachets were used to treat waters containing elevated TOC concentrations to determine the optimum number of sachets for use in the U.S EPA Challenge Test ( 1 to 4 sachets per $10 \mathrm{~L}$ ). Optimization of the number of PŪR ${ }^{\circledR}$ sachets was 
based on TOC removal from initial test water and maintaining adequately low ( $<5 \mathrm{NTU})$ turbidity in treated water over time.

Three prototype waterbags were (1) filled with $10 \mathrm{~L}$ of test water, 2) dosed with up to four $\mathrm{PUTR}^{\circledR}$ sachets, (3) mixed for $5 \mathrm{~min}$ at a speed of $70 \mathrm{bpm}$, and (4) allowed to settle and disinfect for $30 \mathrm{~min}$. Free chlorine residual, TOC, and turbidity samples were taken at intervals for up to $30 \mathrm{hrs}$ after mixing. Sampling was performed over the course of $30 \mathrm{hrs}$ to characterize the free chlorine residual in the prototypes over time. Free chlorine residual results are not reported or discussed here because the method used in this experiment was incorrect; the analysis method was corrected for Experiment C-1. The purpose of sampling over an extended period of time was to determine long-term effects of using multiple PŪR ${ }^{\circledR}$ sachets. Initial water quality characteristics included turbidities varying from 93.5 NTU to 106 NTU (meeting the $>30$ NTU requirement of the U.S. EPA Challenge Test), pH varying from 9.00 to 9.04 , temperatures were $9.0^{\circ} \mathrm{C}$ to $12.0^{\circ} \mathrm{C}$ (target of $4^{\circ} \mathrm{C}$ was not achieved), and TOC concentrations varying from $4.63 \mathrm{mg} / \mathrm{L}$ to $15.40 \mathrm{mg} / \mathrm{L}$.

Turbidity and TOC results from Bag 6 of Experiment C-1 are included in Figure 4.13 and Figure 4.14 for comparison purposes. While Experiment D-1 did not include a prototype treated with one PŪR ${ }^{\circledR}$ sachet against test water with $>10$ mg/L TOC, Bag 6 of Experiment C-1 was tested under those conditions.

Post-treatment turbidities over time for Bags 1 and 2 maintained a general downward trend before stabilizing midway throughout the 30-hr sample period (Figure 4.13). Bag 3 (four PŪR ${ }^{\circledR}$ sachets) had sporadic results, with a large turbidity spike to after two hours of mixing. Bag 3 had several more turbidity increases over the sampling period, and ended with a final 
turbidity higher than Bags 1 and 2. Bag 3 was the only prototype that did not meet the desired <5 NTU post-treatment emergency relief guideline. Bag 2 (two sachets) performed the best in achieving the lowest turbidity with high-TOC test water.

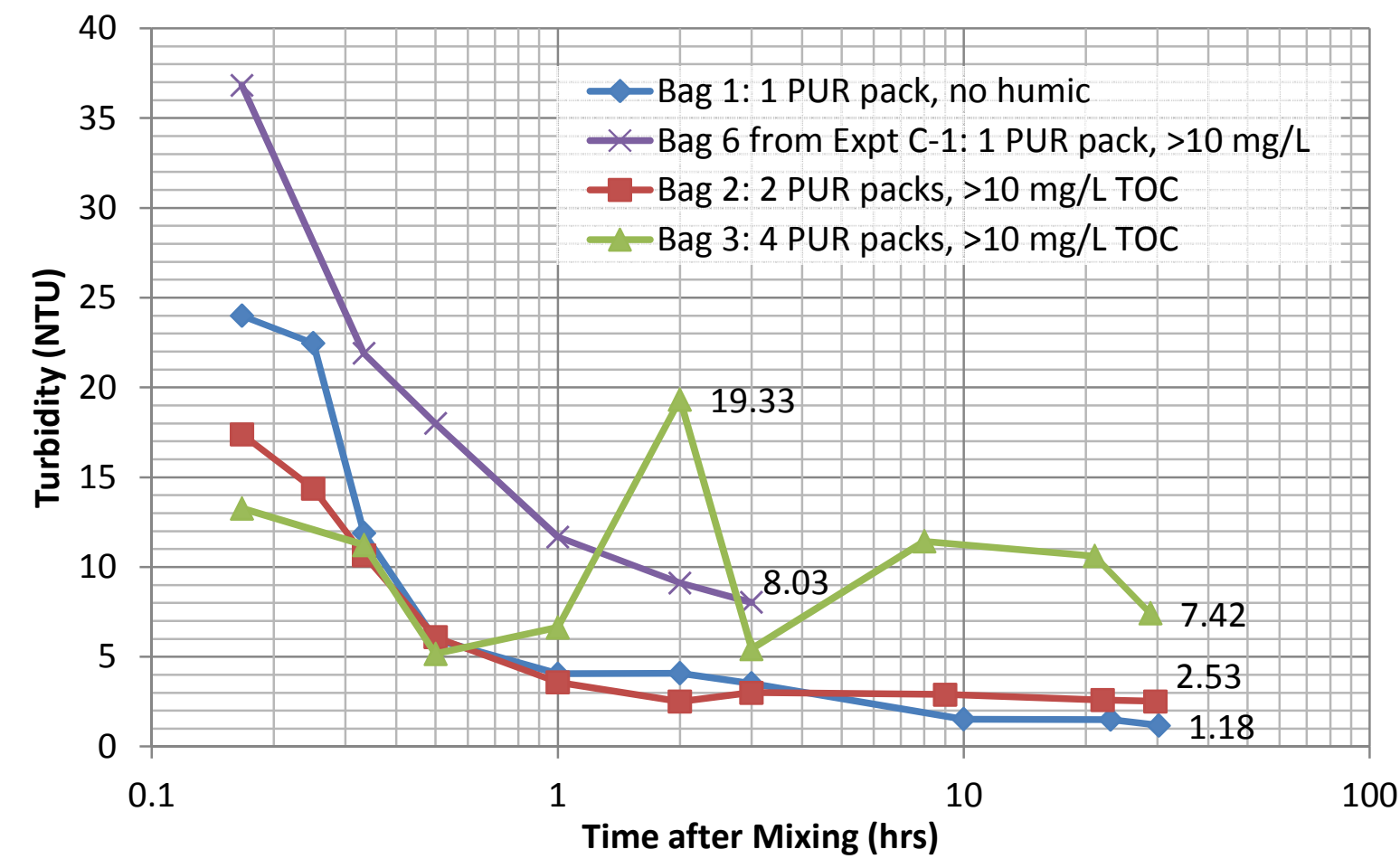

Figure 4.13: Post-treatment turbidities over time for prototypes treated with different numbers of $P \bar{U} R^{\circledR}$ sachets in the presence of $10 \mathrm{mg} / \mathrm{L}$ TOC from added humic acid. Bag 6 from Experiment C-1 is included for comparison purposes (test water conditions were similar for each experiment).

Bag 1 (the control) did not contain any added TOC, but did contain all other initial water quality conditions required for the Challenge Test (Table 2.6). The test water for Bags 2 and 3 included all of the Challenge Test Water \#2 constituents. As in Experiment C-1, initial TOC concentrations were higher than expected based on established humic acid-TOC correlations (Appendix A), potentially due to interference in the test water with the TOC analytical method used. 
TOC concentrations decreased after treatment for all three prototypes (Figure 4.14). After the initial 30-min settling and disinfection period, TOC levels remained relatively constant for all prototypes throughout the 30-hr sampling period. All post-treatment TOC concentrations were between 3 and $4 \mathrm{mg} / \mathrm{L}$ TOC, representing a relatively small difference in final TOC levels between prototypes treated with different numbers of PÜR ${ }^{\circledR}$ sachets. The TOC removal was similar in all three prototypes that received added TOC. In addition, posttreatment TOC levels did not fluctuate significantly over time. This indicates that most of the chlorine demand from the organic carbon in the test water was exerted within the first $30 \mathrm{~min}$ of treatment.

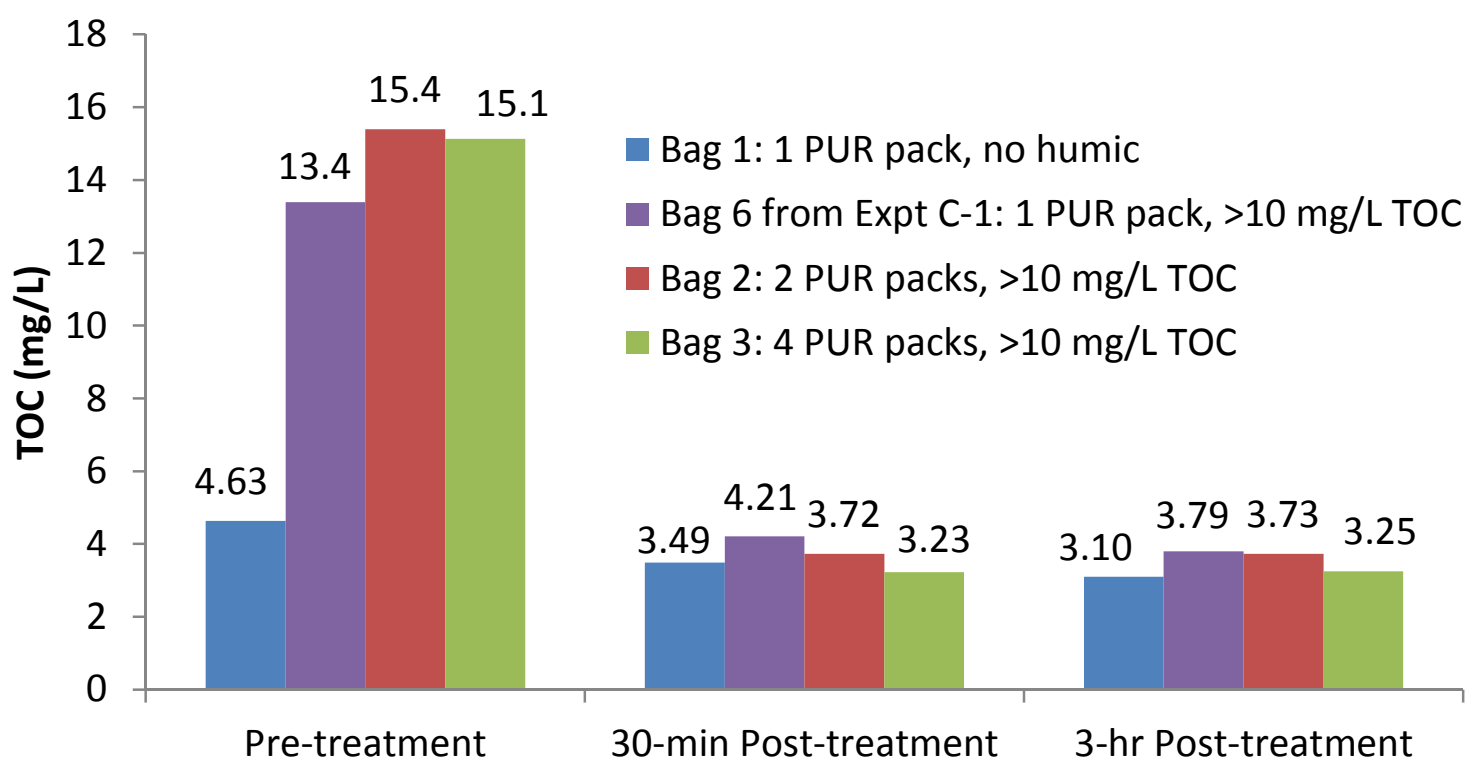

Figure 4.14: TOC concentrations over time for waterbags treated with different numbers of PŪ ${ }^{\circledR}$ sachets. Bag 6 from Experiment $C-1$ is included for comparison purposes (test water conditions were similar for each experiment).

The results of Experiment D-1 show that the number of PŪR ${ }^{\circledR}$ sachets does not highly affect TOC removals from high-TOC source waters. The results also show that too many PŪR ${ }^{\circledR}$ sachets negatively affect post-treatment turbidity values compared to prototypes treated with 
lower numbers of sachets. Two PŪR ${ }^{\circledR}$ sachets ultimately presented the most desirable turbidity and TOC removal results in the presence of elevated TOC.

The use of four PŪR ${ }^{\circledR}$ sachets in Bag 3 resulted in elevated turbidities throughout the 30-hr sampling period (Figure 4.13). A layer of floating, flocculated particles was consistently maintained on the water surface of Bag 3 throughout the sample period (Figure 4.15). In addition to the persistent layer of floating flocs, some smaller flocs were continuously suspended in the water inside the bag, never settling. The existence of these continuallysuspended flocs contributed to the erratic turbidity readings from Bag 3. The floating/suspended flocs (Figure 4.15) were likely caused as a result of a general overdose of coagulant, flocculent and flocculating aids, and oxidizing chemicals. The relatively thick layer of floating flocs at the water surface may have been a result of entrainment of gas produced during the oxidation of the TOC by the $\mathrm{KMnO}_{4}$ and chlorine present in $\mathrm{PU}^{\circledR}$. 


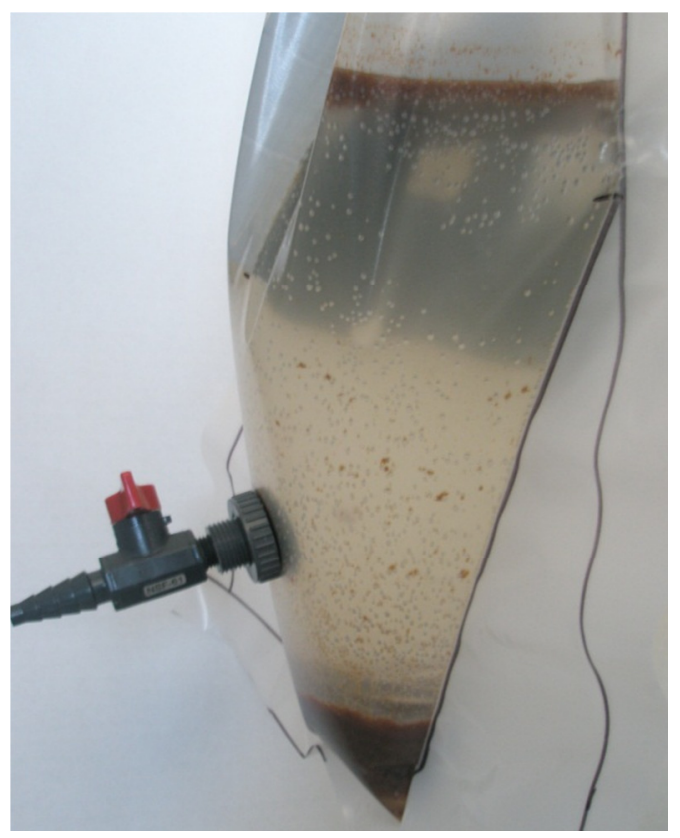

Figure 4.15: Significant numbers of floating flocs occurred for Bag 3, the prototype treated with four $\mathbf{P} \overline{\mathbf{U}} \mathbf{R}^{\circledR}$ sachets. Floating flocs contributed to sporatic increases in turbidity during the 30-hour sampling period in Bag 3.

Each of the three prototypes displayed benefits and drawbacks in terms of turbidity and TOC removal over time. Based on these results, it was decided that two PŪR ${ }^{\circledR}$ sachets should be further investigated for potential use at the U.S. EPA Challenge Test at BioVir Laboratories. Two PŪR ${ }^{\circledR}$ sachets did not have the same overdosing consequences of four PŪR ${ }^{\circledR}$ sachets. In addition, the use of two PŪR ${ }^{\circledR}$ sachets displayed a reasonable post-treatment, pre-filter turbidity even under the challenge conditions of this experiment.

\subsubsection{Experiment D-2: PŪ ${ }^{\circledR}$ Dose Needed with High TOC, Part II}

To determine which number of sachets would result in the bacterial removals required by the U.S. EPA Guide Standard and Protocol for Testing Microbiological Water Purifiers, an experiment similar to D-1 was carried out but with addition of a high concentration of E. coli bacteria. A range of PŪR ${ }^{\circledR}$ sachets additions were tested using the U.S. EPA Challenge Test Water \#2 recipe, excluding only the virus and oocyst surrogates. Experiment D-2 tested the 
ability of multiple $\mathrm{P} \overline{\mathrm{UR}}{ }^{\circledR}$ sachets to treat challenge-level bacteria concentrations in addition to the interferences of the other non-microbiological challenge water constituents (Table 2.5, Table 2.6). These results, with the optimal two $P \bar{U} R^{\circledR}$ sachet recommendation from Experiment D-1, were used to determine the final treatment procedure to be used in Experiment E-1 at BioVir Laboratories.

Four Mark II prototypes were (1) filled with $10 \mathrm{~L}$ of test water, (2) dosed with the specified number of PŪR ${ }^{\circledR}$ sachets, (3) mixed for 5 min at 70 bpm, (4) allowed to settle and disinfect for $30 \mathrm{~min}$. E. coli and TOC samples were filtered through a $1-\mu \mathrm{m}$ polypropylene filter pad housed with a clamshell filter. This was the first used of a filter in the experiments conducted; the filter was meant mainly to improve the consistency of the E. coli concentration measurements by eliminating floc carry-over. Samples included initial water quality, intermediate samples during the 30-min treatment period, a 30-min pre-filter sample, and a post-filtered sample. All prototypes treated test water with elevated ( $>10 \mathrm{mg} / \mathrm{L} \mathrm{TOC})$ TOC concentrations. Bag 1 was treated with a single PÛR ${ }^{\circledR}$ sachet. Bags 2 and 3 were duplicates using two PŪR ${ }^{\circledR}$ sachets, which was the optimal number of sachets determined in Experiment D-1. Bag 4 was treated with three PŪR ${ }^{\circledR}$ sachets. A control bag (with no added humic) was not used in this experiment because a control bag was used in Experiment D-1 under similar test water and treatment conditions. Initial turbidities varied from $80.1 \mathrm{NTU}$ to 87.9 NTU, pH varied from 8.77 to 8.94 , temperatures were $6.9^{\circ} \mathrm{C}$ to $13.6^{\circ} \mathrm{C}$, and TOC concentrations varied from $13.5 \mathrm{mg} / \mathrm{L}$ to $16.93 \mathrm{mg} / \mathrm{L}$. Turbidity, free chlorine residual, TOC, and bacterial testing were all performed during this experiment. Free chlorine residual is not reported or discussed here because the method used was later determined to be incorrect; the 
analysis method was corrected for other experiments in which chlorine residual is reported and discussed.

In general, treatment with two $\mathrm{PU}^{\circledR}{ }^{\circledR}$ sachets provided the optimum results for pathogen removal and turbidity. Initial concentrations of E. coli in the prototypes ranged from 9.9 $\times 10^{6} / 100 \mathrm{~mL}$ to $2.54 \times 10^{7} / 100 \mathrm{~mL}$ (Table 4.3). Only Bags 3 and 4 , treated with two and three PŪR ${ }^{\circledR}$ sachets, respectively, resulted in the 6-log E. coli removal required by the U.S. EPA Guide Standard and Protocol for Testing Microbiological Water Purifiers. Only one of the two prototypes treated with two $\mathrm{PUTR}^{\circledR}$ sachets (Bag 3) met the pathogen removal standard with a 7.6-log removal. Post-treatment $\mathrm{pH}$ values were sufficiently decreased from elevated 9.0 levels to within the $\mathrm{pH} 6$ to 8 range prescribed by the WHO for optimal chlorine disinfection. On average, temperatures increased about $2{ }^{\circ} \mathrm{C}$ during the 30 -minute treatment from pre-treatment temperatures of $6.9^{\circ} \mathrm{C}$ to $13.6^{\circ} \mathrm{C}$. Post-treatment (30-min), pre-filter turbidities were higher, as expected, than 30-min post-filter turbidities (Figure 4.16). Posttreatment (filtered) TOC concentrations ranged from $7.31 \mathrm{mg} / \mathrm{L}$ to $9.33 \mathrm{mg} / \mathrm{L}$ (Figure 4.17).

Table 4.3: $E$. coli removals of prototypes treated with different numbers of PŪR ${ }^{\circledR}$ sachets under conditions similar to the U.S. EPA challenge conditions.

\begin{tabular}{cccccc}
\hline Bag & $\begin{array}{c}\text { Number } \\
\text { of P } \overline{\mathbf{U} R} \mathbf{B}^{\circledR} \\
\text { Sachets }\end{array}$ & $\begin{array}{c}\text { Average Initial } \\
\text { (MPN/100 mL) }\end{array}$ & $\begin{array}{c}\text { Average Post- } \\
\text { treatment, Post-filter } \\
\text { (MPN/100 mL) }\end{array}$ & $\begin{array}{c}\text { Removal } \\
\text { Achieved } \\
(\%)\end{array}$ & $\begin{array}{c}\text { Log } \\
\text { Removal } \\
\text { Achieved }\end{array}$ \\
\hline 1 & 1 & $9.91 \mathrm{E}+06$ & $>2419.6$ & 99.976 & 3.7 \\
2 & 2 & $4.75 \mathrm{E}+06$ & 5.5 & 99.99988 & 5.8 \\
3 & 2 & $2.54 \mathrm{E}+07$ & $<1$ & 99.999996 & 7.6 \\
4 & 3 & $\mathrm{NS}^{1}$ & $<1$ & $99.999993^{2}$ & $7.3^{2}$ \\
\hline
\end{tabular}

${ }^{1}$ Not sampled due to an error.

${ }^{2}$ The percent removal shown for Bag 4 was calculated using the average initial MPNs for Bags 1 through 3. 


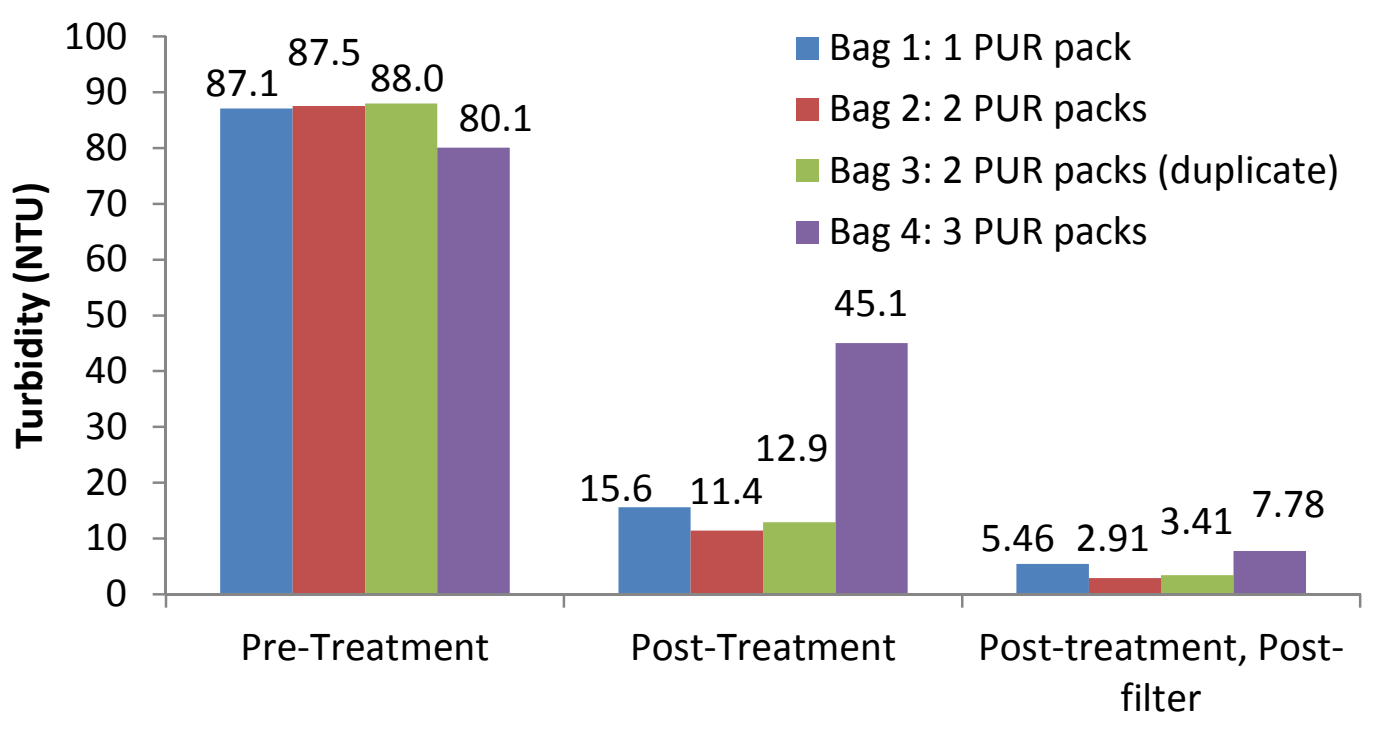

Figure 4.16: Pre-treatment, post-treatment, and post-filter turbidity measurements for prototypes treated with varying numbers of $\mathbf{P} \overline{\mathbf{U}} \mathbf{R}^{\circledR}$ sachets under challenge conditions.

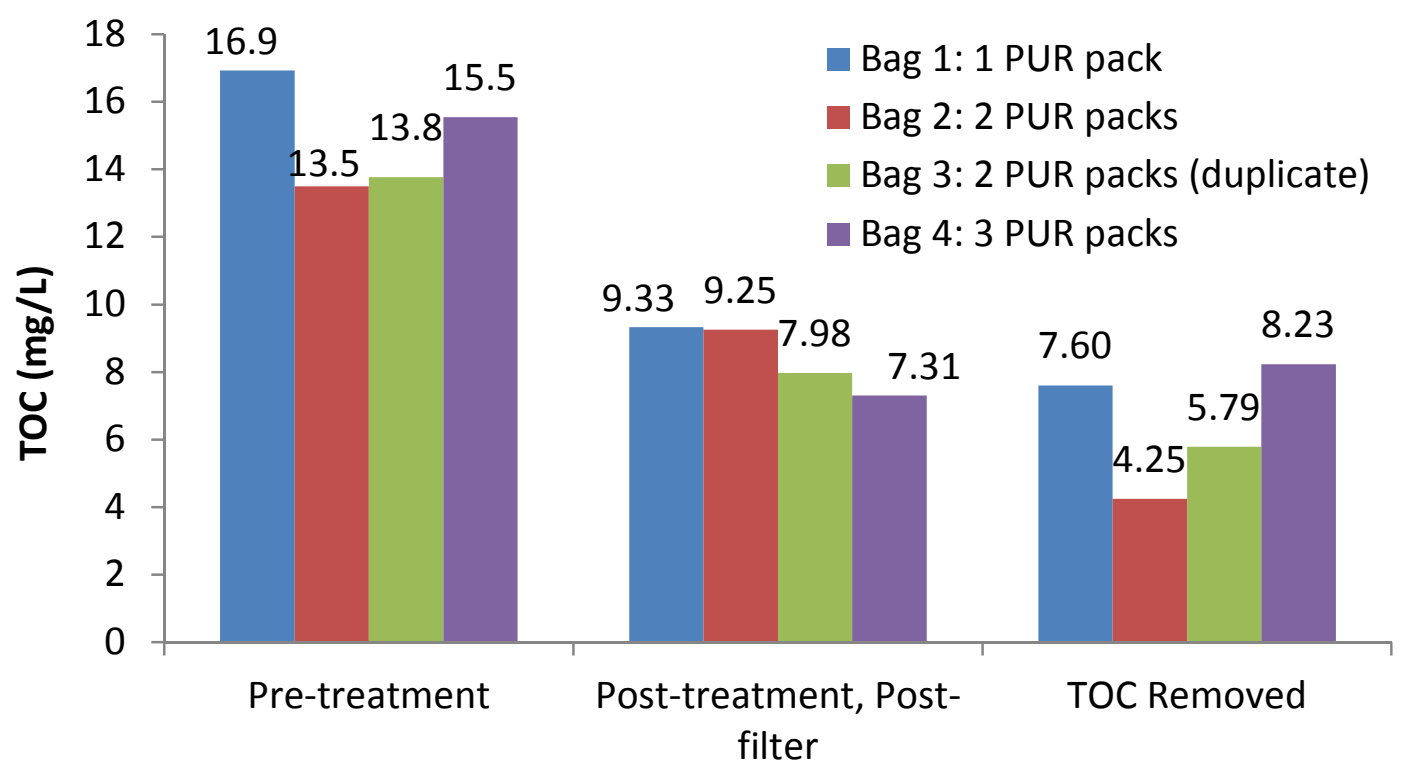

Figure 4.17: Pre-treatment and post-filter TOC measurements for prototypes treated with varying numbers of $P \bar{U} R^{\circledR}$ sachets under challenge conditions. Also, the TOC removed between the initial and post-filter conditions. 
Experiment D-2 showed that treatment of the U.S. EPA Challenge Test Water \#2 recipe with two PŪR ${ }^{\circledR}$ sachets can provide the bacteria removals required by the U.S. EPA Guide Standard. In addition, two PŪR ${ }^{\circledR}$ sachets provided optimal post-treatment turbidities and a moderate amount of TOC removal.

Although Bags 2 and 3 were duplicates with two PŪR ${ }^{\circledR}$ sachets, Bag 3 achieved nearly 2-logs higher E. coli removal than Bag 2. The overall log removal of Bag 2 was likely affected by the fact that the initial concentration of E. coli in Bag 2 did not meet the initial bacteria concentration of $10^{7} / 100 \mathrm{~mL}$ required; instead, an initial E. coli concentration of $9.9 \times 10^{6} / 100$ $\mathrm{mL}$ was measured. Though the post-treatment E. coli concentrations were similar for Bags 2 and 3, the higher initial concentration in Bag 3 allowed for a higher final log removal achieved. Since the required log removal was achieved with two PŪR ${ }^{\circledR}$ sachets, two-sachet doses were confirmed to be the optimum number to meet the bacteria removal standard.

The turbidity results (Figure 4.16) for this experiment reiterate the conclusions made from Experiment D-1. In general, high numbers of PŪR ${ }^{\circledR}$ sachets can cause negative effects on turbidity. In Experiment D-1, treatment with four PŪR ${ }^{\circledR}$ sachets caused sporadic jumps in turbidity, with a final turbidity higher than the other prototypes tested. The prototypes treated with two PŪR ${ }^{\circledR}$ sachets resulted in lowest post-treatment (pre-filtered) turbidities as well as post-filtered turbidities. In fact, only Bags 2 and 3 met the desired $<5$ NTU guideline after filtration; Bags 1 and 4 had post-filter turbidities $>5$ NTU. The chemical dosage from the addition of two PŪR ${ }^{\circledR}$ sachets instead of one or three provided optimal solids removal, and therefore had the least interference with disinfection due to turbidity. 
TOC reduction was observed over the 30-min treatment period for all four prototype waterbags. However, the TOC results from this experiment varied from expected values. For example, all four prototypes were filled with the same initial test water, but initial TOC measurements varied from $13.5 \mathrm{mg} / \mathrm{L}$ to $16.9 \mathrm{mg} / \mathrm{L}$ (Figure 4.17). Post-treatment TOC concentrations also varied unexpectedly; since Bags 2 and 3 were duplicate runs, it would be expected that their post-treatment TOC results would have more similar. Total TOC removals over the treatment period were also unexpected. While four PŪR ${ }^{\circledR}$ sachets achieved the highest TOC removal (an expected result), a single PŪR ${ }^{\circledR}$ sachet achieved a TOC removal only slightly lower than four sachets. The unexpected concentrations reported by the TOC analyzer may have resulted from interference in the test water. It is unlikely that the TOC concentrations were due to uneven distribution of humic acid in the test water because the water was sufficiently homogenized in the large drum before distribution to the prototypes after first being blended in the Osterizer ${ }^{\circledR}$ blender. Despite unexpected TOC results, two PŪR ${ }^{\circledR}$ sachets were chosen for use in Experiment E-1.

\subsubsection{Experiment E-1: U.S. EPA Challenge Water Experiment at BioVir Laboratories}

The Mark II prototype version was tested in the U.S EPA Microbiological Water Purifier Guide Standard and Testing Protocol at BioVir Laboratories on June 30, 2010. Dr. Robert Cooper managed the testing session. The purpose of this test was to show that the Mark II waterbags could meet the pathogen removal requirements of Test Water \#2. Triplicate prototype waterbags were (1) filled with Challenge Test Water \#2 (Table 2.5, Table 2.6), (2) dosed with two PŪR ${ }^{\circledR}$ sachets, (3) mixed for 5 min at $70 \mathrm{bpm}$, (4) allowed to settle and disinfect for $30 \mathrm{~min}$, and (5) filtered for sample collection and analysis. Two filters in series were used for the final step. The first filter was the clamshell filter with the $1-\mu \mathrm{m}$ nominally- 
rated polypropylene filter pad enclosed in a clamshell filter housing. The second filter in series was the $0.2-\mu \mathrm{m}$ absolute-rated microfilter. Experiment E-1 was the only experiment performed that included the use of the microfilter. All post-treatment samples were filtered through the clamshell filter, though only some (another sample set) were filtered through the microfilter. Post-pad-filter samples comprise those that were filtered only through the clamshell filter. Post-microfilter samples comprise those that were filtered through the microfilter after filtration through the clamshell filter. For more information on these filter types and on the materials and methods used in this experiment, see Chapter 3.

Dr. Cooper and his staff prepared the challenge test water and performed the analysis of the initial and final water quality samples. The initial microbiological challenges included $0.833 \times 10^{7}$ colony forming units (CFU)/100 mL of E. coli, $1.2 \times 10^{5}$ plaque forming units $(\mathrm{PFU}) / \mathrm{mL}$ of coliphage, and $6.5 \times 10^{5}$ fluorescent microspheres/L; these three constituents represented the bacteria, virus, and protozoan cyst components of the Challenge Test (BioVir, 2010). Other initial water quality constituents (measured by BioVir staff) include the characteristics listed in Table 3.5. Final pathogen removals of the three prototypes are listed in Table 4.4, Table 4.5, and Table 4.6. See Appendix B for the complete BioVir Laboratories Test Report for Experiment E-1. 
Table 4.4: E. coli $(\mathrm{CFU} / 300 \mathrm{~mL})$ removal results from the U.S. EPA Challenge Water experiment performed at BioVir Laboratories (BioVir, 2010).

\begin{tabular}{ccccccc}
\hline \multirow{2}{*}{ Initial } & \multicolumn{2}{c}{ Bag 1 } & \multicolumn{2}{c}{ Bag 2 } & \multicolumn{2}{c}{ Bag 3 } \\
\cline { 2 - 7 } & $\begin{array}{c}\text { Post- } \\
\text { pad }\end{array}$ & $\begin{array}{c}\text { Post- } \\
\text { microfilter }\end{array}$ & $\begin{array}{c}\text { Post- } \\
\text { pad }\end{array}$ & $\begin{array}{c}\text { Post- } \\
\text { microfilter }\end{array}$ & $\begin{array}{c}\text { Post- } \\
\text { pad }\end{array}$ & $\begin{array}{c}\text { Post- } \\
\text { microfilter }\end{array}$ \\
\hline $2.50 \mathrm{E}+07$ & $<1$ & $<1$ & $<1$ & $<1$ & $<1$ & $<1$ \\
Log Reduction & & & \multicolumn{2}{c}{$>7.4$ for all three prototypes } & \\
\hline
\end{tabular}

Table 4.5: Coliphage (PFU/mL) removal results from the U.S. EPA Challenge Water experiment performed at BioVir Laboratories (BioVir, 2010).

\begin{tabular}{ccccccc}
\hline \multirow{2}{*}{ Initial } & \multicolumn{2}{c}{ Bag 1 } & \multicolumn{2}{c}{ Bag 2 } & \multicolumn{2}{c}{ Bag 3 } \\
\cline { 2 - 7 } & $\begin{array}{c}\text { Post- } \\
\text { pad }\end{array}$ & $\begin{array}{c}\text { Post- } \\
\text { microfilter }\end{array}$ & $\begin{array}{c}\text { Post- } \\
\text { pad }\end{array}$ & $\begin{array}{c}\text { Post- } \\
\text { microfilter }\end{array}$ & $\begin{array}{c}\text { Post- } \\
\text { pad }\end{array}$ & $\begin{array}{c}\text { Post- } \\
\text { microfilter }\end{array}$ \\
\hline $1.20 \mathrm{E}+05$ & $<1$ & $<1$ & $<1$ & $<1$ & $<1$ & $<1$ \\
$\begin{array}{c}\text { Log } \\
\text { Reduction }\end{array}$ & & & $>5.1$ for all three prototypes & & \\
\hline
\end{tabular}

Table 4.6: Microsphere (spheres/L) removal results from the U.S. EPA Challenge Water experiment performed at BioVir Laboratories (BioVir, 2010).

\begin{tabular}{ccccccc}
\hline \multirow{2}{*}{ Initial } & \multicolumn{2}{c}{ Bag 1 } & \multicolumn{2}{c}{ Bag 2 } & \multicolumn{2}{c}{ Bag 3 } \\
\cline { 2 - 7 } & $\begin{array}{c}\text { Post- } \\
\text { pad }\end{array}$ & $\begin{array}{c}\text { Post- } \\
\text { microfilter }\end{array}$ & $\begin{array}{c}\text { Post- } \\
\text { pad }\end{array}$ & $\begin{array}{c}\text { Post- } \\
\text { microfilter }\end{array}$ & Post-pad & $\begin{array}{c}\text { Post- } \\
\text { microfilter }\end{array}$ \\
\hline $2.50 \mathrm{E}+07$ & 290 & $<10$ & 200 & $<10$ & 1 & $<10$ \\
$\begin{array}{c}\text { Log } \\
\text { Reduction }\end{array}$ & 3.4 & $>4.8$ & 3.5 & $>4.8$ & 4.8 & $>4.8$ \\
\hline
\end{tabular}

In addition to the microbiological constituents measured by BioVir staff, turbidity, TOC, and free chlorine residual were measured on-site by Cal Poly researchers. Free chlorine residual results are not reported or discussed here because the method used in this experiment was incorrect; the analysis method was corrected for Experiment C-1. Initial turbidity values were all $>30$ NTU (as required by the U.S. EPA Guide Standard and Testing Protocol), and TOC ranged from $10.5 \mathrm{mg} / \mathrm{L}$ to $11.9 \mathrm{mg} / \mathrm{L}$ (Figure 4.18). All prototypes showed reduction from 
initial TOC concentrations to post-treatment (after clamshell-only filtration) values between $3.51 \mathrm{mg} / \mathrm{L}$ and $4.68 \mathrm{mg} / \mathrm{L}$. Filtration through the microfilter had little effect on post-treatment TOC concentrations. Post-treatment, pre-filter turbidities varied significantly among bags, from 5.79 NTU to 32.2 NTU (Figure 4.19). Post-pad-filtration through the clamshell filter improved turbidities to a range between $0.55 \mathrm{NTU}$ and 2.2 NTU. Further filtration through the microfilter decreased turbidities to $0.15 \mathrm{NTU}$ to $0.30 \mathrm{NTU}$. It should be noted that the turbidity values reported for this experiment may be higher than actual conditions due to interference of turbidity readings from humic acid in the test water.

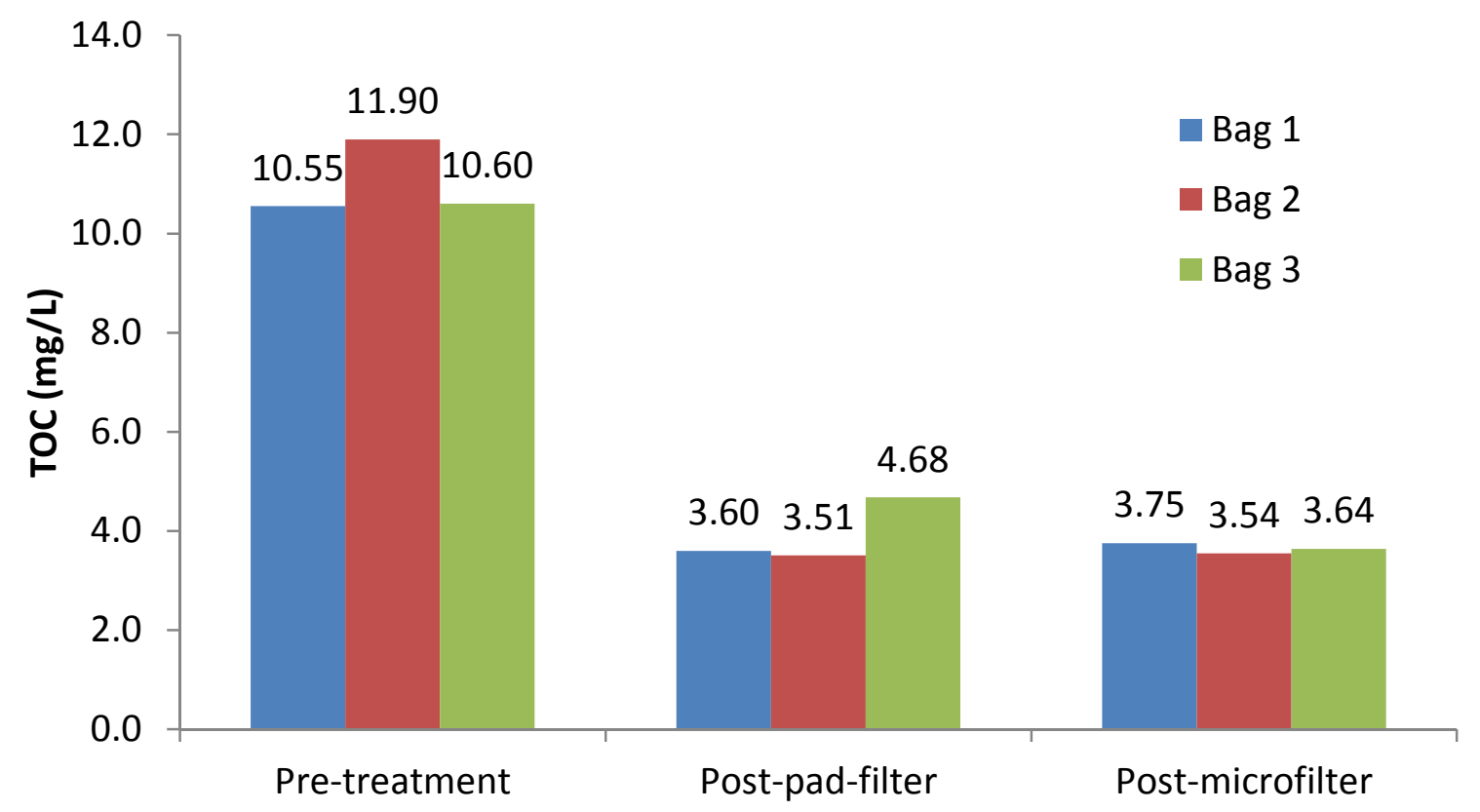

Figure 4.18: TOC concentrations of samples collected by Cal Poly researchers during the U.S. EPA Challenge Water test at BioVir Laboratories. 


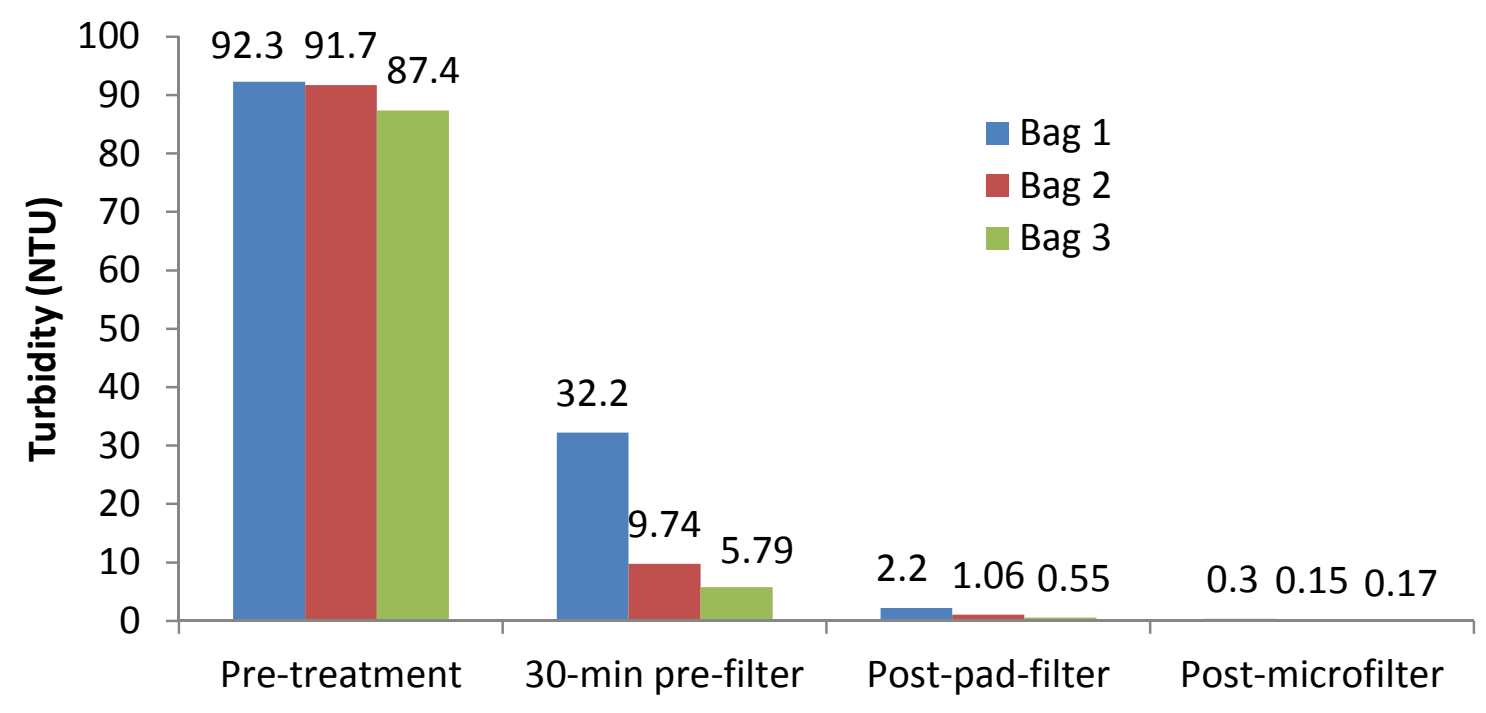

Figure 4.19: Turbidity of samples collected by Cal Poly researchers during the U.S. EPA Challenge Water test at BioVir Laboratories.

The results of the U.S. EPA Challenge Water experiment showed that with two PŪR ${ }^{\circledR}$ sachets, treatment of a contaminated water source with the waterbag can successfully meet turbidity and pathogen reductions for emergency relief required by The Sphere Project and the U.S. EPA. In contrast to the earlier BioVir testing using a single $\mathrm{PU}^{\circledR}{ }^{\circledR}$ sachet (Compas, 2009a), the use of two $P \overline{U R}^{\circledR}$ sachets resulted in impressive bacteria, virus, and microsphere reductions (Table 4.4, Table 4.5, Table 4.6). In fact, both of the post-filter samples taken (filtration through the clamshell filter alone and filtration through the clamshell plus microfilter) resulted in log reductions that met and exceeded the removals required by the U.S. EPA. Even under the elevated TOC conditions of the challenge water, two PŪR ${ }^{\circledR}$ sachets provided sufficient free chlorine to bring the E. coli and coliphage concentrations below the detection limit. In addition, the double doses of coagulant and flocculating chemicals resulted in effective flocculation and sedimentation of the fluorescent microspheres (oocyst surrogates). This is evident from a comparison of the microsphere log reductions achieved in this experiment versus the microsphere reductions achieved in the 
same challenge water test at BioVir in 2009 (Compas, 2009a). In Compas' experiment, all three prototypes used the same clamshell filter with $1-\mu \mathrm{m}$ filter pad, but none of the three prototypes tested met the 3-log microsphere reduction required by the U.S. EPA. In Experiment E-1, all three clamshell-filtered post-treatment samples met the 3-log reduction requirement. Additional filtration through the $0.2-\mu \mathrm{m}$ microfilter provided complete removals of the microspheres with $>4.8$ log-reductions in all three prototypes.

After filtration through the clamshell filter, all three prototypes met the $<5$ NTU turbidity standard for treatment units utilizing chlorine disinfection. In previous experiments, prototypes had consistently met the $<5$ NTU standard without filtration. The prototypes in Experiment E-1 likely did not meet the $<5$ NTU standard prior to filtration due to the effect of low temperature on the coagulation and flocculation process; chemical reaction rates are lowered in low temperature environments (MWH, 2005). However, the use of a filter is a required step in the waterbag treatment method to ensure that disinfection-resistant microorganisms are physically removed. Therefore, with the use of at least a $1-\mu \mathrm{m}$ nominally-rated polypropylene filter pad such as the one used in the clamshell filter, waterbag treatment can achieve sufficiently low post-treatment turbidities.

TOC concentrations were reduced from $>10 \mathrm{mg} / \mathrm{L}$ challenge levels to $<4.70 \mathrm{mg} / \mathrm{L}$ for all post-treatment and post-filtered samples. The high organic carbon content of the test water would be expected to exert a high chlorine demand, consuming some of the available chlorine. Because low free chlorine residuals can pose a risk to human health by allowing for a treated water source to become re-contaminated, the use of two PÜR ${ }^{\circledR}$ sachets would provide an additional dose of free chlorine which might be helpful in the presence of high TOC. 


\section{CHAPTER 5: CONCLUSIONS}

In addition to the conclusions drawn from the nine experiments performed, several important topics exist for future research on the waterbag.

\subsection{Optimization and U.S. EPA Challenge Water}

The conclusions of the optimization experiments include the prescription of both treatment protocol and physical construction of the bag. The optimal treatment protocol for the Mark II waterbag is critical because incorrect usage can result in insufficient treatment of contaminated water. The optimal mixing time and method of waterbag use was determined to be five minutes at a moderate mixing speed $(70 \mathrm{bpm})$ with relatively rapid $180^{\circ}$ twisting motions, where one beat represented a complete $180^{\circ}$ twist. Delay between $\mathrm{PUR}^{\circledR}$ sachet addition and the mixing start was not found to affect post-treatment water quality. Therefore, no recommendation is made for delay between $\mathrm{PUTR}^{\circledR}$ addition and mixing time. However, in general water treatment engineering, instantaneous and complete mixing of coagulants is recommended, and the same would be prudent in waterbag usage. The optimal baffle configuration chosen was a $12.7-\mathrm{cm}$ wide, $16.5-\mathrm{cm}$ long internal baffle with two circular cutout holes (Figure 4.9).

Test waters with high organic contents challenged the ability of the waterbag (treated with one PŪR ${ }^{\circledR}$ sachet) to maintain the free chlorine residual of at least $0.2-0.5 \mathrm{mg} / \mathrm{L}$ as prescribed by emergency relief guidelines. The waterbag's ability to maintain a chlorine residual was dependent on the amount of organic carbon in the test water. Typically, the amount of free chlorine available for disinfection will be unknown because the TOC of water collected during emergency relief operations will be unknown. In the presence of a less-than-desirable 
amount of free chlorine residual, keeping the waterbag sealed after use to prevent recontamination is recommended.

With the use of two PŪR ${ }^{\circledR}$ sachets, the Mark II waterbag met the pathogen removal requirements of the U.S. EPA Challenge Test. With the use of the clamshell filter with 1- $\mu \mathrm{m}$ nominally-rated polypropylene filter cloth only, bacteria, virus, and protozoan cyst removal goals were met or exceeded in the triplicate bags tested. Surface water sources encountered during emergencies generally do not exhibit such extremely poor water quality characteristics as used in the U.S. EPA Challenge Test. If contaminated source water is encountered with characteristics similar to that of the Test Water \#2, two PÜR ${ }^{\circledR}$ sachets are recommended to provide sufficient pathogen inactivation and removal. However, in most disaster relief circumstances, one $\mathrm{PU}^{\circledR}{ }^{\circledR}$ sachet should provide adequate treatment if appropriately used with the prescribed waterbag treatment protocol.

\subsection{Future Research}

Future research on the waterbag is necessary to ensure that the final product not only provides safe, clean drinking water but also is a useable product for a variety of consumers under a range of circumstances, backgrounds, and environmental conditions.

The 6-mil LPDE plastic sheeting used for the waterbag material was effective for the experiments performed over the course of this research period, but a different material for long-term use should be investigated. For most experiments, new waterbags were created from unused plastic sheeting but in some cases, waterbags were used twice for subsequent experiments. However, after two or three uses, the plastic sheeting started to show signs of stress and in some cases holes formed in the plastic material. Is it expected that future users 
of the waterbag product will use each bag ten or more times so that $>100$ liters of drinking water can be treated with each bag. For the final product, more durable plastic materials should continue to be evaluated.

A primary focus of future research should be on filtration, which is a required final step of the waterbag treatment process for removal of pathogens that are resistant to disinfection. The clamshell filter design with a replaceable 1- $\mu \mathrm{m}$ nominally-rated polypropylene filter pad did remove sufficient microspheres when two sachets were used in the present research. With further iterations of the clamshell design, an appropriate clamshell might be developed for the final product. The microfilter used in the present research, though effective, has a higher cost than desirable for the disaster relief market.

Though a variety of test waters were used throughout experimentation, it would be useful to test the optimized Mark II waterbag treatment protocol against source waters with different initial water quality characteristics. Characterization of the waterbag's treatment abilities using PŪR ${ }^{\circledR}$ could be important when determining appropriateness in treating source waters around the world.

In the development process, the number of times of reuse should be considered a priority so as to maximize treatable water volumes for users. Additional features of the waterbag, such as backpack style straps or carrying handles should be investigated to make transport of treated water an easier feat. As the waterbag becomes ready for commercial fabrication, cost per unit and shipping capabilities should be considered to ensure low cost for relief agencies and maximum provision of supplies to relief victims. 
Usability is another primary research topic that must be addressed in all research activities with the waterbag. Despite the water treatment capabilities of the bag, uninitiated users must be able to interpret the instructions of use of the waterbag and perform the correct treatment protocol. Included in usability research should be how users perceive the waterbag, treatment method, and final treated water. For example, user reception to post-treated color and taste of water should be investigated. In addition, the physical configuration must usable by users within a wide range of statures and physical abilities. Evaluating user response to the waterbag is imperative to understanding the application of the waterbag in a variety of cultural and environmental settings, and will ultimately determine appropriateness of the waterbag for use in disaster relief situations. 


\section{REFERENCES}

Bakhir, V.M., Leonov, B.I., Panicheva, S.A., Prilutsky, V.I., \& Shomovskaya, N.Y. (2003). Issues of chemical composition and operating properties of chlorine based inorganic liquid chemical germicides. VNMT Magazine, 4. The Russian Scientific \& Research Institute for Medical Engineering.

Bartlett, G. (2009, April 24). Design and Manufacturing Discussions. (T. Lundquist, J. Dunning, T. Compas, M. Herzog Interviewers).

BioVir Laboratories, Inc. (ND). EPA “Guide Standard.” Benicia: BioVir Laboratories, Inc.

BioVir Laboratories, Inc. (BioVir) (2010). Test Report: Polytech Waterbag Challenge \#2, Project \#101495. Benicia, BioVir Laboratories.

Centers for Disease Control and Prevention. (2005). Chlorine Residual Testing. Retrieved October 26, 2010, from CDC Safe Water System Publications: http://www.cdc.gov/safewater/publications_pages/chlorineresidual.pdf.

Centers for Disease Control and Prevention (CDC). (2007). Safe Water System (SWS) Effect of Chlorination on Inactivating Selected Pathogens. Retrieved October 26, 2010, from CDC Safe Water System Publications: http://www.cdc.gov/safewater/about_pages/CTfactor-final.pdf.

Centers for Disease Control and Prevention (CDC). (2008). Household Water Treatment Options in Developing Countries: Flocculant/Disinfectant Powder. Cincinnati: CDC.

Compas, T. (2009a). Point-of-Use Water Treatment Device for Disaster Relief. (Master's thesis). California Polytechnic State University, San Luis Obispo.

Compas, T. (2009b). Mark II Waterbag Dimension Blueprint.

Hach Company (2010). Water quality testing instruments and reagents for laboratory, portable, and on-line applications. Retrieved October 13, 2010, from http://www.hach.com/

Hach Company (2000). DR/890 Colorimeter Procedures Manual. United States of America: $\mathrm{HACH}$. 
Huck, P.M., Coffey, B.M., Anderson, W.B., Emelko, M.B., Maurizio, D.D., Slawson, R.M., et al. (2002). Using Turbidity and Particle Counts to Monitor Cryptosporidium Removals by Filters. Water Science \& Technology: Water Supply. 2 (3), 65-71.

IDEXX (2010). Colilert®. Retrieved October 13, 2010, from http://www.idexx.com/view/xhtml/en_us/water/colilert.jsf?conversationId=104219

IRC International Water and Sanitation Centre (2008). Integrated Risk Management to Protect Drinking Water and Sanitation Services Facing Natural Disasters. Netherlands: IRC.

Lantagne, D. \& Clasen T. (2009). Point of Use Water Treatment in Emergency Response. London, UK: London School of Hygiene and Tropical Medicine.

Lundquist, T. (2009a). Lecture on Coagulation and Flocculation for Cal Poly ENVE 535 Graduate Class.

Lundquist, T. (2009b). Polytech Waterbag: Clean Water for Disaster Relief. Informational Sheet.

Lundquist, T. (2009c). Patent No. 7,514,006. United States of America.

Metcalf \& Eddy. (2003). Wastewater Engineering, Treatment and Reuse. (4 ${ }^{\text {th }}$ ed.). New York: McGraw-Hill, Inc.

MWH. (2005). Water Treatment Principles and Design. ( $2^{\text {nd }}$ ed.). New Jersey: John Wiley \& Sons, Inc.

Procter \& Gamble. (2010). PUR packet. Children's Safe Drinking Water. Retrieved November 4, 2010, from http://www.csdw.org/csdw/pur_packet.shtml

Reller, M. E., Mendoza, C. E., Lopez, M. B., Alvarez, M., Hoekstra, R. M., Olson, C. A., et al. (2003). A Randomized Controlled Trial of Household-Based Flocculant-Disinfectant Drinking Water Treatment for Diarrhea Prevention in Rural Guatemala. American Journal of Tropical Medicine \& Hygiene, 69 (4), 411-419.

Sawyer, C.N., McCarthy, P.L, \& Parkin, G.F. (2003). Chemistry for Environmental Engineering and Science. ( $5^{\text {th }}$ ed.). New York: McGraw-Hill. 
Shuler, M. L., \& Kargi, F. (2002). Bioprocess Engineering Basic Concepts. (2 ${ }^{\text {nd }}$ ed.). New Jersey: Prentice Hall.

Souter, P. F., Cruickshank, G. D., Tankerville, M. Z., Keswick, B. H., Ellis, B. D., Langworthy, D. E., et al. (2003). Evaluation of a New Water Treatment for Point-of-Use Household Applications to Remove Microorganisms and Arsenic from Drinking Water. Journal of Water and Health, 1 (2), 73-84.

Souter, P. F., Cruickshank, G. D., \& Stoddart, B. (2007). Patent No. 7,201,856 B2. United States of America.

Tchobanoglous, G. \& Schroeder, E.D. (1987). Water Quality: Characteristics, Modeling, Modification. California: Addison Wesley Longman.

The Sphere Project. (2004). Humanitarian Charter and Minimum Standards in Disaster Response. Geneva: The Sphere Project.

United Nations High Commissioner for Refugees (UNHCR). (2000). Handbook for Emergencies. ( $2^{\text {nd }}$ ed.). Geneva: UNHCR.

U.S. Environment Protection Agency. (1987). Guide Standard and Protocol for Testing Microbiological Water Purifiers. Report of Task Force. U.S. Environmental Protection Agency.

U.S. Environmental Protection Agency (U.S. EPA). (2010, September 21). Drinking Water Contaminants; National Primary Drinking Water Regulations. Retrieved November 1, 2010, from http://water.epa.gov/drink/contaminants/index.cfm\#1.

Wisner, B. \& Adams, J. (2002). Environmental Health in Emergencies and Disasters: A Practical Guide. Geneva: World Health Organization.

World Health Organization. (2006). Guidelines for Drinking-water Quality: incorporating first addendum. Vol. 1 recommendations, $3^{\text {rd }}$ Edition. Geneva: WHO Press. 


\section{APPENDIX A: INGREDIENT CORRELATIONS \\ Constituent Amounts and Correlations for Source Water Recipes, Based on U.S. EPA \\ Microbiological Water Purifier Standard and Testing Protocol (1987) \\ Source: Compas, T. (2009). Point-of-Use Water Treatment Device for Disaster Relief (Master's thesis, California Polytechnic State University-San Luis Obispo, 2009).}

The parameter tests described below were performed by Tricia Compas during the 2008/2009 research period. The results from these tests were used to determine A2 Fine Test Dust, Sea Salt, and humic acid ingredient amounts to add to test water for each experiment performed during the current research period.

According to the U.S. EPA Protocol for Testing Water Purifiers, the recommended materials (non-microbiological) for adjusting test water characteristics include:

- $\mathrm{pH}$; inorganic acids or bases (i.e., $\mathrm{HCl}, \mathrm{NaOH}$ )

- Turbidity: A2 Fine Test Dust (ISO 12103-1)

- Total Dissolved Solids (TDS): sea salts or another equivalent source of TDS.

- Total Organic Carbon (TOC): humic acids

In order for the Test Water \#2 (Challenge Test Water/Halogen Disinfection) to be at the challenge level, specified concentrations of each constituent is called for; this is detailed in Chapter 2, Error! Reference source not found. These challenge amounts were also used in the Optimal Protocol and Mock Run U.S. EPA Challenge Water Experiments, and information on the materials used at the Cal Poly laboratories for turbidity, TDS, and TOC is detailed below.

\section{Increasing Turbidity using A2 Fine Test Dust (ISO 12103-1)}

The objective of this parameter test was to identify an approximate correlation of the dust to the corresponding turbidity. The correlation was then used as a guide when a desired turbidity level was needed for treatment experiments.

For this test, increasing increments of dust were added to individual, 1-L deionized water,

blended for 30 seconds on the liquefy settling, using an Osterizer ${ }^{\circledR}$ glass blender, a turbidity measurement was then taken of the blended water, using a HACH Turbidimeter 2100P. 


\begin{tabular}{|c|c|c|c|c|}
\hline \multicolumn{5}{|c|}{ Fine Test Dust vs. Turbidity Correlation } \\
\hline \multirow{2}{*}{$\begin{array}{l}\text { Dust } \\
\text { (mg) }\end{array}$} & \multicolumn{4}{|c|}{ Turbidity Readings (NTU) } \\
\hline & 1 & 2 & 3 & Average \\
\hline 100 & 64 & 63.9 & 65.7 & 64.5 \\
\hline 200 & 152 & 154 & 152 & 153 \\
\hline 250 & 184 & 184 & 181 & 183 \\
\hline 350 & 306 & 309 & 303 & 306 \\
\hline 450 & 412 & 422 & 414 & 416 \\
\hline 550 & 531 & 530 & 522 & 528 \\
\hline 650 & 673 & 673 & 663 & 670 \\
\hline 750 & 575 & 771 & 766 & 704 \\
\hline 1000 & \multicolumn{4}{|c|}{ > >too high for turbidimeter to read } \\
\hline
\end{tabular}

\section{Dust vs. Turbidity (for 1 Liter DI Water)}

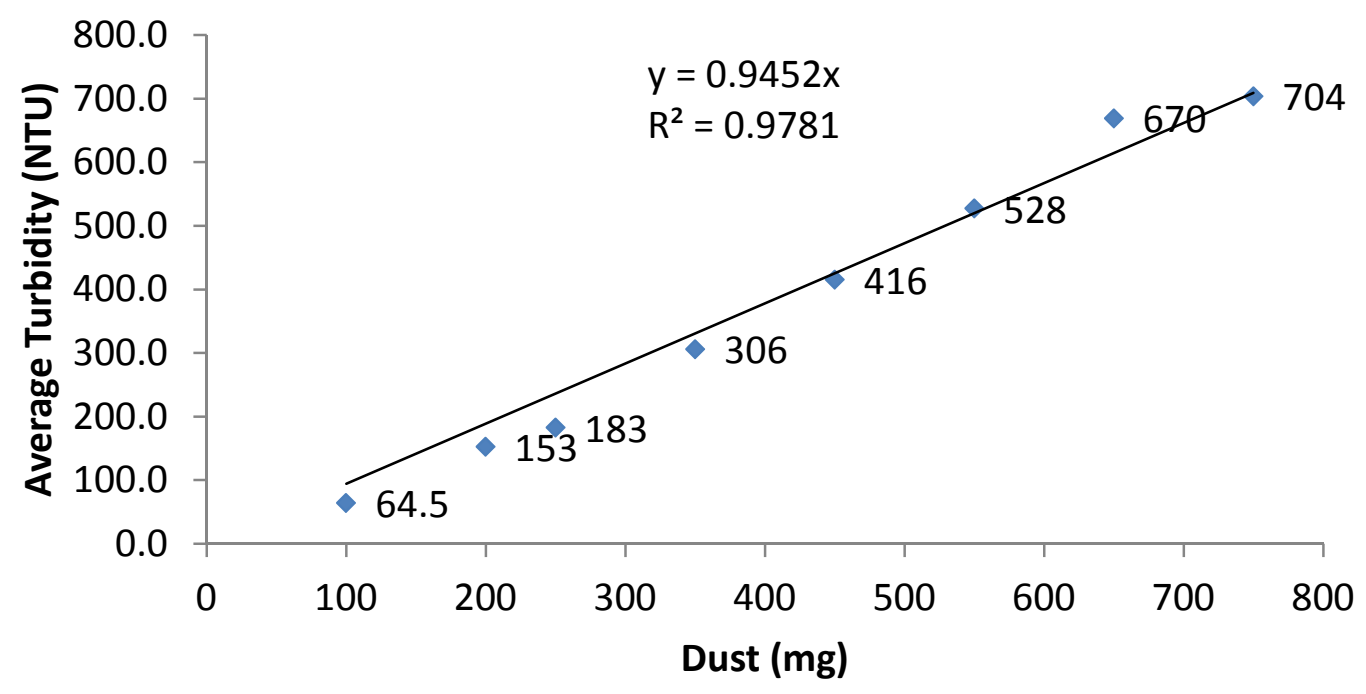

\section{Total Dissolved Solids Concentrations with the Addition of Instant Ocean}

The objective of this parameter test was to identify the total dissolved solids (TDS) concentration of Instant Ocean. Prior to analysis, the water compositions were blended for 30 seconds on the liquefy settling, using an Osterizer® glass blender. The TDS test was performed according to Standard APHA Methods 2540 D. Fisher Scientific G4 glass fiber filter circles, with a nominal pore size of $1.2 \mu \mathrm{m}$, were prewashed and ashed; and the filtrate from the filtration was used for TDS testing (APHA et al., 1995). TDS tests were performed on (1) $0.5 \mathrm{~g} / \mathrm{L}$ of Instant Ocean added to $1 \mathrm{~L}$ of Drumm Reservoir Water; (2) $1.0 \mathrm{~g} / \mathrm{L}$ of Instant Ocean added to $1 \mathrm{~L}$ of Drumm Reservoir Water; (3) $1.5 \mathrm{~g} / \mathrm{L}$ Instant Ocean added to 1 
L of Drumm Reservoir Water; (4) Drumm Reservoir Water; and, (5) $1.5 \mathrm{mg} / \mathrm{L}$ of Instant Ocean added to $1 \mathrm{~L}$ of deionized water. Based on the results, the combination of $1.0 \mathrm{~g} / \mathrm{L}$ added to Drumm Reservoir Water was selected for the Optimal Protocol Experiment. Additionally, when deionized water was used, as for the EPA Challenge waters, the combination of $1.5 \mathrm{~g} / \mathrm{L}$ added to deionized water was selected.

\section{Resulting TDS Concentrations for Various Instant Ocean and Water Compositions}

\begin{tabular}{cc}
\hline Water Composition & $\begin{array}{c}\text { Average TDS Concentration } \\
(\mathrm{mg} / \mathrm{L})\end{array}$ \\
\hline $0.5 \mathrm{~g} / \mathrm{L}$ Instant Ocean + Drumm Reservoir Water & 1110 \\
$1.0 \mathrm{~g} / \mathrm{L}$ Instant Ocean + Drumm Reservoir Water & 1350 \\
$1.5 \mathrm{~g} / \mathrm{L}$ Instant Ocean + Drumm Reservoir Water & 1900 \\
$0.0 \mathrm{~g} / \mathrm{L}$ Instant Ocean + Drumm Reservoir Water & 650 \\
$1.5 \mathrm{~g} / \mathrm{L}$ Instant Ocean + deionized water & 1400 \\
\hline
\end{tabular}

\section{Total Organic Carbon Concentrations with the Addition of Humic Acid}

The objective of this parameter test was to identify total organic carbon (TOC) content of the humic acid used in the Initial EPA Challenge Water Experiments. The humic acid selected was Alfa Aesar® $25 \mathrm{~g}$ bottle (Stock \#41747, Lot \#D25S004, CAS \#1415-93-6). Prior to sampling, the water compositions were blended for 30 seconds on the liquefy settling, using an Osterizer ${ }^{\circledR}$ glass blender. Three samples, run in duplicate, were analyzed by Creek Environmental Laboratories, Inc., in San Luis Obispo, CA. VOA vials with $\mathrm{HCl}$ preservative were used to store the samples, were kept preserved until brought to the lab in order to not decrease to TOC due to biodegradation. Creek Environmental Laboratories performed the analysis according to Standard APHA Methods 5310 B.

TOC tests were performed on (1) 1 L Drumm Reservoir Water, $10 \mathrm{~mL}$ Swine Pond Water, with no addition of humic acid; (2) 1 L Drumm Reservoir Water, $10 \mathrm{~mL}$ Swine Pond Water, with the addition of $20 \mathrm{mg} / \mathrm{L}$ humic acid; (3) $1 \mathrm{~L}$ of deionized water with the addition of 20 $\mathrm{mg} / \mathrm{L}$ of humic acid. According to the EPA Challenge Water, TOC concentrations need to be 
greater than $10 \mathrm{mg} / \mathrm{L}$. Thus, it was estimated, based on the $6.6 \mathrm{mg} / \mathrm{L} \mathrm{TOC}$ concentration from adding $20 \mathrm{mg} / \mathrm{L}$ humic acid, that by adding $40 \mathrm{mg} / \mathrm{L}$ of humic acid to deionized water, greater than $10 \mathrm{mg} / \mathrm{L}$ of TOC will be achieved.

\section{TOC Concentrations for Various Water Compositions}

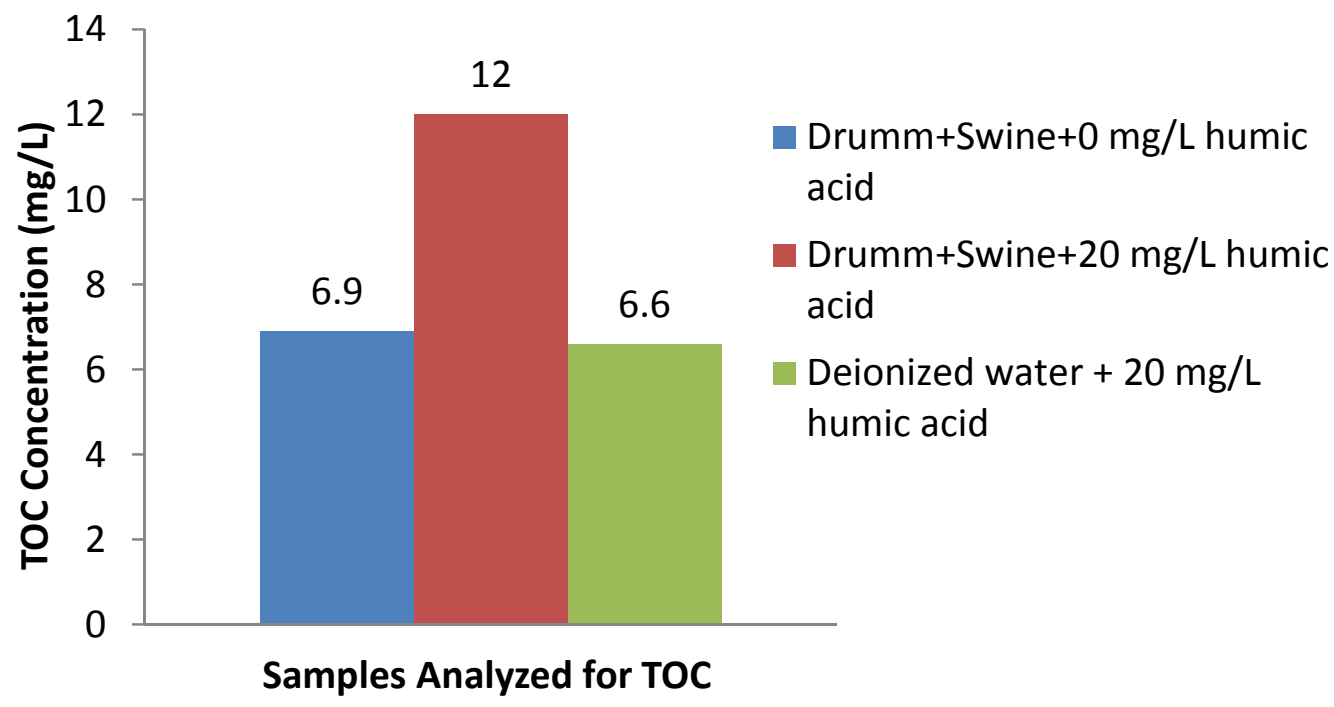




\section{APPENDIX B: BIOVIR REPORT (2010)}

BioVir Laboratories, Inc. Report for Experiment E-1, performed June 30, 2010

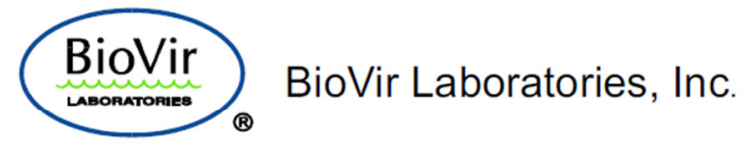

685 Stone Road, Unit $6 \bullet$ Benicia, CA $94510 \bullet$ (707) 747-5906 •1-800-GIARDIA • FAX (707) 747-1751 • WEB: www.biovir.com

TEST REPORT

\begin{tabular}{|l|l|}
\hline Project Title & Polytech Waterbag Challenge \#2 \\
\hline Project No. & 101495 \\
\hline Sponsor: & Cal Poly Corporation \\
\hline C/O: & $\begin{array}{l}\text { Prof. Tryg Lundquist } \\
\text { California Polytechnic State University } \\
\text { Civil \& Environmental Engineering Department } \\
\text { San Luis Obispo, CA 93407 }\end{array}$ \\
\hline Date: & June 30, 2010 \\
\hline $\begin{array}{l}\text { Project } \\
\text { Manager: }\end{array}$ & Robert C. Cooper, VP \\
\hline
\end{tabular}

Introduction: The Cal Poly Corp contracted with BioVir Laboratories to perform microbiological challenges of a second generation Polytech Waterbag device being developed by Professor Lundquist and his students. Three bags were challenged with the bacterium Escherichia coli (ATCC 11229), two coliphage types (MS2 ATCC 15597-B1) and fr (ATCC15767-B1) and with 3.1 $\mu$ m diameter fluorescent microspheres (Thermo Scientific, Freemont, CA.) as a surrogate for Cryptosporidium oocysts On June 29, 2010 Professor Lundquist and two students arrived at BioVir Labs with three test bags and the necessary ancillary equipment needed to operate the treatment units.

The challenge water (40L of Test water) was prepared by BioVir staff and had the quality shown in Table 1 below:

\begin{tabular}{|l|l|}
\hline \multicolumn{2}{|l|}{ Table 1. Challenge Water } \\
\hline \hline Parameter & Value- \\
\hline \hline Volume & $40 \mathrm{~L}:$ \\
\hline $\mathrm{pH}$ & 8.3 \\
\hline Chlorine & ND Non Detect \\
\hline TDS & $1570 \mathrm{mg} / \mathrm{L}$ \\
\hline NTU & $>30$ \\
\hline TOC & $11.6 \mathrm{mg} / \mathrm{L}$ \\
\hline Temperature & $4^{\circ} \mathrm{C}$ \\
\hline
\end{tabular}


Just prior to the challenge the test water was inoculated with the challenge microorganisms and microspheres. The seed microorganisms were prepared as per BioVir protocols. The test water was constantly mixed using a magnetic stirring device. Each bag was filled with $10 \mathrm{~L}$ of the seeded test water at which point the Cal Poly group performed the treatment operation (adding the coagulantdisinfectant, mixing the contents, allowing the flocculated material to settle and post filtering.) At the end of the required settling time the treated bag water was passed, by gravity, through a "needle punched" filter followed by a final filtration step through a hollow fiber filter. Two sets of samples were collected from each bag operation: 1) the Bag effluent after "needle punched" filtration; and, 2) The final effluent after the hollow fiber filtration step. The samples were collected in sterile bottles containing sodium thiosulfate to neutralize any residual chlorine that might be present. An influent sample was collected from the $40 \mathrm{~L}$ test water reservoir.

The influent and product water samples were kept refrigerated until assayed, a period of no more than 3 hours. The $E$. coli assays were performed using the membrane filter method and employing $\mathrm{mFC}$ agar incubated for 20 to 24 hours at $44.5^{\circ} \mathrm{C}$; the results being reported as colony forming units ( $\mathrm{Cfu}$ ) per $300 \mathrm{~mL}$. The combined bacterophage were assayed using the Adams Double Agar overlay method and reported as plaque forming units (Pfu) per $\mathrm{mL}$. The microspheres were enumerated by direct microscopic count using epi-fluorescent microscopy and reported as spheres per L.

Results: The results of the challenged are shown in the following Tables:

\begin{tabular}{|c|c|c|c|c|c|c|}
\hline \multirow{2}{*}{ Influent } & \multicolumn{2}{|c|}{ Test Unit \#1 } & \multicolumn{2}{|c|}{ Test Unit \#2 } & \multicolumn{2}{|c|}{ Test Unit \#3 } \\
\hline & $\begin{array}{l}\text { Bag } \\
\text { Effluent }\end{array}$ & $\begin{array}{l}\text { Post Filter } \\
\text { Effluent }\end{array}$ & $\begin{array}{l}\text { Bag } \\
\text { Effluent }\end{array}$ & $\begin{array}{l}\text { Post Filter } \\
\text { Effluent }\end{array}$ & $\begin{array}{l}\text { Bag } \\
\text { Effluent }\end{array}$ & $\begin{array}{l}\text { Post Filter } \\
\text { Effluent }\end{array}$ \\
\hline $2.5 \times 10^{7}$ & $<1$ & $<1$ & $<1$ & $<1$ & $<1$ & $<1$ \\
\hline
\end{tabular}

\begin{tabular}{|c|c|c|c|c|c|c|}
\hline \multirow{2}{*}{ Influent } & \multicolumn{2}{|c|}{ Test Unit \#1 } & \multicolumn{2}{|c|}{ Test Unit \#2 } & \multicolumn{2}{|c|}{ Test Unit \#3 } \\
\hline & $\begin{array}{l}\text { Bag } \\
\text { Effluent }\end{array}$ & $\begin{array}{l}\text { Post Filter } \\
\text { Effluent }\end{array}$ & $\begin{array}{l}\text { Bag } \\
\text { Effluent }\end{array}$ & $\begin{array}{l}\text { Post Filter } \\
\text { Effluent }\end{array}$ & $\begin{array}{l}\text { Bag } \\
\text { Effluent }\end{array}$ & $\begin{array}{l}\text { Post Filter } \\
\text { Effluent }\end{array}$ \\
\hline $1.2 \times 10^{5}$ & $<1$ & $<1$ & $<1$ & $<1$ & $<1$ & $<1$ \\
\hline
\end{tabular}

\begin{tabular}{|c|c|c|c|c|c|c|}
\hline \multirow{2}{*}{ Influent } & \multicolumn{2}{|c|}{ Test Unit \#1 } & \multicolumn{2}{|c|}{ Test Unit \#2 } & \multicolumn{2}{|c|}{ Test Unit \#3 } \\
\hline & $\begin{array}{c}\text { Bag } \\
\text { Effluent }\end{array}$ & $\begin{array}{l}\text { Post Filter } \\
\text { Effluent }\end{array}$ & $\begin{array}{c}\text { Bag } \\
\text { Effluent }\end{array}$ & $\begin{array}{l}\text { Post Filter } \\
\text { Effluent }\end{array}$ & $\begin{array}{c}\text { Bag } \\
\text { Effluent }\end{array}$ & $\begin{array}{l}\text { Post Filter } \\
\text { Effluent }\end{array}$ \\
\hline $6.5 \times 10^{5}$ & $2.9 \times 10^{2}$ & $<10$ & $2.0 \times 10^{2}$ & $<10$ & $1.0 \times 10^{1}$ & $<10$ \\
\hline $\begin{array}{c}\log \\
\text { Reduction }\end{array}$ & 3.4 & $>4.8$ & 3.5 & $>4.8$ & 4.8 & $>4.8$ \\
\hline
\end{tabular}

Daber. Mopar, Ph, D.

Robert C. Cooper Ph.D., Vice President 


\section{APPENDIX C: CHLORINE RESIDUAL BENCH METHOD}

The purpose of this bench method is to provide a standard in-lab method of measuring free and total chlorine residual. The information contained in this bench method was obtained from the HACH DR/890 colorimeter operation manual and Standard Methods 4500-Cl G.

\section{$\underline{\text { Materials and Equipment }}$}

The materials and equipment required for testing free and total chlorine residual are the following:

1. HACH DR/890 Colorimeter

2. HACH DPD Free or Total Chlorine Reagent powder pillows for $10 \mathrm{~mL}$ samples

3. Glass sample vial with $10 \mathrm{~mL}$ mark.

4. Scissors

5. Clean, fiber-free towel or cloth

6. DI water (chlorine-free rinse water)

\section{Preparation}

To prepare the colorimeter for use, take off the black cap covering the machine and place it upright so that it now covers the vial holding cell.

All glass vials should be rinsed with DI water or other chlorine-free rinse water prior to use.

Set out the DPD pillow packets and scissors for use in cutting open the packets. Note: When cutting the pillow packets open, be sure to shake the reagent to the bottom of the pillow to ensure that all of the reagent gets added to your sample.

Find the appropriate page in the $\mathrm{HACH}$ colorimeter manual for the specific test you are going to perform. Follow the instructions to set the colorimeter on the appropriate program setting for the test.

\section{Testing}

Testing for free or total chlorine residual involves collecting a sample of whatever water is being tested, zeroing the colorimeter, adding reagent, mixing, and finally reading the sample. The specific steps are as follows:

1. Fill a clean glass sample vial with $10 \mathrm{~mL}$ of the sample to be tested. Place the vial on a flat surface and verify that the bottom of the meniscus of the water is at the $10 \mathrm{~mL}$ mark on the vial.

2. Cap the vial and dry off any water, smudges, or fingerprints on the outside of the vial. Place into the colorimeter, replace the black cap over the sample vial, and press 
"Zero." The colorimeter should be "zeroed" with your sample every time you take and measure a new sample. The reason for zeroing the colorimeter before every reading with your sample is to avoid the false positive interference that turbidity has on colormetric readings.

3. Take the glass sample vial out of the colorimeter. Remove the cap. Cut a single reagent packet (for either total or free chlorine, whichever is being measured), and add the contents to the sample.

4. Immediately mix the vial vigorously by twirling the water in circles and/or by inverting the vial. Perform this mixing procedure consistently with each sample. Try to completely dissolve the reagent into the sample before reading. However, do not spend much longer than 30 seconds mixing. It is important to read the sample as quickly as possible to avoid false positive chlorine residual readings.

5. Place sample with added (\& mixed) reagent into the colorimeter. Press "Read." Record reading.

6. Rinse out the vial with DI water. Invert and place on a papertowel to drain before the next sample is taken.

7. Repeat for additional samples. Note: If possible, use only one glass sample vial for all of your chlorine residual readings. Minor scratches on the glass surface can interfere with chlorine residual readings, so using a single glass sample vial can help maintain consistency throughout an experiment.

\section{Using a Standard}

In some cases it will be necessary to use a chlorine standard to help develop a calibration curve or for use in quality control spike procedures.

Calibration Curve - To develop a calibration curve using a standard chlorine solution with a known free chlorine concentration, perform a 3 to 5 point calibration using known volumes of the standard with DI water. First confirm that the DI water indeed has no chlorine residual. Then, added pre-determined amounts of the chlorine standard to $10 \mathrm{~mL}$ of DI water. Repeat this reading several times for varying amounts of chlorine, to develop a calibration curve over the range of chlorine concentrations that are expected. Be sure that your high and low values on the curve are above and below, respectively, the values that you expect to measure from your water sample.

Standard Spikes - To add a quality control aspect to your experiment, use some of your chlorine standard to develop matrix spikes. To perform a spike, you will need two duplicate samples. The duplicate samples can be collected simultaneously in different vials, or consecutively after reading in the same vial. First, collect and read a sample using the procedure described above. Based on the concentration of chlorine measured in the sample, determine the mass of chlorine that exists in the $10 \mathrm{~mL}$ sample. The spike should add enough chlorine to approximately double the mass that naturally exists in the water sample. Calculate 
how much chlorine standard should be added to a $10 \mathrm{~mL}$ sample to double the mass in the 10 $\mathrm{mL}$ sample. Next, take the duplicate sample, add the calculated amount of chlorine standard to the sample, and follow the general procedure described above. The concentration of the spiked sample should be approximately double that of the original, non-spiked sample.

\section{Clean-up and Storage}

Glass vials should be rinsed with DI water and left to dry (inverted) on a paper towel. Once dry, the caps can be placed on the vials and the vials stored for future use.

Make sure that the DPD pillow packets will not expire before their next use. If so, order more. 


\section{APPENDIX D: CHLORINE RESIDUAL CALIBRATION CURVE}

Determination of Calibration Curve for Measurement of Free Chlorine Residual using HACH DR/890 Colorimeter

Over the course of this experiment, free residual was measured with a HACH DR/890 Colorimeter (Catalog \#4847000) in combination with HACH DPD Free Chlorine Reagent powder pillows for $10 \mathrm{~mL}$ samples (Catalog \#2105569). Ten milliliter samples were collected in glass sample vials, and a single reagent pillow packet was added to the sample. Vials were mixed by inversions for approximately 20 seconds and continuous swirling to dissolve the reagent, and analyzed immediately after mixing. The $\mathrm{HACH}$ Colorimeter analysis program used was Program 9, which has a method detection limit of $0.02 \mathrm{mg} / \mathrm{L}$ and a readable chlorine residual range of 0 to $2.00 \mathrm{mg} / \mathrm{L}$. This method is accepted by the U.S. EPA for reporting drinking water analysis (HACH Company 2010), and is equivalent to Standard Method 4500-Cl G (HACH Colorimeter Manual, not dated).

When free chlorine was measured in an experiment, matrix spikes were included and analyzed using the sampling method described above. The free chlorine standard used for the matrix spikes was a single batch of HACH Chlorine Standard Solution, 25-30 mg/L as $\mathrm{Cl}_{2}, 2$ $\mathrm{mL}$ PourRite Ampules (Lot \#A0112, Catalog \#2630020). The reported free chlorine concentration in the batch of chlorine standard was $27.6 \pm 0.438 \mathrm{mg} / \mathrm{L}$. To administer the matrix spike, a pre-determined amount of the free chlorine standard was added to a $10 \mathrm{~mL}$ sample. After briefly mixing, the $10 \mathrm{~mL}$ sample+standard was used to zero the colorimeter. A single free chlorine reagent pillow was added to the vial, mixed according to the procedure described above, and the free chlorine concentration was read using the colorimeter. The amount of standard added to a sample was determined based on the amount of standard needed to approximately double the mass of chlorine in the $10 \mathrm{~mL}$ sample. The mass of free chlorine in the sample was determined by first analyzing a duplicate sample without added standard. Duplicate samples were taken at the same time in sequence. The first sample was analyzed to determine the approximate mass of chlorine in the sample, and the duplicate sample was then used with the standard to determine the matrix spike.

In the process of using the standard with samples and with plain DI water, it was determined that a calibration curve was necessary to correlate the free chlorine residual readings from the 
colorimeter with the expected free chlorine concentration based on added standard. The following calibration curve was determined using DI water. The pipette used in this experiment was checked for accuracy before use using a digital scale. A single glass cuvette was used for all sample readings to ensure minimal interference from microscopic scratches on the glass surface.

\section{Free Chlorine Residual Calibration Curve}

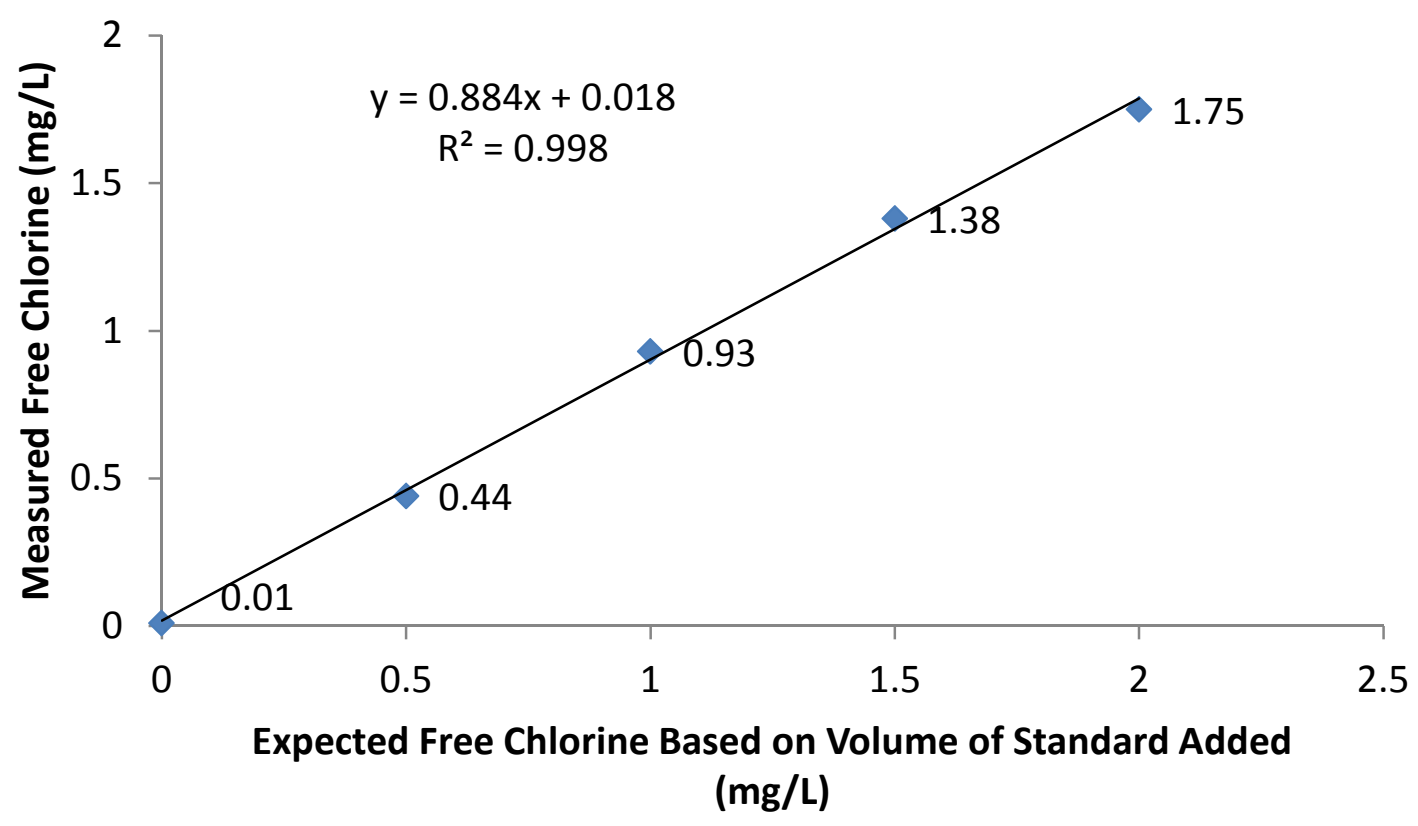

The linear equation displayed on the above calibration curve was used to determine actual (adjusted) free chlorine residuals from measured values. The used of this calibration curve assumed that the specified chlorine concentration in the $\mathrm{HACH}$ standard was accurate and consistent throughout the entire batch of ampules available. 


\section{APPENDIX E: EXPERIMENTAL DATA}

\section{EXPERIMENT A-1}

\begin{tabular}{|c|c|c|c|c|c|c|c|}
\hline \multirow{2}{*}{ Water } & \multirow{2}{*}{ Test } & \multicolumn{4}{|c|}{ Turbidity (NTU) } & \multirow{2}{*}{$\frac{\text { Temp }}{{ }^{\circ} \mathrm{C}}$} & \multirow{2}{*}{$\mathrm{pH}$} \\
\hline & & 1 dup & 2 dup & 3 dup & Avg & & \\
\hline \multicolumn{8}{|c|}{ Bag 1: 30 sec twisting rotations ( $40 \mathrm{bmp}$ ), 30 minutes settling } \\
\hline${ }^{* *}$ Re-suspend solids & Before treatment (in bag) & 372 & 376 & 373 & 374 & 26.1 & 8.23 \\
\hline \multirow[t]{8}{*}{ **Set timer after mixing! } & 10 min after mixing & 402 & 401 & 364 & 389 & & \\
\hline & 15 min after mixing & 143 & 143 & 143.0 & 143 & & \\
\hline & 20 min after mixing & 102.0 & 103.0 & 103.0 & 103 & & \\
\hline & 25 min after mixing & 108.00 & 108.0 & 108.00 & 108 & & \\
\hline & 30 min after mixing & 91.7 & 92.1 & 91.5 & 91.77 & & \\
\hline & After $1 \mathrm{~L}$ drained & 74.40 & 75.6 & 74.50 & 74.83 & & \\
\hline & After 5 L drained & 63.20 & 63.10 & 63.00 & 63.10 & & \\
\hline & After 8 L drained & 55.50 & 54.50 & 54.40 & 54.80 & & \\
\hline \multirow{2}{*}{ Water } & \multirow{2}{*}{ Test } & \multicolumn{4}{|c|}{ Turbidity (NTU) } & Temp & \multirow{2}{*}{$\mathrm{pH}$} \\
\hline & & 1 dup & 2 dup & 3 dup & Avg & ${ }^{\circ} \mathrm{C}$ & \\
\hline \multicolumn{8}{|c|}{ Bag 2: 1 min twisting rotations (70 bpm), 30 minutes settling } \\
\hline${ }^{* *} \operatorname{Re}$-suspend solids & Before treatment (in bag) & 382 & 382 & 383 & 382 & 23.4 & 7.94 \\
\hline \multirow[t]{8}{*}{${ }^{* *}$ Set timer after mixing! } & 10 min after mixing & 330 & 322 & 312 & 321 & & \\
\hline & 15 min after mixing & 55.7 & 55.4 & 55.8 & 55.63 & & \\
\hline & 20 min after mixing & 36.2 & 36.8 & 35.6 & 36.20 & & \\
\hline & 25 min after mixing & 31.20 & 30.6 & 29.90 & 30.57 & & \\
\hline & 30 min after mixing & 26.1 & 27.2 & 26.5 & 26.60 & & \\
\hline & After $1 \mathrm{~L}$ drained & 18.40 & 18.60 & 18.30 & 18.43 & & \\
\hline & After 5 L drained & 17.80 & 17.70 & 17.20 & 17.57 & & \\
\hline & After 8 L drained & 16.40 & 16.20 & 15.60 & 16.07 & & \\
\hline \multirow{2}{*}{ Water } & \multirow{2}{*}{ Test } & \multicolumn{4}{|c|}{ Turbidity (NTU) } & Temp & \multirow{2}{*}{$\mathrm{pH}$} \\
\hline & & 1 dup & 2 dup & 3 dup & Avg & ${ }^{\circ} \mathrm{C}$ & \\
\hline Bag 3: 1.5 min twisting & ions (70 bpm), 30 minutes s & & & & & & \\
\hline${ }^{* *}$ Re-suspend solids & Before treatment (in bag) & 419 & 421 & 425 & 422 & 23.3 & 8.14 \\
\hline \multirow[t]{8}{*}{${ }^{* *}$ Set timer after mixing! } & 10 min after mixing & 334 & 306 & 300 & 313 & & \\
\hline & 15 min after mixing & 61.8 & 58.6 & 60.1 & 60.17 & & \\
\hline & 20 min after mixing & 24.4 & 25.1 & 23.6 & 24.37 & & \\
\hline & 25 min after mixing & 15.60 & 16.5 & 15.40 & 15.83 & & \\
\hline & 30 min after mixing & 14.4 & 15.3 & 14.9 & 14.87 & & \\
\hline & After $1 \mathrm{~L}$ drained & 11.10 & 10.30 & 10.60 & 10.67 & & \\
\hline & After 5 L drained & 8.96 & 8.62 & 8.54 & 8.71 & & \\
\hline & After $8 \mathrm{~L}$ drained & 8.38 & 7.91 & 8.09 & 8.13 & & \\
\hline
\end{tabular}




\begin{tabular}{|c|c|c|c|c|c|c|c|}
\hline \multirow{2}{*}{ Water } & \multirow{2}{*}{ Test } & \multicolumn{4}{|c|}{ Turbidity (NTU) } & \multirow{2}{*}{$\frac{\text { Temp }}{{ }^{\circ} \mathrm{C}}$} & \multirow{2}{*}{$\mathrm{pH}$} \\
\hline & & 1 dup & 2 dup & 3 dup & Avg & & \\
\hline \multicolumn{8}{|c|}{ Bag 4: 2 min twisting rotations (70 bpm), 30 minutes settling } \\
\hline${ }^{* *}$ Re-suspend solids & Before treatment (in bag) & 443 & 445 & 446 & 445 & 23.4 & 7.78 \\
\hline \multirow[t]{8}{*}{${ }^{* *}$ Set timer after mixing! } & 10 min after mixing & 252 & 238 & 205 & 232 & & \\
\hline & 15 min after mixing & 10.2 & 9.2 & 9.7 & 9.67 & & \\
\hline & 20 min after mixing & 20.7 & 19.3 & 21.2 & 20.40 & & \\
\hline & 25 min after mixing & 8.24 & 7.6 & 7.81 & 7.88 & & \\
\hline & 30 min after mixing & 8.6 & 8.6 & 9.9 & 9.03 & & \\
\hline & After $1 \mathrm{~L}$ drained & 5.64 & 5.85 & 5.98 & 5.82 & & \\
\hline & After 5 L drained & 4.67 & 4.94 & 4.76 & 4.79 & & \\
\hline & After $8 \mathrm{~L}$ drained & 4.34 & 3.85 & 3.67 & 3.95 & & \\
\hline \multirow{2}{*}{ Water } & \multirow{2}{*}{ Test } & \multicolumn{4}{|c|}{ Turbidity (NTU) } & Temp & \multirow{2}{*}{$\mathrm{pH}$} \\
\hline & & 1 dup & 2 dup & 3 dup & Avg & ${ }^{\circ} \mathrm{C}$ & \\
\hline \multicolumn{8}{|c|}{ Bag 5: 3 min twisting rotations (70 bpm), 30 minutes settling } \\
\hline${ }^{* *}$ Re-suspend solids & Before treatment (in bag) & 461 & 451 & 460 & 457 & 23.1 & 7.72 \\
\hline \multirow[t]{8}{*}{${ }^{* *}$ Set timer after mixing! } & 10 min after mixing & 183 & 142 & 126 & 150 & & \\
\hline & 15 min after mixing & 12.1 & 15.4 & 11.7 & 13.07 & & \\
\hline & 20 min after mixing & 16.0 & 13.7 & 11.6 & 13.77 & & \\
\hline & 25 min after mixing & 9.48 & 9.2 & 7.74 & 8.80 & & \\
\hline & 30 min after mixing & 6.4 & 5.4 & 4.9 & 5.57 & & \\
\hline & After $1 \mathrm{~L}$ drained & 4.67 & 4.17 & 4.49 & 4.44 & & \\
\hline & After 5 L drained & 3.56 & 3.48 & 3.39 & 3.48 & & \\
\hline & After $8 \mathrm{~L}$ drained & 3.74 & 3.73 & 3.42 & 3.63 & & \\
\hline \multirow[t]{2}{*}{ Water } & \multirow[t]{2}{*}{ Test } & \multicolumn{4}{|c|}{ Turbidity (NTU) } & Temp & \multirow[t]{2}{*}{$\mathrm{pH}$} \\
\hline & & 1 dup & 2 dup & 3 dup & Avg & ${ }^{\circ} \mathrm{C}$ & \\
\hline \multicolumn{8}{|c|}{ Bag 6: 5 min twisting rotations $(70 \mathrm{bpm}), 30$ minutes settling } \\
\hline${ }^{* *}$ Re-suspend solids & Before treatment (in bag) & 429 & 419 & 416 & 421 & 24.7 & 8.12 \\
\hline \multirow[t]{8}{*}{${ }^{* *}$ Set timer after mixing! } & 10 min after mixing & 16 & 13 & 12 & 13 & & \\
\hline & 15 min after mixing & 3.65 & 3.2 & 3.7 & 3.50 & & \\
\hline & 20 min after mixing & 2.7 & 2.7 & 2.4 & 2.60 & & \\
\hline & 25 min after mixing & 2.73 & 2.5 & 2.44 & 2.56 & & \\
\hline & 30 min after mixing & 2.5 & 2.6 & 2.5 & 2.51 & & \\
\hline & After 1 L drained & 2.19 & 2.20 & 2.20 & 2.20 & & \\
\hline & After 5 L drained & 2.45 & 2.34 & 2.27 & 2.35 & & \\
\hline & After $8 \mathrm{~L}$ drained & 2.25 & 2.28 & 2.15 & 2.23 & & \\
\hline
\end{tabular}

PUR lot \# 7223032202 MFG Aug07 
EXPERIMENT A-2

\begin{tabular}{|c|c|c|c|c|c|c|c|}
\hline \multirow{2}{*}{ Water } & \multirow{2}{*}{ Test } & \multicolumn{4}{|c|}{ Turbidity (NTU) } & \multirow{2}{*}{$\begin{array}{l}\text { Temp } \\
{ }^{\circ} \mathrm{C} \\
\end{array}$} & \multirow{2}{*}{$\mathrm{pH}$} \\
\hline & & 1 dup & 2 dup & 3 dup & Avg & & \\
\hline \multicolumn{8}{|c|}{ Bag 1: 2 min twisting (JERKING) rotations (70 bpm), 30 minutes settling } \\
\hline${ }^{* *}$ Re-suspend solids & Before treatment (in bag) & 505 & 503 & 500 & 503 & 25.0 & 7.21 \\
\hline \multirow[t]{8}{*}{${ }^{* *}$ Set timer after mixing! } & 10 min after mixing & 17.50 & 18.00 & 16.30 & 17.27 & & \\
\hline & 15 min after mixing & 14.70 & 14.30 & 14.30 & 14.43 & & \\
\hline & 20 min after mixing & 12.70 & 12.00 & 11.60 & 12.10 & & \\
\hline & 25 min after mixing & 8.79 & 8.61 & 7.81 & 8.40 & & \\
\hline & 30 min after mixing & 7.69 & 6.23 & 6.20 & 6.71 & & \\
\hline & After $1 \mathrm{Ld}$ drained & 6.48 & 5.29 & 5.74 & 5.84 & & \\
\hline & After $5 \mathrm{~L}$ drained & 4.34 & 4.86 & 4.43 & 4.54 & & \\
\hline & After $8 \mathrm{~L}$ drained & 4.44 & 3.67 & 3.76 & 3.96 & & \\
\hline \multirow{2}{*}{ Water } & \multirow{2}{*}{ Test } & \multicolumn{4}{|c|}{ Turbidity (NTU) } & Temp & \multirow{2}{*}{$\mathrm{pH}$} \\
\hline & & 1 dup & 2 dup & 3 dup & Avg & ${ }^{\circ} \mathrm{C}$ & \\
\hline \multicolumn{8}{|c|}{ Bag 3: 2 min twisting (FLUID) rotations (70 bpm), 30 minutes settling } \\
\hline **Re-suspend solids & Before treatment (in bag) & 495 & 494 & 491 & 493 & 24.5 & 7.39 \\
\hline \multirow[t]{8}{*}{${ }^{* *}$ Set timer after mixing! } & 10 min after mixing & 37.70 & 36.70 & 36.50 & 36.97 & & \\
\hline & $15 \mathrm{~min}$ after mixing & 18.20 & 17.70 & 18.00 & 17.97 & & \\
\hline & 20 min after mixing & 13.50 & 13.80 & 14.20 & 13.83 & & \\
\hline & 25 min after mixing & 10.30 & 11.00 & 10.60 & 10.63 & & \\
\hline & 30 min after mixing & 9.25 & 8.57 & 9.23 & 9.02 & & \\
\hline & After $1 \mathrm{Ldrained}$ & 7.12 & 6.87 & 6.58 & 6.86 & & \\
\hline & After $5 \mathrm{~L}$ drained & 6.92 & 5.91 & 6.22 & 6.35 & & \\
\hline & After $8 \mathrm{~L}$ drained & 5.89 & 5.96 & 6.14 & 6.00 & & \\
\hline \multirow{2}{*}{ Water } & \multirow{2}{*}{ Test } & \multicolumn{4}{|c|}{ Turbidity (NTU) } & Temp & \multirow{2}{*}{ pH } \\
\hline & & 1 dup & 2 dup & 3 dup & Avg & ${ }^{\circ} \mathrm{C}$ & \\
\hline \multicolumn{8}{|c|}{ Bag 2: 2 min twisting (JERKING) rotations ( $70 \mathrm{bpm}), 30$ minutes settling } \\
\hline${ }^{* *}$ Re-suspend solids & Before treatment (in bag) & 456 & 459 & 458 & 458 & 24.5 & 7.61 \\
\hline \multirow[t]{8}{*}{${ }^{* *}$ Set timer after mixing! } & $10 \mathrm{~min}$ after mixing & 16.80 & 15.90 & 14.80 & 15.83 & & \\
\hline & 15 min after mixing & 12.00 & 11.80 & 11.20 & 11.67 & & \\
\hline & 20 min after mixing & 9.11 & 8.78 & 9.72 & 9.20 & & \\
\hline & 25 min after mixing & 7.64 & 8.38 & 7.57 & 7.86 & & \\
\hline & 30 min after mixing & 5.87 & 6.32 & 5.97 & 6.05 & & \\
\hline & After $1 \mathrm{Ld}$ drained & 5.60 & 5.12 & 5.06 & 5.26 & & \\
\hline & After $5 \mathrm{~L}$ drained & 5.10 & 4.28 & 4.07 & 4.48 & & \\
\hline & After $8 \mathrm{~L}$ drained & 3.99 & 4.08 & 3.42 & 3.83 & & \\
\hline \multirow{2}{*}{ Water } & \multirow{2}{*}{ Test } & & Turbi & (NTU) & & Temp & pH \\
\hline & & 1 dup & 2 dup & 3 dup & Avg & ${ }^{\circ} \mathrm{C}$ & \\
\hline Bag 4: $2 \mathrm{~min}$ & 30 & s settl & & & & & \\
\hline${ }^{* *}$ Re-suspend solids & Before treatment (in bag) & 441 & 444 & 444 & 443 & 24.5 & 7.48 \\
\hline${ }^{* *}$ Set timer after mixing! & 10 min after mixing & 30.30 & 29.50 & 30.30 & 30.03 & & \\
\hline & 15 min after mixing & 24.00 & 23.30 & 22.70 & 23.33 & & \\
\hline & 20 min after mixing & 14.30 & 14.30 & 14.80 & 14.47 & & \\
\hline & 25 min after mixing & 12.20 & 11.30 & 11.80 & 11.77 & & \\
\hline & $30 \mathrm{~min}$ after mixing & 10.40 & 10.70 & 10.60 & 10.57 & & \\
\hline & After $1 \mathrm{Ld}$ drained & 8.14 & 8.28 & 8.94 & 8.45 & & \\
\hline & After $5 \mathrm{Ldrained}$ & 5.63 & 5.81 & 5.60 & 5.68 & & \\
\hline & After $8 \mathrm{Ldrained}$ & 5.52 & 5.06 & 5.05 & 5.21 & & \\
\hline
\end{tabular}

PUR lot \# 7223032202 MFG Aug07 
EXPERIMENT A-3

\begin{tabular}{|c|c|c|c|c|c|c|c|}
\hline \multirow{2}{*}{ Water } & \multirow{2}{*}{ Test } & \multicolumn{4}{|c|}{ Turbidity (NTU) } & \multirow{2}{*}{$\begin{array}{c}\text { Temp } \\
{ }^{\circ} \mathrm{C} \\
\end{array}$} & \multirow{2}{*}{$\mathrm{pH}$} \\
\hline & & 1 dup & 2 dup & 3 dup & Avg & & \\
\hline \multicolumn{8}{|c|}{ Bag 1: 5 min mixing, no mixing delay $(20-25 \mathrm{sec})$} \\
\hline **Re-suspend solids & Before treatment (in bag) & 441.00 & 446.00 & 446.00 & 444 & 22.3 & 8.31 \\
\hline \multirow[t]{6}{*}{ **Set timer after mixing! } & 10 min after mixing & 18.50 & 10.60 & 15.00 & 14.70 & & \\
\hline & 15 min after mixing & 6.33 & 4.97 & 4.50 & 5.27 & & \\
\hline & 20 min after mixing & 3.29 & 2.99 & 3.41 & 3.23 & & \\
\hline & 25 min after mixing & 2.82 & 2.15 & 2.51 & 2.49 & & \\
\hline & 30 min after mixing & 1.60 & 1.62 & 1.30 & 1.51 & & \\
\hline & 40 min after mixing & 1.56 & 1.88 & 1.91 & 1.78 & & \\
\hline \multirow{2}{*}{ Water } & \multirow{2}{*}{ Test } & \multicolumn{4}{|c|}{ Turbidity (NTU) } & Temp & \multirow{2}{*}{$\mathrm{pH}$} \\
\hline & & 1 dup & 2 dup & 3 dup & Avg & ${ }^{\circ} \mathrm{C}$ & \\
\hline \multicolumn{8}{|c|}{ Bag 2: 5 min mixing, 1 min mixing delay } \\
\hline **Re-suspend solids & Before treatment (in bag) & 412.67 & 414.67 & 410.00 & 412 & $\mathrm{DID} \mathrm{NO}$ & MPLE. \\
\hline \multirow[t]{6}{*}{ **Set timer after mixing! } & 10 min after mixing & 4.89 & 3.37 & 3.15 & 3.80 & & \\
\hline & 15 min after mixing & 2.27 & 2.51 & 2.44 & 2.41 & & \\
\hline & 20 min after mixing & 3.78 & 4.68 & 4.79 & 4.42 & & \\
\hline & 25 min after mixing & 1.61 & 1.79 & 1.80 & 1.73 & & \\
\hline & 30 min after mixing & 1.52 & 1.53 & 1.57 & 1.54 & & \\
\hline & 40 min after mixing & 1.51 & 1.38 & 1.52 & 1.47 & & \\
\hline
\end{tabular}

\begin{tabular}{|c|c|c|c|c|c|c|c|}
\hline \multirow{2}{*}{ Water } & \multirow{2}{*}{ Test } & \multicolumn{4}{|c|}{ Turbidity (NTU) } & \multirow{2}{*}{$\frac{\text { Temp }}{{ }^{\circ} \mathrm{C}}$} & \multirow{2}{*}{$\mathrm{pH}$} \\
\hline & & 1 dup & 2 dup & 3 dup & Avg & & \\
\hline \multicolumn{8}{|c|}{ Bag 3: 5 min mixing, 2 minute mixing delay } \\
\hline **Re-suspend solids & Before treatment (in bag) & 369.00 & 360.00 & 355.00 & 361 & 21.3 & 8.18 \\
\hline \multirow[t]{6}{*}{ **Set timer after mixing! } & 10 min after mixing & 10.60 & 4.49 & 3.63 & 6.24 & & \\
\hline & 15 min after mixing & 2.92 & 2.54 & 2.79 & 2.75 & & \\
\hline & 20 min after mixing & 2.43 & 2.17 & 2.71 & 2.44 & & \\
\hline & 25 min after mixing & 2.08 & 1.96 & 2.29 & 2.11 & & \\
\hline & 30 min after mixing & 2.00 & 1.94 & 2.12 & 2.02 & & \\
\hline & 40 min after mixing & 1.64 & 1.61 & 1.43 & 1.56 & & \\
\hline \multirow[t]{2}{*}{ Water } & \multirow[t]{2}{*}{ Test } & \multicolumn{4}{|c|}{ Turbidity (NTU) } & Temp & \multirow{2}{*}{$\mathrm{pH}$} \\
\hline & & 1 dup & 2 dup & 3 dup & Avg & ${ }^{\circ} \mathrm{C}$ & \\
\hline \multicolumn{8}{|c|}{ Bag 4: 5 min mixing, 5 minute mixing delay } \\
\hline **Re-suspend solids & Before treatment (in bag) & 428 & 438 & 429 & 432 & 21.4 & 8.33 \\
\hline \multirow[t]{6}{*}{ **Set timer after mixing! } & 10 min after mixing & 9.46 & 6.18 & 5.03 & 6.89 & & \\
\hline & 15 min after mixing & 13.40 & 8.94 & 7.64 & 9.99 & & \\
\hline & 20 min after mixing & 4.03 & 3.90 & 2.99 & 3.64 & & \\
\hline & 25 min after mixing & 2.13 & 2.54 & 2.19 & 2.29 & & \\
\hline & 30 min after mixing & 1.28 & 1.31 & 1.29 & 1.29 & & \\
\hline & 40 min after mixing & 1.85 & 1.3 & 1.25 & 1.48 & & \\
\hline
\end{tabular}

PUR lot \# 7223032202 MFG Aug 07 ExpJul10 


\section{EXPERIMENT B-1}

\begin{tabular}{|c|c|c|c|c|c|c|c|}
\hline \multirow{2}{*}{ Water } & \multirow{2}{*}{ Test } & \multicolumn{4}{|c|}{ Turbidity (NTU) } & \multirow{2}{*}{$\begin{array}{c}\text { Temp } \\
{ }^{\circ} \mathrm{C} \\
\end{array}$} & \multirow{2}{*}{$\mathrm{pH}$} \\
\hline & & 1 dup & 2 dup & 3 dup & Avg & & \\
\hline \multicolumn{8}{|c|}{ Bag 2: 2.5 min mixing, 1 baffle, 30 min settling } \\
\hline${ }^{* *}$ Re-suspend solids & Before treatment (in bag) & 493 & 489 & 488 & 490 & 22.5 & 8.07 \\
\hline \multirow[t]{6}{*}{${ }^{* *}$ Set timer after mixing! } & 10 min after mixing & 30.9 & 29.3 & 29.4 & 30 & & \\
\hline & 15 min after mixing & 22.4 & 21.7 & 22.0 & 22 & & \\
\hline & 20 min after mixing & 17.8 & 17.7 & 17.4 & 18 & & \\
\hline & 25 min after mixing & 13.70 & 13.8 & 14.10 & 14 & & \\
\hline & 30 min after mixing & 12.4 & 12.5 & 12.5 & 12.47 & & \\
\hline & 40 min after mixing & 10.50 & 10.3 & 10.10 & 10.30 & & \\
\hline \multirow[t]{2}{*}{ Water } & \multirow[t]{2}{*}{ Test } & \multicolumn{4}{|c|}{ Turbidity (NTU) } & Temp & \multirow[t]{2}{*}{ pH } \\
\hline & & 1 dup & 2 dup & 3 dup & Avg & ${ }^{\circ} \mathrm{C}$ & \\
\hline \multicolumn{8}{|c|}{ Bag 3: 2.5 min mixing, 2 baffles, 30 min settling } \\
\hline${ }^{* *}$ Re-suspend solids & Before treatment (in bag) & 477 & 477 & 476 & 477 & 23.6 & 8.03 \\
\hline \multirow[t]{6}{*}{${ }^{* *}$ Set timer after mixing! } & 10 min after mixing & 26.20 & 26.00 & 25.70 & 25.97 & & \\
\hline & 15 min after mixing & 11.20 & 10.70 & 10.40 & 10.77 & & \\
\hline & 20 min after mixing & 10.10 & 10.10 & 9.17 & 9.79 & & \\
\hline & 25 min after mixing & 8.13 & 7.99 & 7.48 & 7.87 & & \\
\hline & 30 min after mixing & 6.60 & 6.90 & 7.00 & 6.83 & & \\
\hline & 40 min after mixing & 5.07 & 5.0 & 4.89 & 5.00 & & \\
\hline \multirow[t]{2}{*}{ Water } & \multirow[t]{2}{*}{ Test } & \multicolumn{4}{|c|}{ Turbidity (NTU) } & Temp & \multirow[t]{2}{*}{$\mathrm{pH}$} \\
\hline & & 1 dup & 2 dup & 3 dup & Avg & ${ }^{\circ} \mathrm{C}$ & \\
\hline \multicolumn{8}{|c|}{ Bag 4: 2.5 min mixing, 3 baffles, 30 min settling } \\
\hline${ }^{* *}$ Re-suspend solids & Before treatment (in bag) & 489 & 488 & 486 & 488 & \multicolumn{2}{|c|}{ NOT SAMPLED } \\
\hline \multirow[t]{6}{*}{${ }^{* *}$ Set timer after mixing! } & 10 min after mixing & 20.90 & 18.60 & 19.80 & 19.77 & & \\
\hline & 15 min after mixing & 9.50 & 9.26 & 9.33 & 9.36 & & \\
\hline & 20 min after mixing & 8.37 & 7.58 & 7.63 & 7.86 & & \\
\hline & 25 min after mixing & 6.65 & 6.80 & 6.80 & 6.75 & & \\
\hline & 30 min after mixing & 5.87 & 5.63 & 5.29 & 5.60 & & \\
\hline & 40 min after mixing & 5.02 & 5.15 & 4.77 & 4.98 & & \\
\hline Water & Test & \multicolumn{4}{|c|}{ Turbidity (NTU) } & Temp & \multirow[t]{2}{*}{ pH } \\
\hline & & 1 dup & 2 dup & 3 dup & Avg & ${ }^{\circ} \mathrm{C}$ & \\
\hline \multicolumn{8}{|c|}{ Bag 1: 2.5 min mixing, 1 baffle (side-to-side), 30 min settling ${ }^{* * *}$} \\
\hline${ }^{* *}$ Re-suspend solids & Before treatment (in bag) & 498 & 498 & 494 & 497 & 22.9 & 8.04 \\
\hline \multirow[t]{6}{*}{${ }^{* *}$ Set timer after mixing! } & 10 min after mixing & 84.30 & 85.30 & 83.50 & 84.37 & & \\
\hline & 15 min after mixing & 46.00 & 45.20 & 44.40 & 45.20 & & \\
\hline & 20 min after mixing & 39.80 & 39.70 & 39.90 & 39.80 & & \\
\hline & 25 min after mixing & 27.60 & 27.30 & 27.10 & 27.33 & & \\
\hline & 30 min after mixing & 28.20 & 28.40 & 28.10 & 28.23 & & \\
\hline & 40 min after mixing & 23.40 & 23.1 & 23.60 & 23.37 & & \\
\hline
\end{tabular}

PUR lot \# 7223032202 MFG Aug07 Exp Jul10 


\section{EXPERIMENT B-2}

\begin{tabular}{|c|c|c|c|c|c|c|c|}
\hline \multirow{2}{*}{ Water } & \multirow{2}{*}{ Test } & \multicolumn{4}{|c|}{ Turbidity (NTU) } & \multirow{2}{*}{$\frac{\text { Temp }}{{ }^{\circ} \mathrm{C}}$} & \multirow{2}{*}{ pH } \\
\hline & & 1 dup & 2 dup & 3 dup & Avg & & \\
\hline \multicolumn{8}{|c|}{ Bag 1: 2.5 min mixing, 2 baffles (current Mark II) } \\
\hline$\bullet$ Re-suspend solids & Before treatment (in bag) & 456.00 & 452.00 & 449.00 & 452 & 22.5 & 8.19 \\
\hline \multirow[t]{6}{*}{ * Set timer after mixing! } & 10 min after mixing & 24.90 & 24.70 & 24.40 & 25 & & \\
\hline & 15 min after mixing & 16.00 & 16.90 & 16.10 & 16 & & \\
\hline & 20 min after mixing & 12.70 & 12.10 & 11.80 & 12 & & \\
\hline & 25 min after mixing & 10.90 & 10.60 & 10.20 & 11 & & \\
\hline & 30 min after mixing & 8.03 & 7.45 & 7.65 & 7.71 & & \\
\hline & 40 min after mixing & 6.72 & 6.22 & 6.29 & 6.41 & & \\
\hline \multirow{2}{*}{ Water } & \multirow{2}{*}{ Test } & \multicolumn{4}{|c|}{ Turbidity (NTU) } & Temp & \multirow{2}{*}{$\mathrm{pH}$} \\
\hline & & 1 dup & 2 dup & 3 dup & Avg & ${ }^{\circ} \mathrm{C}$ & \\
\hline \multicolumn{8}{|c|}{ Bag 2: 2.5 min mixing, WIDE baffle with side-by-side circular holes } \\
\hline **Re-suspend solids & Before treatment (in bag) & 449.00 & 451.00 & 448.00 & 449 & 22.5 & 8.17 \\
\hline \multirow[t]{6}{*}{ * Set timer after mixing! } & 10 min after mixing & 18.40 & 17.70 & 17.40 & 17.83 & & \\
\hline & 15 min after mixing & 13.40 & 12.60 & 12.20 & 12.73 & & \\
\hline & 20 min after mixing & 11.70 & 11.50 & 11.70 & 11.63 & & \\
\hline & 25 min after mixing & 8.41 & 8.17 & 8.07 & 8.22 & & \\
\hline & 30 min after mixing & 7.27 & 7.02 & 6.88 & 7.06 & & \\
\hline & 40 min after mixing & 5.37 & 5.34 & 5.45 & 5.39 & & \\
\hline \multirow[t]{2}{*}{ Water } & \multirow{2}{*}{ Test } & \multicolumn{4}{|c|}{ Turbidity (NTU) } & Temp & \multirow{2}{*}{ pH } \\
\hline & & 1 dup & 2 dup & 3 dup & Avg & ${ }^{\circ} \mathrm{C}$ & \\
\hline \multicolumn{8}{|c|}{ Bag 3: 2.5 min mixing, WIDE baffle with diagonal circular holes } \\
\hline *Re-suspend solids & Before treatment (in bag) & 437.00 & 446.00 & 442.00 & 442 & 22.2 & 8.16 \\
\hline \multirow[t]{6}{*}{ * Set timer after mixing! } & 10 min after mixing & 21.50 & 21.80 & 21.10 & 21.47 & & \\
\hline & 15 min after mixing & 14.20 & 12.90 & 13.60 & 13.57 & & \\
\hline & 20 min after mixing & 9.57 & 9.26 & 9.14 & 9.32 & & \\
\hline & 25 min after mixing & 8.89 & 8.87 & 9.32 & 9.03 & & \\
\hline & 30 min after mixing & 8.13 & 7.95 & 7.55 & 7.88 & & \\
\hline & 40 min after mixing & 5.70 & 5.95 & 5.67 & 5.77 & & \\
\hline \multirow[t]{2}{*}{ Water } & \multirow[t]{2}{*}{ Test } & \multicolumn{4}{|c|}{ Turbidity (NTU) } & Temp & \multirow[t]{2}{*}{ pH } \\
\hline & & 1 dup & 2 dup & 3 dup & Avg & ${ }^{\circ} \mathrm{C}$ & \\
\hline \multicolumn{8}{|c|}{ Bag 4: 2.5 min mixing, WIDE baffle with top-to-bottom rectangular holes } \\
\hline * Re-suspend solids & Before treatment (in bag) & 416 & 424 & 426 & 422 & 23.7 & 8.08 \\
\hline \multirow[t]{6}{*}{ *Set timer after mixing! } & 10 min after mixing & 16.80 & 16.60 & 16.50 & 16.63 & & \\
\hline & 15 min after mixing & 11.30 & 12.80 & 12.20 & 12.10 & & \\
\hline & 20 min after mixing & 10.50 & 10.40 & 10.20 & 10.37 & & \\
\hline & 25 min after mixing & 8.27 & 7.78 & 8.29 & 8.11 & & \\
\hline & 30 min after mixing & 7.20 & 8.00 & 7.69 & 7.63 & & \\
\hline & 40 min after mixing & 6.99 & 6.4 & 6.56 & 6.65 & & \\
\hline
\end{tabular}

PUR lot \# 7223032202 MFG Aug 07 ExpJul10 


\section{EXPERIMENT C-1}

Bag 1: O\% EPA challenge water-TOC concentration, $0 \mathrm{mg} / \mathrm{L} \mathrm{TOC}$

\begin{tabular}{|c|c|c|c|c|c|c|c|c|c|c|}
\hline \multirow{2}{*}{ Sample Time } & \multirow{2}{*}{$\begin{array}{c}\text { Free Cl } \\
\text { Residual } \\
\mathrm{mg} / \mathrm{L}\end{array}$} & \multirow{2}{*}{$\begin{array}{c}\text { Std Spike } \\
\mathrm{mg} / \mathrm{L}\end{array}$} & \multirow{2}{*}{$\begin{array}{l}\mathrm{TOC} \\
\mathrm{mg} / \mathrm{L}\end{array}$} & \multicolumn{4}{|c|}{ Turbidity (NTU) } & \multirow{2}{*}{$\frac{\text { Temp }}{{ }^{\circ} \mathrm{C}}$} & \multirow{2}{*}{ pH } & \multirow{2}{*}{\begin{tabular}{|c|}
$\begin{array}{c}\text { Time After } \\
\text { Mixing }\end{array}$ \\
(hours) \\
\end{tabular}} \\
\hline & & & & 1 dup & 2 dup & 3 dup & Avg & & & \\
\hline Before treatment (in bag) & & & & 91.40 & 92.00 & 90.20 & 91.20 & 4.5 & 9.01 & 0 \\
\hline $10 \mathrm{~min}$ after mixing & 1.37 & & & 44.90 & 39.60 & 36.30 & 40.27 & & & 0.17 \\
\hline $20 \mathrm{~min}$ & 1.28 & & & 32.60 & 29.80 & 26.30 & 29.57 & & & 0.33 \\
\hline $30 \min (+s t d)$ & 1.30 & added 212 uL & & 14.70 & 12.40 & 11.30 & 12.80 & 6 & 7.2 & 0.5 \\
\hline $1 \mathrm{hr}$ & 1.21 & Cl spike @ 30=1.51 & & 10.8 & 10.6 & 9.86 & 10.42 & & & 1 \\
\hline 2 & 1.08 & & & 6.63 & 6.26 & 6.47 & 6.45 & & & 2 \\
\hline 3 & 1.00 & & & 5.56 & 5.58 & 5.55 & 5.56 & 10.3 & 7.5 & 3 \\
\hline 5.75 & 0.78 & & & 4.47 & 4.37 & 4.44 & 4.43 & & & 5.75 \\
\hline 10.75 & 0.50 & & & 4.53 & 4.19 & 4.35 & 4.36 & & & 10.75 \\
\hline 21.05 & 0.15 & & & 2.94 & 2.94 & 2.94 & 2.94 & 20.3 & 6.83 & 21.05 \\
\hline
\end{tabular}

\section{Bag 2: $5 \%$ humic, $0.5 \mathrm{mg} / \mathrm{L} \mathrm{TOC}$}

\begin{tabular}{|c|c|c|c|c|c|c|c|c|c|c|}
\hline \multirow{2}{*}{ Sample Time } & \multirow{2}{*}{$\begin{array}{c}\text { Free Cl } \\
\text { Residual } \\
\mathrm{mg} / \mathrm{L}\end{array}$} & \multirow{2}{*}{$\begin{array}{c}\text { Std Spike } \\
\mathrm{mg} / \mathrm{L}\end{array}$} & \multirow{2}{*}{$\begin{array}{l}\mathrm{TOC} \\
\mathrm{mg} / \mathrm{L}\end{array}$} & \multicolumn{4}{|c|}{ Turbidity (NTU) } & \multirow{2}{*}{$\frac{\text { Temp }}{{ }^{\circ} \mathrm{C}}$} & \multirow{2}{*}{ pH } & \multirow{2}{*}{\begin{tabular}{|c|}
$\begin{array}{c}\text { Time After } \\
\text { Mixing }\end{array}$ \\
(hours) \\
\end{tabular}} \\
\hline & & & & 1 dup & 2 dup & 3 dup & Avg & & & \\
\hline Before treatment (in bag) & & & & 84.80 & 80.40 & 79.70 & 81.63 & 3.6 & 8.93 & 0 \\
\hline 10 min after mixing & 1.17 & & & 43.60 & 33.90 & 33.10 & 36.87 & & & 0.17 \\
\hline $20 \mathrm{~min}$ & 1.05 & & & 22.60 & 24.70 & 24.00 & 23.77 & & & 0.33 \\
\hline $30 \mathrm{~min}(+\mathrm{std})$ & 0.98 & added 318 uL & & 13.70 & 13.00 & 12.30 & 13.00 & 9 & 7.05 & 0.5 \\
\hline $1 \mathrm{hr}$ & 0.91 & Cl spike @ 30= 1.41 & & 8.83 & 8.76 & 7.95 & 8.51 & & & 1 \\
\hline 2 & 0.74 & & & 6.93 & 7.08 & 7.09 & 7.03 & & & 2 \\
\hline 3 & 0.60 & & & 4.93 & 4.66 & 4.63 & 4.74 & 11 & 7.1 & 3 \\
\hline 5.28 & 0.45 & & & 4.42 & 4.38 & 4.4 & 4.40 & & & 5.28 \\
\hline 10.3 & 0.23 & & & 3.91 & 3.95 & 3.88 & 3.91 & & & 10.30 \\
\hline 20.72 & 0.05 & & & 3.21 & 2.93 & 2.94 & 3.03 & 20.2 & 6.89 & 20.72 \\
\hline
\end{tabular}

Bag 3: $10 \%$ humic, $1.0 \mathrm{mg} / \mathrm{L} \mathrm{TOC}$

\begin{tabular}{|c|c|c|c|c|c|c|c|c|c|c|}
\hline \multirow{2}{*}{ Sample Time } & \multirow{2}{*}{$\begin{array}{c}\text { Free } \mathrm{Cl} \\
\text { Residual } \\
\mathrm{mg} / \mathrm{L}\end{array}$} & \multirow{2}{*}{$\begin{array}{c}\text { Std Spike } \\
\mathrm{mg} / \mathrm{L}\end{array}$} & \multirow{2}{*}{$\begin{array}{l}\text { TOC } \\
\mathrm{mg} / \mathrm{L}\end{array}$} & \multicolumn{4}{|c|}{ Turbidity (NTU) } & \multirow{2}{*}{$\frac{\text { Temp }}{{ }^{\circ} \mathrm{C}}$} & \multirow{2}{*}{$\mathrm{pH}$} & \multirow{2}{*}{\begin{tabular}{|c|}
$\begin{array}{c}\text { Time After } \\
\text { Mixing }\end{array}$ \\
(hours) \\
\end{tabular}} \\
\hline & & & & 1 dup & 2 dup & 3 dup & Avg & & & \\
\hline Before treatment (in bag) & & & & 82.70 & 79.40 & 81.10 & 81.07 & 4.8 & 8.87 & 0 \\
\hline 10 min after mixing & 1.19 & & & 55.50 & 47.20 & 54.90 & 52.53 & & & 0.17 \\
\hline $20 \mathrm{~min}$ & 1.10 & & & 20.90 & 19.90 & 17.80 & 19.53 & & & 0.33 \\
\hline $30 \mathrm{~min}(+\mathrm{std})$ & 1.04 & added 340 uL & & 14.50 & 14.30 & 12.70 & 13.83 & 6.4 & 7.19 & 0.5 \\
\hline $1 \mathrm{hr}$ & 1.00 & Cl spike @ 30=1.54 & & 9.88 & 8.73 & 8.96 & 9.19 & & & 1 \\
\hline 3 & 0.73 & & & 4.59 & 4.65 & 4.64 & 4.63 & 10.8 & 7.19 & 3 \\
\hline 4.5 & 0.62 & & & 4.62 & 4.38 & 4.34 & 4.45 & & & 4.50 \\
\hline 9.42 & 0.29 & & & 4.12 & 4.02 & 3.94 & 4.03 & & & 9.42 \\
\hline 19.97 & 0.06 & & & 2.96 & 2.86 & 2.89 & 2.90 & 20.2 & 6.84 & 19.97 \\
\hline
\end{tabular}

Bag 4: $10 \%$ humic, $1.0 \mathrm{mg} / \mathrm{L} \mathrm{TOC}$

\begin{tabular}{|c|c|c|c|c|c|c|c|c|c|c|}
\hline \multirow{2}{*}{ Sample Time } & \multirow{2}{*}{$\begin{array}{c}\text { Free } \mathrm{Cl} \\
\text { Residual } \\
\mathrm{mg} / \mathrm{L}\end{array}$} & \multirow{2}{*}{$\begin{array}{c}\text { Std Spike } \\
\mathrm{mg} / \mathrm{L}\end{array}$} & \multirow{2}{*}{$\begin{array}{l}\mathrm{TOC} \\
\mathrm{mg} / \mathrm{L}\end{array}$} & \multicolumn{4}{|c|}{ Turbidity (NTU) } & \multirow{2}{*}{$\begin{array}{c}\text { Temp } \\
{ }^{\circ} \mathrm{C}\end{array}$} & \multirow{2}{*}{ pH } & \multirow{2}{*}{\begin{tabular}{|c|}
$\begin{array}{c}\text { Time After } \\
\text { Mixing }\end{array}$ \\
(hours) \\
\end{tabular}} \\
\hline & & & & 1 dup & 2 dup & 3 dup & Avg & & & \\
\hline Before treatment (in bag) & & & & 80.00 & 79.40 & 78.30 & 79.23 & 3.4 & 8.98 & 0 \\
\hline 10 min after mixing & 0.82 & & & 42.60 & 38.10 & 32.50 & 37.73 & & & 0.17 \\
\hline $20 \mathrm{~min}$ & 0.79 & & & 25.80 & 22.70 & 19.90 & 28.00 & & & 0.33 \\
\hline $30 \min (+s t d)$ & 0.73 & added 239 uL & & 14.50 & 13.60 & 14.80 & 14.30 & 5.9 & 7.04 & 0.5 \\
\hline $1 \mathrm{hr}$ & 0.66 & Cl spike @ 30=1.10 & & 12.6 & 12.2 & 12.7 & 12.50 & & & 1 \\
\hline 2 & 0.55 & & & 7.36 & 6.57 & 6.51 & 6.81 & & & 2 \\
\hline 3 & 0.43 & & & 7.48 & 7.56 & 7.28 & 7.44 & 10.5 & 7.02 & 3 \\
\hline 4 & 0.38 & & & 5.14 & 5.05 & NS & 5.10 & & & 4 \\
\hline 8.95 & 0.19 & & & 4.77 & 4.65 & 4.61 & 4.68 & & & 8.95 \\
\hline 19.58 & 0.02 & & & 2.91 & 3.01 & 2.85 & 2.92 & 20.3 & 7.01 & 19.58 \\
\hline
\end{tabular}


Bag 5: 25\% humic, $2.5 \mathrm{mg} / \mathrm{L} \mathrm{TOC}$

\begin{tabular}{|c|c|c|c|c|c|c|c|c|c|c|}
\hline \multirow{2}{*}{ Sample Time } & \multirow{2}{*}{$\begin{array}{c}\text { Free Cl } \\
\text { Residual } \\
\mathrm{mg} / \mathrm{L}\end{array}$} & \multirow{2}{*}{$\begin{array}{c}\text { Std Spike } \\
\mathrm{mg} / \mathrm{L}\end{array}$} & \multirow{2}{*}{$\begin{array}{l}\mathrm{TOC} \\
\mathrm{mg} / \mathrm{L}\end{array}$} & \multicolumn{4}{|c|}{ Turbidity (NTU) } & \multirow{2}{*}{$\begin{array}{c}\text { Temp } \\
{ }^{\circ} \mathrm{C}\end{array}$} & \multirow{2}{*}{$\mathrm{pH}$} & \multirow{2}{*}{\begin{tabular}{|c|}
$\begin{array}{c}\text { Time After } \\
\text { Mixing }\end{array}$ \\
(hours) \\
\end{tabular}} \\
\hline & & & & 1 dup & 2 dup & 3 dup & Avg & & & \\
\hline Before treatment (in bag) & & & & 78.90 & 82.80 & 82.50 & 81.40 & 3.6 & 8.91 & 0 \\
\hline $10 \mathrm{~min}$ after mixing & 0.44 & & & 46.40 & 42.00 & 43.70 & 44.03 & & & 0.17 \\
\hline $20 \mathrm{~min}$ & 0.42 & & & 33.20 & 33.20 & 33.70 & 33.37 & & & 0.33 \\
\hline $30 \min (+s t d)$ & 0.38 & added 127 uL & & 17.30 & 16.50 & 15.60 & 16.47 & 6.2 & 6.96 & 0.5 \\
\hline $1 \mathrm{hr}$ & 0.36 & Cl spike @ 30=0.64 & & 11.2 & 11.1 & 10.3 & 10.87 & & & 1 \\
\hline 2 & 0.25 & & & 8.36 & 7.88 & 7.53 & 7.92 & & & 2 \\
\hline 3 & 0.21 & & & 10.7 & 9.19 & 8.99 & 9.63 & 11.6 & 6.69 & 3 \\
\hline 8 & 0.10 & & & 5.93 & 5.57 & 5.79 & 5.76 & 16.5 & 6.98 & 8 \\
\hline
\end{tabular}

Bag 6: $100 \%$ humic, $10 \mathrm{mg} / \mathrm{L} \mathrm{TOC}$

\begin{tabular}{|c|c|c|c|c|c|c|c|c|c|c|}
\hline \multirow{2}{*}{ Sample Time } & \multirow{2}{*}{$\begin{array}{c}\text { Free } \mathrm{Cl} \\
\text { Residual } \\
\mathrm{mg} / \mathrm{L}\end{array}$} & \multirow{2}{*}{$\begin{array}{c}\text { Std Spike } \\
\mathrm{mg} / \mathrm{L}\end{array}$} & \multirow{2}{*}{$\begin{array}{l}\mathrm{TOC} \\
\mathrm{mg} / \mathrm{L}\end{array}$} & \multicolumn{4}{|c|}{ Turbidity (NTU) } & \multirow{2}{*}{$\frac{\text { Temp }}{{ }^{\circ} \mathrm{C}}$} & \multirow{2}{*}{$\mathrm{pH}$} & \multirow{2}{*}{\begin{tabular}{|c|}
$\begin{array}{c}\text { Time After } \\
\text { Mixing }\end{array}$ \\
(hours) \\
\end{tabular}} \\
\hline & & & & 1 dup & 2 dup & 3 dup & Avg & & & \\
\hline Before treatment (in bag) & & & & 80.60 & 80.30 & 81.30 & 80.73 & 4.0 & 8.89 & 0 \\
\hline $10 \mathrm{~min}$ after mixing & 0.23 & & & 38.90 & 38.20 & 33.40 & 36.83 & & & 0.17 \\
\hline $20 \mathrm{~min}$ & 0.16 & & & 23.80 & 22.50 & 19.40 & 21.90 & & & 0.33 \\
\hline $30 \min (+s t d)$ & 0.15 & added $108 \mathrm{uL}$ & & 23.80 & 15.70 & 14.50 & 18.00 & 6.7 & 6.94 & 0.5 \\
\hline $1 \mathrm{hr}$ & 0.12 & Cl spike @ 30=0.32 & & 12.3 & 11.7 & 11 & 11.67 & & & 1 \\
\hline 2 & 0.07 & & & 9.9 & 8.79 & 8.65 & 9.11 & & & 2 \\
\hline 3 & 0.05 & & & 8.39 & 7.95 & 7.75 & 8.03 & 11.1 & 6.98 & 3 \\
\hline
\end{tabular}

PUR lot \# 9289032230 MFG Oct09 Exp Sep12 


\section{EXPERIMENT D-1}

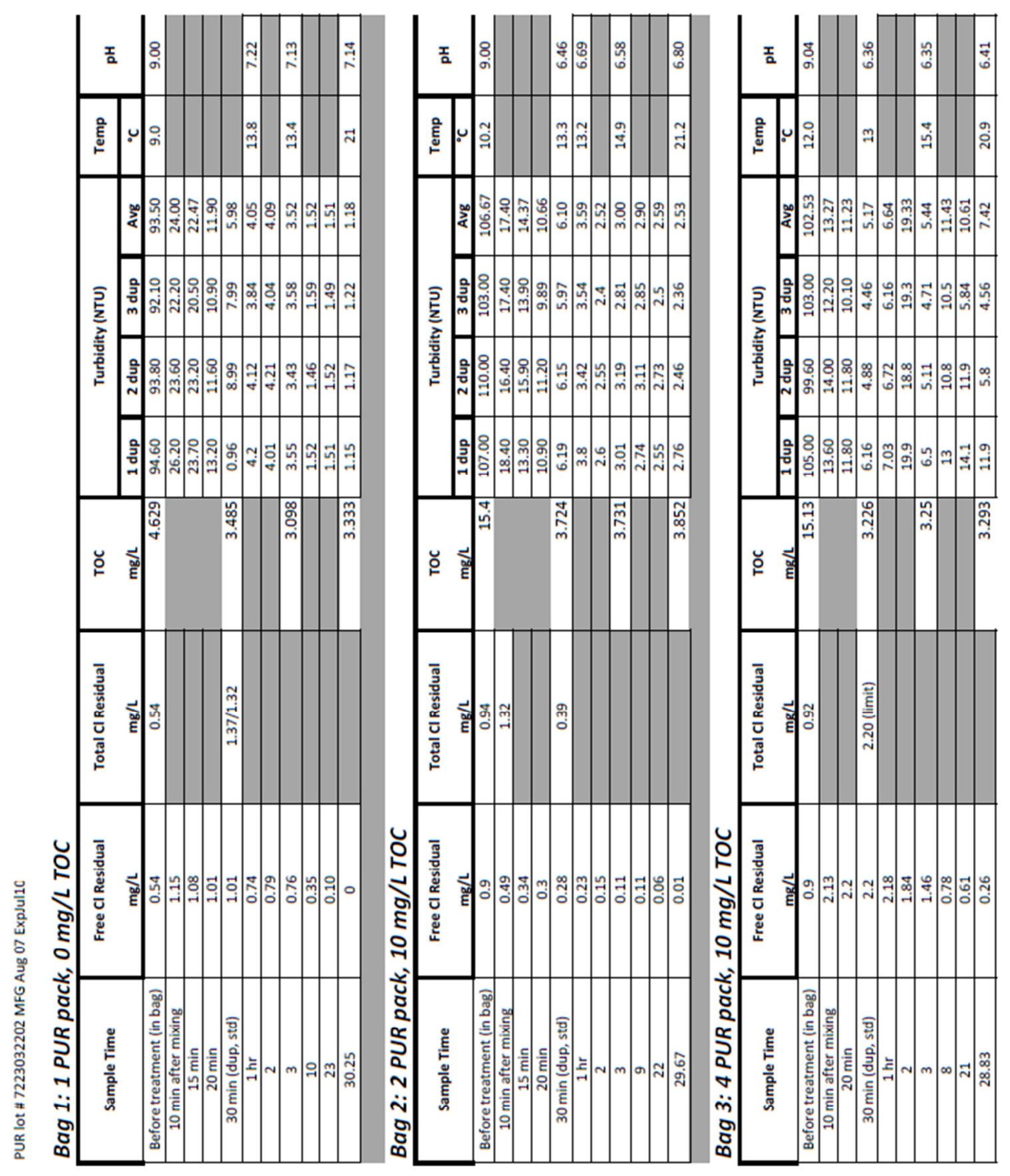




\section{EXPERIMENT D-2}

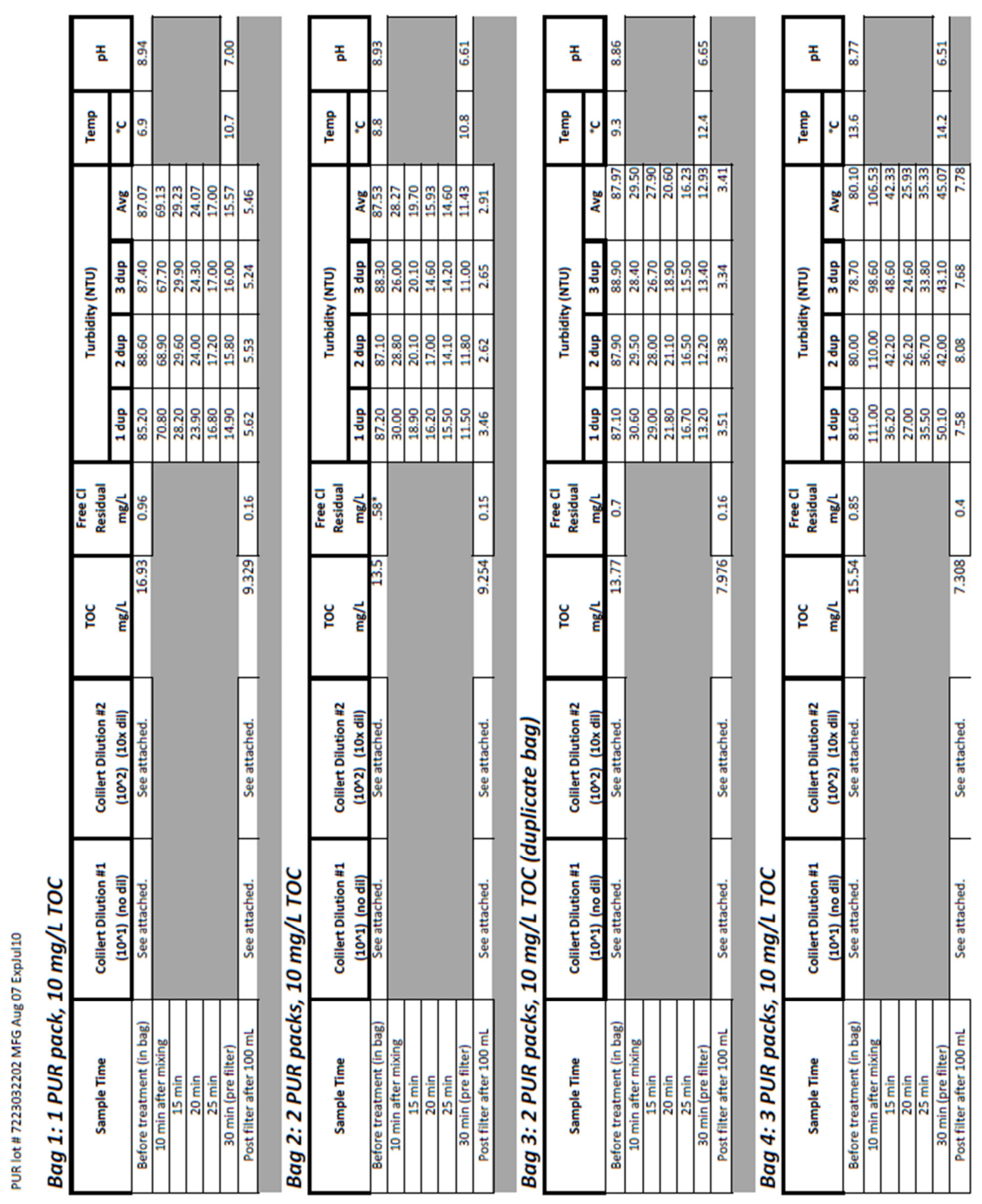




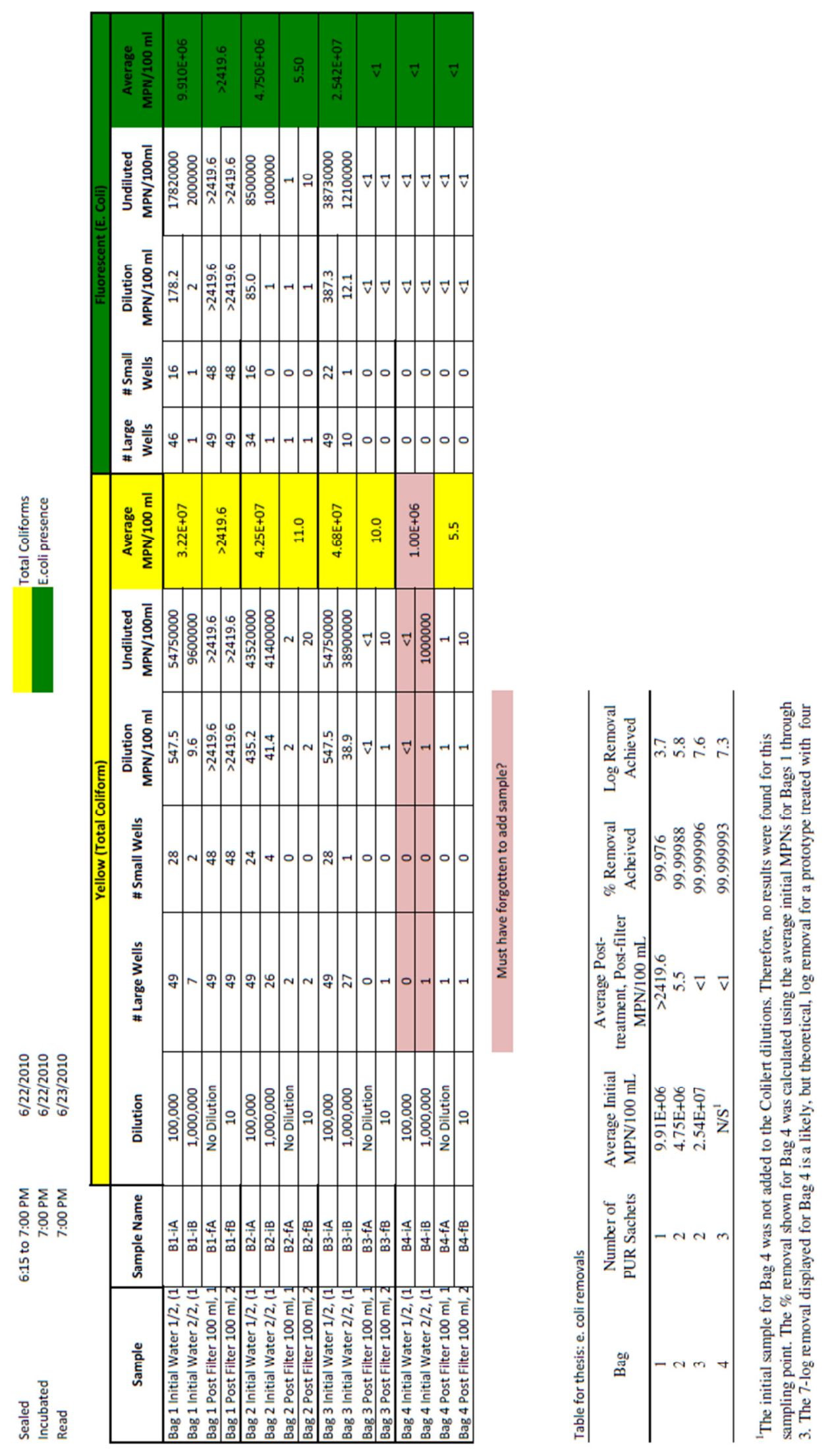




\section{EXPERIMENT E-1}

PUR lot \# 7223032202 MFG Aug 07 ExpJul10

Bag \# 1

\begin{tabular}{|c|c|c|c|c|c|c|c|c|c|c|c|}
\hline \multirow{2}{*}{ Sampling Point } & \multirow{2}{*}{$\begin{array}{c}\text { Filter(s) Used } \\
\text { Clamshell ( C) } \\
\text { or Bullet (B) }\end{array}$} & \multicolumn{4}{|c|}{ Turbidity } & \multirow{2}{*}{$\begin{array}{c}\begin{array}{c}\text { Free Cl } \\
\text { Residual }\end{array} \\
\mathrm{mg} / \mathrm{L}\end{array}$} & \multirow{2}{*}{$\begin{array}{c}\text { TOC } \\
\text { mg/L }\end{array}$} & \multirow{2}{*}{$\frac{\text { Flow Time }}{\min }$} & \multirow{2}{*}{$\begin{array}{c}\text { Volume } \\
\text { Filtered } \\
\text { liters }\end{array}$} & \multirow{2}{*}{$\begin{array}{c}\text { Flow Rate } \\
\text { L/min }\end{array}$} & \multirow{2}{*}{$\begin{array}{c}\text { BioVir Sample } \\
\text { Name }\end{array}$} \\
\hline & & 1 & 2 & 3 & avg & & & & & & \\
\hline Initial $^{*}$ & & 95.4 & 91.4 & 90.0 & 92.3 & 0.81 & 10.55 & & & & \\
\hline $\begin{array}{c}10 \text { min after } \\
\text { mixing }\end{array}$ & & & & & & 1.82 & & & & & \\
\hline $\begin{array}{l}30 \text { min after } \\
\text { mixing }\end{array}$ & & 35.5 & 32.6 & 28.6 & 32.2 & & & & & & \\
\hline $\begin{array}{l}\text { 3-4.5 liters } \\
\text { filtered }\end{array}$ & $\mathrm{C}+\mathrm{B}$ & 0.38 & 0.39 & 0.21 & 0.3 & 0.18 & 3.597 & 6.42 & 3 & 0.47 & $F-1$ \\
\hline $\begin{array}{l}4.5-6 \text { liters } \\
\text { filtered }\end{array}$ & C & 2.34 & 2.26 & 1.97 & 2.2 & 0.26 & 3.754 & 1.75 & 1 & 0.57 & B-1 \\
\hline
\end{tabular}

Bags were filled separately i.e. Bag1 was filled, and the rest of the initial drum water was left in the drum to mix while Bag 1 treatment was perfo Mixing was done using a magnetic stir bar on a large stir plate.

Used clear clamshell and bullet filter \#1.

When filtering, the bag was raised up to provide more

Initial drum water had been mixing for approximately 18 minutes.

Wead and distance for the filter setup to occur.

When samples were taken, valve was set to "notch \#4" i.e. not full flow.

"This initial sample was taken through the valve of the bag. This could have introduced some contamination in the valve for

later samples. For future bags, DO NOT take initial samples through the valve to prevent possible contamination. All further

initial samples were taken as the bags were being filled directly from the large drum.

All mixing was done for 5 minutes and at $70 \mathrm{bpm}$.

$\mathrm{Cl}$ residual samples were uniformly mixed with reagent packets, $\sim 30$ times gently rocking inversions.

Bag \# 2

\begin{tabular}{|c|c|c|c|c|c|c|c|c|c|c|c|}
\hline \multirow{2}{*}{ Sampling Point } & \multirow{2}{*}{$\begin{array}{c}\text { Filter(s) Used } \\
\text { Clamshell ( C) } \\
\text { or Bullet (B) }\end{array}$} & \multicolumn{4}{|c|}{ Turbidity } & \multirow{2}{*}{$\begin{array}{c}\begin{array}{c}\text { Free Cl } \\
\text { Residual }\end{array} \\
\mathrm{mg} / \mathrm{L}\end{array}$} & \multirow{2}{*}{$\begin{array}{c}\text { TOC } \\
\mathrm{mg} / \mathrm{L}\end{array}$} & \multirow{2}{*}{$\frac{\text { Flow Time }}{\min }$} & \multirow{2}{*}{$\begin{array}{c}\text { Volume } \\
\text { Filtered } \\
\text { liters }\end{array}$} & \multirow{2}{*}{$\begin{array}{c}\text { Flow Rate } \\
\mathrm{L} / \mathrm{min}\end{array}$} & \multirow{2}{*}{$\begin{array}{c}\text { BioVir Sample } \\
\text { Name }\end{array}$} \\
\hline & & 1 & 2 & 3 & avg & & & & & & \\
\hline Initial & & 94 & 90.6 & 90.5 & 91.70 & 0.85 & 11.99 & & & & \\
\hline $\begin{array}{l}30 \text { min after } \\
\text { mixing }\end{array}$ & & 11.5 & 9.16 & 8.6 & 9.74 & & & & & & \\
\hline $\begin{array}{l}\text { 3-4.5 liters } \\
\text { filtered }\end{array}$ & $\mathrm{C}+\mathrm{B}$ & 0.14 & 0.17 & 0.15 & 0.15 & 0.11 & 3.507 & 7.02 & 3 & 0.43 & $F-2$ \\
\hline $\begin{array}{l}4.5-6 \text { liters } \\
\text { filtered }\end{array}$ & C & 1.1 & 1.02 & 1.06 & 1.06 & 0.11 & 3.543 & 1.38 & 1 & 0.72 & B-2 \\
\hline
\end{tabular}

Took initial conditions from large drum while filling bag.

Used opaque (white) clamshell and bullet filter \#2.

Bag was not elevated while filtering.

$V$ alve set at notch \#4 for all samples.

Bag \# 3

\begin{tabular}{|c|c|c|c|c|c|c|c|c|c|c|c|}
\hline \multirow{2}{*}{ Sampling Point } & \multirow{2}{*}{$\begin{array}{c}\text { Filter(s) Used } \\
\text { Clamshell ( C) } \\
\text { or Bullet (B) }\end{array}$} & \multicolumn{4}{|c|}{ Turbidity } & \multirow{2}{*}{$\begin{array}{c}\begin{array}{c}\text { Free Cl } \\
\text { Residual }\end{array} \\
\mathrm{mg} / \mathrm{L}\end{array}$} & \multirow{2}{*}{$\begin{array}{c}\text { TOC } \\
\mathrm{mg} / \mathrm{L}\end{array}$} & \multirow{2}{*}{$\frac{\text { Flow Time }}{\min }$} & \multirow{2}{*}{$\begin{array}{c}\text { Volume } \\
\text { Filtered } \\
\text { liters }\end{array}$} & \multirow{2}{*}{$\frac{\text { Flow Rate }}{L / \min }$} & \multirow{2}{*}{$\begin{array}{c}\text { BioVir Sample } \\
\text { Name }\end{array}$} \\
\hline & & 1 & 2 & 3 & avg & & & & & & \\
\hline Initial & & 85.5 & 89 & 87.6 & 87.37 & 0.78 & 10.6 & & & & \\
\hline $\begin{array}{c}30 \text { min after } \\
\text { mixing }\end{array}$ & & 5.52 & 5.9 & 6.0 & 5.79 & & & & & & \\
\hline $\begin{array}{c}\text { 3-4.5 liters } \\
\text { filtered }\end{array}$ & $\mathrm{C}+\mathrm{B}$ & 0.22 & 0.14 & 0.15 & 0.17 & 0.15 & 4.675 & 8.30 & 3 & 0.36 & $F-3$ \\
\hline $\begin{array}{l}\text { 4.5-6 liters } \\
\text { filtered }\end{array}$ & C & 0.57 & 0.55 & 0.53 & 0.55 & 0.15 & 3.639 & 1.83 & 1 & 0.55 & B-3 \\
\hline
\end{tabular}

Clear clamshell filter and bullet filter \#3 was used.

Bag was not elevated while filtering.

Valve set at notch \#4 for all samples.

Estimated mixing time in large drum $=18+30+13+30+15=106$ minutes 